\title{
Intelligent concrete with self-x capabilities for smart cities
}

\author{
Xin Wang ${ }^{1}$, Zhen $\mathrm{Li}^{1}$, Bing Han ${ }^{1}$, Baoguo Han ${ }^{1 *}$, Xun Yu ${ }^{2,3}$, Shuzhu Zeng' and Jinping Ou ${ }^{1,4}$ \\ ${ }^{1}$ School of Civil Engineering, Dalian University of Technology, Dalian, 116024 China \\ ${ }^{2}$ Department of Mechanical Engineering, New York Institute of Technology, New York, 11568, USA \\ ${ }^{3}$ School of Machinery and Automation, Wuhan University of Science and Technology, Wuhan, 430081 China \\ ${ }^{4}$ School of Civil Engineering, Harbin Institute of Technology, Harbin, 150090 China
}

\begin{abstract}
Intelligent concrete refers to the structural materials which can sense the changes of environment and make suitable responses by altering one or more working parameters in real time. The 'intelligent' properties of concrete are achieved mainly by improving the composition of raw materials or combining some functional materials with concrete matrix, thus leading to the concrete possessing bionic features. Compared to conventional concrete, a properly designed intelligent concrete can be applied to optimize the safety, longevity and function of infrastructures and reduce the life-cycle costs, resource consumption and environment pollution, which will lay a material foundation for building smart cities. In the past few decades, considerable efforts have been put towards the research of intelligent concrete and many innovative achievements have been gained in the development and application of intelligent concrete. Thirteen types of intelligent concrete emphasizing on its self-x capabilities are systematically reviewed in this paper, with attentions to their principles, composition, fabrication, properties, research progress and structural applications. In addition, some comments and prospects for the development of self-x concrete are also discussed.
\end{abstract}

Keywords: intelligent concrete; self-x capacity; principle; properties; structural applications

*Correspondence to: Baoguo Han, School of Civil Engineering, Dalian University of Technology, Dalian, 116024 China; E-mail: hithanbaoguo@163.com, hanbaoguo@dlut.edu.cn

Received: October 25, 2016; Accepted: November 16, 2016; Published Online: December 15, 2016

Citation: Wang X, Li Z, Han B, et al.,2016, Framing a satellite based asset tracking (SPARTACUS) within smart city technology. Journal of Smart Cities, vol.2(2): 1-39. http://dx.doi.org/10.26789/JSC.2016.02.005.

\section{Introduction}

S ince the appearance of Portland cement in 1824, concrete has become the most widely used building materials in the infrastructure construction for its low cost, high compressive strength and extensive adaptability ${ }^{[1]}$. However, the mechanical properties in terms of toughness, tensile strength and impact resistance of concrete are extremely weak due to its quasi-brittle nature. Meanwhile, the obvious discreteness of raw materials and the complexity of environment conditions lead to the reliability of concrete structures challenged in service. Under the effect of load, temperature, humidity and other factors, the concrete materials are inclined to crack and failure. After a series of engineering disasters caused by material failures in the 1970s and 1980s, researchers realized that the security and reliability of structures may be significantly improved if materials have the capacities of self-sensing, self-adjusting and self-healing to monitor and repair the potential defects. Therefore, the occurrence of catastrophic accidents can be reduced and even avoided. Since then, the intelligent materials, which is defined as 'a material with the function of sensible and controllable to the variation of environment', was developed ${ }^{[2]}$. And the primary working proce-

Intelligent concrete with self-x capabilities for smart cities. (C) 2016 Xin Wang, Zhen Li, Bing Han, et al. This is an Open Access article distributed under the terms of the Creative Commons Attribution-NonCommercial 4.0 International License (http://creativecommons.org/licenses/by- nc/4.0/), permitting all non-commercial use, distribution, and reproduction in any medium, provided the original work is properly cited. 
sses of the intelligent concrete are illustrated in Figure 1.

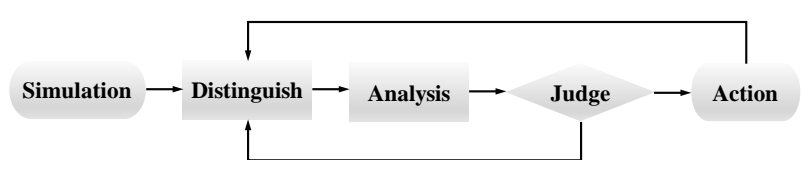

Figure 1. Information flow of intelligent concrete $\mathrm{e}^{[3]}$

To date, extensive researches have been performed on various intelligent concretes ${ }^{[4]}$. The composition, proceeding, property and mechanism, measurement and application of intelligent concretes were widely investigated by experimental study, theoretical analysis and numerical simulation. This paper reviews the research achievements of intelligent concrete, focusing on its principles, properties, research progress and structural applications. Although intelligent concrete has more than ten categories of smart capacity, this review is only focused on the progress in concrete with self-x capabilities, i.e., possessing intrinsically intelligent capabilities as shown in Figure 2. Among the 13 self-x concrete, the first six kinds are the common intelligent concrete written by the order of fabrication, curing and hardened properties. The subsequent seven kinds self-x concrete are the recently developed ones.

\section{Self-Compacting Concrete}

Self-compacting concrete (SCC) is also named as self-consolidating concrete, self-leveling concrete or vibration free concrete. The prototype of SCC was originally completed by Okamura in 1986. SCC has the advantages of high liquidity, no segregation and bleeding phenomenon compared with traditional concrete. SCC not only has the good ability to go through the space among steel rebars, but also has the ability of levelling under its own gravity which could make compacting concrete structure by itself. Besides, it could have a shorter construction period to enhance efficiency because of the uselessness for vibration ${ }^{[5-7]}$.

Contrast between the mix proportion of SCC and that of conventional concrete is shown in Figure $3^{[8]}$. In order to test whether the mix proportion of the concrete is appropriate, some test methods such as U-flow test method, box test method, V-funnel test method and T500 test method were developed. In the U-flow test method as shown in Figure 4, the height that the concrete flowing through the obstacle can represent the degree of compactability of the concrete. If the concrete can flow through a height over $320 \mathrm{~mm}$, the concrete can be judged as SCC. The box test method is appropriate for testing concrete which has higher segregation between mortar and aggregate. If the concrete $\mathrm{s}$ determined to have inadequate self-compactability, the mix proportion of the concrete has to be re-iadjusted.

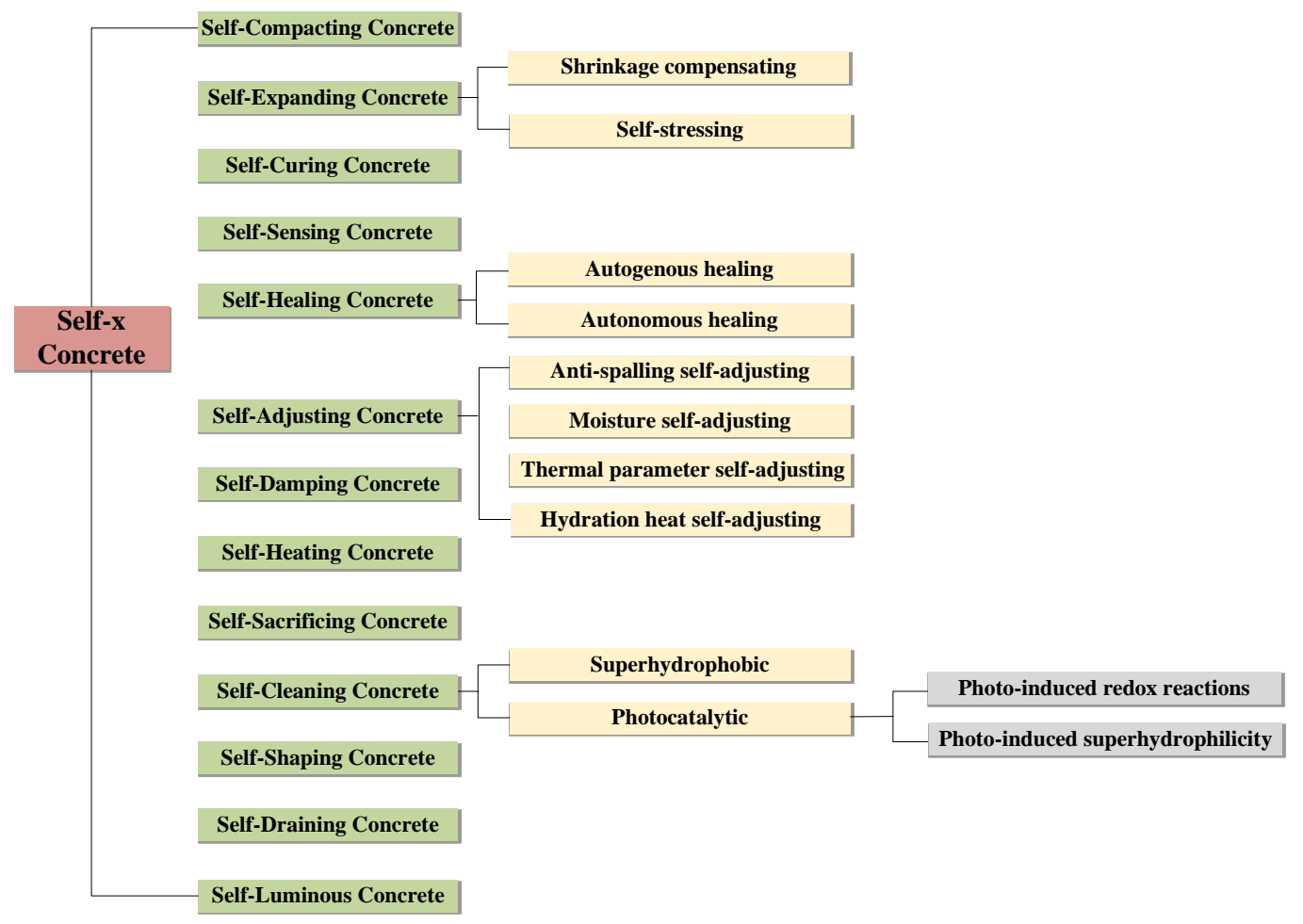

Figure 2. Categories of self-x concrete 
Self-Compacting Concrete

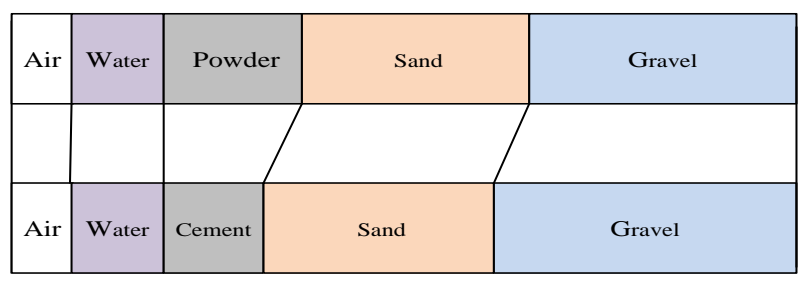

Conventional Concrete

Figure 3. Contrast between the mix proportion of SCC and that of conventional concrete ${ }^{[8]}$

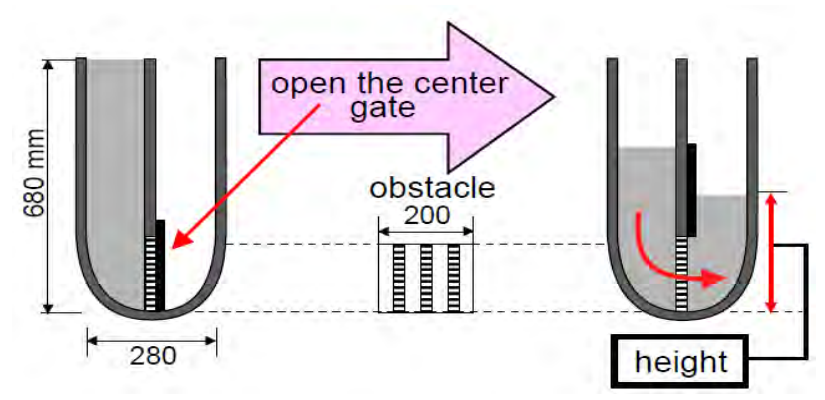

Figure 4. U-flow test ${ }^{[8]}$

The performance index of SCC is proposed in the Standardization Institute of Chinese Construction Standard 'SCC Application Specification' as shown in Table $1^{[9]}$.

Table 1. Performance index of SCC

\begin{tabular}{lccc}
\hline Performance Level & First Class & Second Class & Third Class \\
\hline $\begin{array}{l}\text { Rising height } \\
\text { of U-flow/mm }\end{array}$ & $\begin{array}{c}\text { above } 320 \\
\text { ( I barrier) }\end{array}$ & $\begin{array}{c}\text { above } 320 \\
\text { ( II barrier) }\end{array}$ & $\begin{array}{c}\text { above 320 } \\
\text { (barrier-free) }\end{array}$ \\
Slump flow/mm & $650-750$ & $600-700$ & $550-650$ \\
$\begin{array}{l}\text { T500/s } \\
\begin{array}{l}\text { Time for go } \\
\text { through V-funnel/s }\end{array}\end{array}$ & $5-20$ & $3-20$ & $3-20$ \\
\hline
\end{tabular}

The optimal ratio of self-compacting concrete is mainly determined via a large number of orthogonal experiments. The main design properties of the SCC also include compressive strength, tensile strength, elastic modulus, heat of hydration, durability, creep, shrinkage and stiffness ${ }^{[5]}$. Persson ${ }^{[10]}$ compared the elastic modulus, creep and shrinkage of the SCC with that of traditional concrete after performing a series of studies on strength (fc), and found there is no great difference between them. Nagamoto et al. found that the physical properties of the solids in the mortar can greatly affect the decrease extent of the shear deformation in the mortar. The SCC may bring a loss of compaction due to the increasing of the coarse aggregate content above the range $\mathrm{G} / \mathrm{Glim}=0.50$. The rela- tionship between the decrease in compaction and the increase in coarse aggregate is not linear. When the proportion of coarse aggregate to fine aggregate is varied, the amount of super-plasticizer is needed to be adjusted $^{[11]}$. In addition, it has been proven by many researchers that the SCC is much better than ordinary concrete in durability.

SCC includes a diverse range of mix types with both fresh and hardened properties. It has higher filling rate, better deformability and higher segregation resistance compared with conventional concrete. However, there are still some issues needed to be addressed. For example, the early-age shrinkage of the SCC is large due to low water-binder ratio. This leads to the appearance of cracks. SCC would put great pressure on molds due to its liquidity. In addition, SCC is easier to spall than conventional concrete when it is subjected to high temperature.

\section{Self-Expanding Concrete}

Volume shrinkage would occur during the hydrating and hardening of Portland cement concrete. Micro-cracks will then generate in consequence of this shrinkage. This is detrimental to hardened concrete. Contrasting to ordinary concrete, expansion instead of shrinkage will appear in self-expanding concrete. Hence, the deficiencies caused by shrinkage can be overcome by the expansion. Normally, self-expanding concrete is divided into the shrinkage compensating concrete and the self-stressing concrete according to its expansive energy. Shrinkage compensating concrete is the concrete which expands to some extent intrinsically to prevent shrinkage cracking. Compared with shrinkage compensating concrete, self-stressing concrete possesses a bigger expansion capacity. It can produce a compressive stress of 2.0-8.0 MPa when the concrete expansion is restrained felicitously by reinforcement or other means.

Self-expanding concrete is mainly fabricated by using expansive constituents such as expansive cements or expansive additives. The expansion ability of concrete is largely depended on the dosage and activity of expansive constituents. Detailed information on the various expansive cements and expansive additives is summarized in Table 2. By mixing original minerals into Portland cement during the process of clinker manufacturing, expansive cement is produced and specified into three types by ASTM (i.e., K, M, and S) according to the different original minerals ${ }^{[12]}$. On the other hand, for the sake to conveniently adjust 
Table 2. Summary of expansive cement and expansive additive

\begin{tabular}{clll}
\hline $\begin{array}{c}\text { Expansive } \\
\text { constituent }\end{array}$ & \multicolumn{1}{c}{ Type } & \multicolumn{1}{c}{$\begin{array}{c}\text { Original } \\
\text { mineral }\end{array}$} & $\begin{array}{c}\text { Expansion } \\
\text { resources }\end{array}$ \\
\hline $\begin{array}{c}\text { Expansive } \\
\text { cement }\end{array}$ & $\mathrm{K}$ & $\begin{array}{l}\text { Monosulfate, } \\
\text { gypsum, lime } \\
\text { Aluminate } \\
\text { clinker and } \\
\text { gypsum }\end{array}$ & Ettringite \\
& $\mathrm{M}$ & $\begin{array}{l}\text { Tricalcium } \\
\text { aluminate and } \\
\text { gypsum }\end{array}$ & Ettringite \\
& $\mathrm{S}$ & $\begin{array}{l}\text { Sulfoaluminate } \\
\text { Expansive } \\
\text { additive }\end{array}$ & Calcium sulphoalute- \\
& CaO-based & Ettringite \\
& MgO-Based & Magnesia & Portlandite \\
& Air-entraining-based & $\begin{array}{l}\text { Bron or aluminum } \\
\text { powder, oxidant }\end{array}$ & $\begin{array}{l}\text { Hydrogen, } \\
\text { ferrous } \\
\text { hydroxide }\end{array}$ \\
\hline
\end{tabular}

expansion capacity, expansive mineral are separately produced from cement clinker and then directly mixed into concrete as an expansive additive. Expansion resources of expansive cement and calcium sulphoaluminate-based additive mainly come from the hydration product of acicular ettringite crystals. This kind of self-expanding concrete is the most widely used for the chemical stability of ettringite ${ }^{[13]}$. CaO-based and MgO-based expansive additives have the merits of low hydration water requirements and high volume expansion ratio. The translation of Calcia $(\mathrm{CaO})$ into Portlandite $\left[\mathrm{Ca}(\mathrm{OH})_{2}\right]$ results in a volume augmented of $94 \%$ in theory, and $97.9 \%$ for Magnesia (MgO) becoming Brucite $\left[\mathrm{Mg}(\mathrm{OH})_{2}\right]$. Of the two oxides, $\mathrm{CaO}$ is intrinsically more reactive compared with $\mathrm{MgO}$. Furthermore, the hydration product of $\mathrm{Ca}(\mathrm{OH})_{2}$ is more soluble than that of $\mathrm{Mg}(\mathrm{OH})_{2}{ }^{[14]}$.

Self-expanding concrete has a history of almost eighty years since the invention of expansive cement in 1936, France. It has been demonstrated that selfexpanding concrete is a perfect alternative to increase the durability for both new constructions and refurbishment ${ }^{[15]}$. Shrinkage compensating concrete can effectively mitigate the cracks caused by thermal shrinkage, drying shrinkage and creep. Moreover, the filling effect of expansion products contributes to decreasing porosity and pore diameter, thus improving the density of concrete. Therefore, the major application of shrinkage compensating concrete is in water proofing constructions. Self-stressing concrete is mandatory in the conditions of dense rebar reinforcement or concrete confined in steel tubes, where a large amount of expansion restrained is required. In this way, interfacial bounding strength between concrete and reinforcement is increased and the tensile strength of concrete is substantially elevated ${ }^{[16]}$. Besides, enhancement of self-stressing capability is found to be achievable by adding fibers to confine the expansion of concrete. In this case, triaxial self-stressing developed by the fiber is beneficial to the enhancement of tensile strength as well as the impact and fatigue resistance of concrete ${ }^{[17]}$. Recently, hybrid fibers together with MgO expansion additive (MEA) are applied to improve the volume stability of concrete airport runway in high altitude localities in Tibet, China. Results indicate a decreasing expansion of concrete with the increasing content of steel fiber (SF) and fine denier polyacrylonitrile fiber (SP). As shown in Figure 5a, the volume stability of concrete slabs is improved at an early age. Microstructure analysis by scanning electron microscope illustrates that the micro-cracking inside concrete is locally restrained by the surrounding hybrid fibers, as graphed in Figure $5 b^{[18]}$.

Self-expanding concrete is an efficient substitute to improve some structural behaviors of concrete. However, expansion of concrete caused by the formation of ettringite consumes a large amount of water, which is

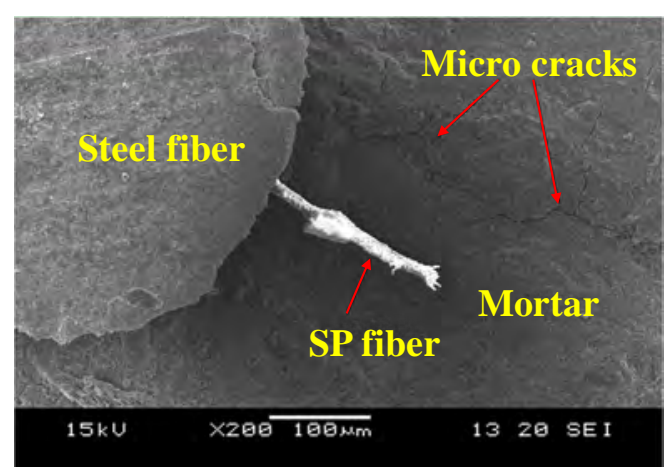

(B)

(A)

Figure 5. (a) Strain deformations of concrete added with hybrid fiber; (b) Microstructure of hybrid fiber inside of concrete ${ }^{\text {[18] }}$ 
strongly reliant on the wet curing ${ }^{[13]}$. Additionally, ettringite may undergo decomposition at high temperature (over $70^{\circ} \mathrm{C}$ ), and thus may be unsuitable for mass concrete with high temperature rise ${ }^{[19,20]}$. Due to the fast hydration of $\mathrm{CaO}$ and the relatively high solubility of hydration product $\mathrm{Ca}(\mathrm{OH})_{2}$, the application of $\mathrm{CaO}$ based expansive additive in the concrete for hydraulic structures is forbade ${ }^{[14]}$. For MgO-based expansive additive, the calcination temperature is a crucial condition for the hydration reactivity of $\mathrm{MgO}^{[21]}$. Once the calcine temperature is higher than needed temperature, dead-burnt MgO may be produced. This may cause heterogeneous expansion, and even lead to the destruction of concrete structure ${ }^{[22-24]}$. In a word, the negative effect of concrete expansion is required for deep investigation and choosing the effective self- expanding concrete based on the practical engineering demands is extremely important.

\section{Self-Curing Concrete}

Curing of concrete is essential immediately after the casting of concrete because of potential shrinkage, settlement and thermal deformation at early ages. Properly curing is significant for concrete to satisfy the requirements of mechanical properties and durability. Traditional curing methods like ponding, spraying, covering wet burlap or plastic films are adequate for ordinary concrete. However, these curing techniques may fail in high-performance concrete (HPC). HPC is chara. cterized by low water binder ratio $(\mathrm{w} / \mathrm{b})$ and high volume additives such as silica fume, which leads to high strength and density at early age. In this condition, the penetration of external water is difficult and only superficial by traditional curing mode. Consequently, with inherent water insufficient and outer curing water inaccessible to satisfy complete hydration of binder, a series of chemical shrinkage and thereby autogenous shrinkage may cause serious premature crack. This premature crack finally induces the degradation of mechanical properties and durability. Considering these issues, self-curing as a new technology adapting to concrete with low w/b is presented.

Self-curing concrete also known as autogenous curing or internal curing concrete is achieved by incorporating pre-saturated component as internal curing agent. The curing agent is uniformly distributed throughout the matrix and acts as an internal water reservoir. The water within curing agent does not participate in the chemical reaction until a humidity gradient generates after a period of early hydration. Water is transported from curing agent to unhydrated cement by the driving forces of capillary suction, vapor diffusion and capillary condensation for supporting continuous hydration. As a result, the chemical shrinkage and self-desiccation caused by low w/b can be considerably diminished.

The self-curing agent should possess both high water absorption capacity in aqueous solution and desorption rates under pressure. Currently, the most popular curing agents are pre-saturated porous lightweight aggregates (LWA) and super absorbing polymers (SAP). LWA such as ceramsite and pumice is the first used self-curing agent, which typically contains water by weight of $5 \%$ to $25 \%{ }^{[25]}$. SAP is described as 'super' for its ultra-high water adsorption capacity, which even 1000 times higher than its own weight ${ }^{[26]}$. The two distinct phases of SAP in dry and swollen are shown in Figure 6.

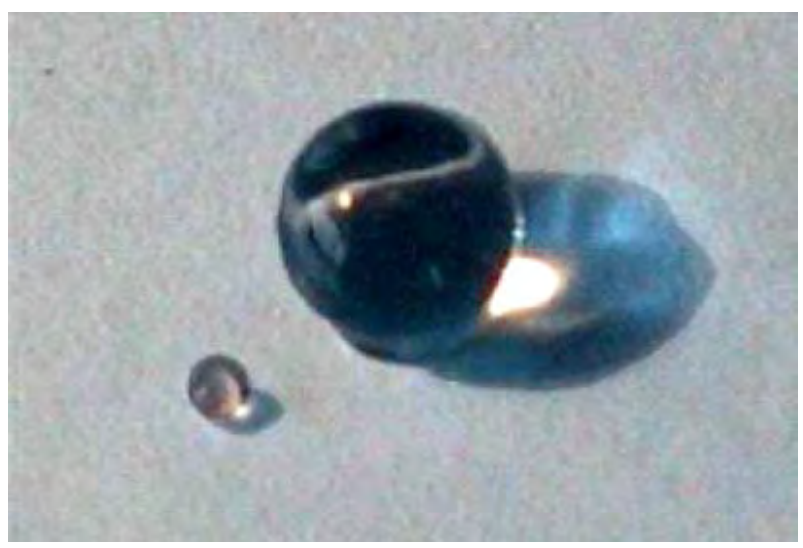

Figure 6. A dry and a swollen SAP ${ }^{[26]}$

Extensive attention has been attracted to the selfcuring concrete in recent half a century and most investigations are conducted based on Powers' model, as illustrated in Figure $7^{[27,28]}$. The model systematically expounds the minimal dose of self-curing water needed

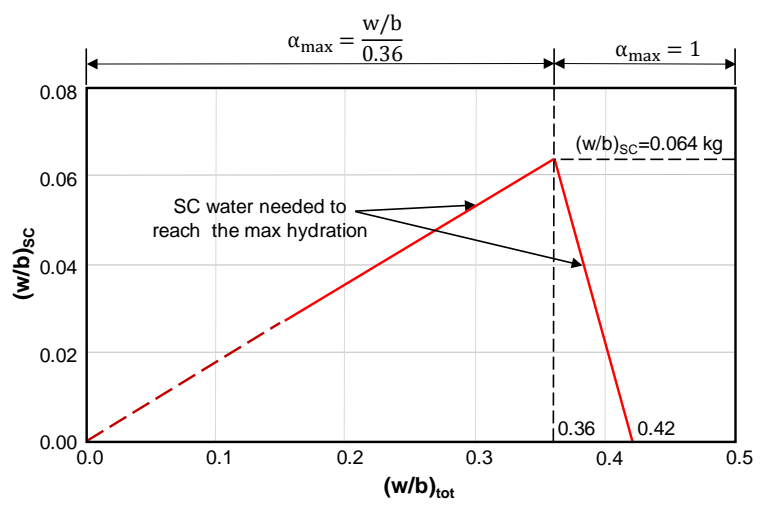

Figure 7. Minimum amount of self-curing water needed to obtain $\alpha_{\max }$ during cement hydration 
to reach the maximum degree of binder hydration $\left(\alpha_{\max }\right)$ at a given w/b. As can be seen in Figure 7, $\alpha_{\max }$ reaches up to the region of 1.0 (i.e., full hydration of binder) only with $\mathrm{w} / \mathrm{b}$ equal to or greater than 0.36 . Below this value, binder hydration is only partially achieved and the $\alpha_{\max }$ under saturated condition is estimated as (w/b)/0.36. Also indicated in Figure 7, fully saturated condition of binder hydration can be achieved with a quantity of self-curing water of $0.064 \mathrm{~kg}$ per kilogram of binder.

As mentioned previously, the $\mathrm{w} / \mathrm{b}$ is generally between 0.30 and 0.40 for HPC. The detrimental deformation caused by autogenous shrinkage can be eliminated through self-curing technology. Here HPC with $\mathrm{w} / \mathrm{b}$ of 0.30 is employed as an example to elaborate the effect of self-curing agent on the performance of HPC on the basis of Powers' model ${ }^{[29]}$. In Figure 8(a), at w/b of 0.30 and self-curing water removed, hydration stops at a degree of 0.73 under sealed curing conditions due to the water shortage. Figure 8(b) shows the mixture provided by an extra self-curing water of $3.20 \%$ by total water volume to the system. The water in curing agent is then drawn out 'filling the pores' created by chemical shrinkage and proceeds further hydration to 0.77 . Once $7.36 \%$ water is replenished, hydration degree can reach up to 0.83 and the chemical shrinkage is totally eliminated as illustrated in Figure 8(c). The maximum theoretical degree of hydration increases with the volume of self-curing water, but comes to a limiting value at $7.36 \%$ as illustrated in Figure 8(d). This is because that at the hydration degree of 0.83 , nearly no void space remains within the hydrating concrete. Therefore, the optimum self-curing water contents is of utter importance for the desired performance of concrete.

In recent twenty years, most investigations indicated that the autogenous shrinkage of concrete was reduced to some extent owing to the incorporation of self-curing agent ${ }^{[26,30-34]}$. Nevertheless, there are still conflicting results in mechanical properties. Some experiments show an increase in a range of $10 \%-20 \%$ compressive strength of concrete with self-curing agent than that without at $28 \mathrm{~d}$, while others manifest a decrease of $8 \%-31 \%{ }^{[30-36]}$. This difference may be attributed to the opposite effect of self-curing water. On the one hand, the incorporated self-curing water can improve the degree of binder hydration. On the other hand, excessive selfcuring water may result in spherical macropores. Once the negative effect of self-curing water cannot compensate by the positive effect, the mechanical properties
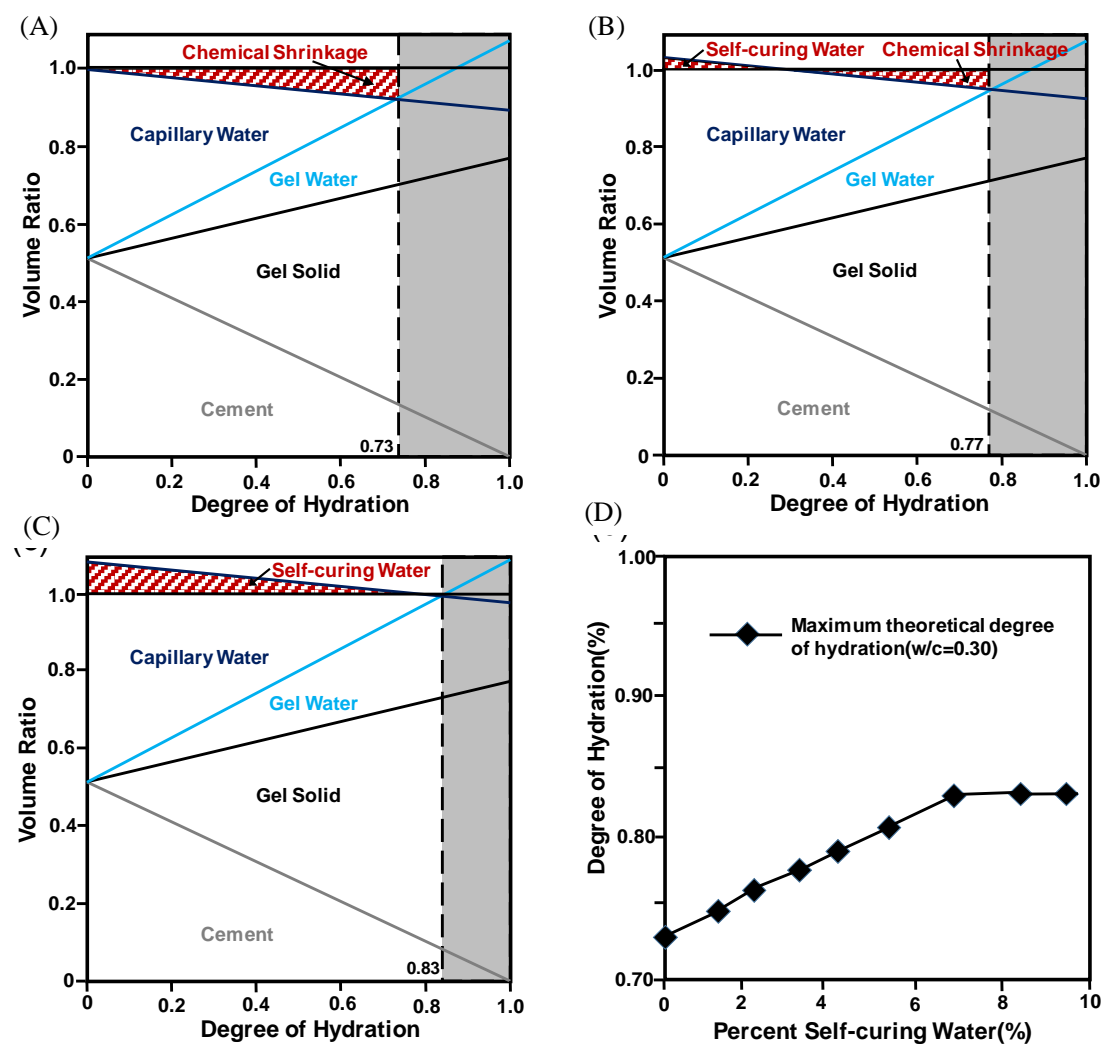

Figure 8. Powers' model showing phase distributions for (a) w/b=0.30 paste (b) $3.20 \%$ self-curing water and (c) $7.36 \%$ self-curing water. (d) Maximum theoretical degree of hydration as a function of self-curing water ${ }^{[29]}$ 
of concrete decreased ${ }^{[37]}$. Additionally, most findings illustrated an increasing durability of concrete by means of self-curing. For instance, the chloride permeability of concrete goes down contributed by the reduced percolation of interfacial transition zone between cement paste and aggregate ${ }^{[38-40]}$. The freezing and thawing resistance of concrete can also be improved due to the pores and air voids forming in the matrix after selfcuring agent becomes dry ${ }^{[41-43]}$.

Self-curing concrete accompanied with well-designed mechanical properties and outstanding durability has been employed in engineering applications. In January 2005, about $190000 \mathrm{~m}^{3}$ of self-cured HPC with presoaked LWA was successfully casted in a large railway transit yard in Texas, America. After placing, the flexural strength at $7 \mathrm{~d}$ reached $90 \%$ to $100 \%$ of those required at $28 \mathrm{~d}$ as a consequence of improved cement hydration process ${ }^{[44]}$. Additionally, shrinkage cracks are extremely minimal compared with conventional paving concrete. In 2010, self-curing concrete was used in the construction of 9 bridges by New York Department of Transportation. A special mixture design, which is similar to the one of conventional deck design except for the extra $120 \mathrm{~kg} / \mathrm{m}^{3}$ of fine LWA, was applied. Noticeable increases in strength from $2 \%$ to $10 \%$ of Count Street Bridge and 15\% of Bartell Road Bridge at $28 \mathrm{~d}$ were reported $^{[45]}$.

Self-curing method is effective for improving performance of HPC both in laboratory and actual practice. Extensive research demonstrated that self-curing property of concrete can keep autogenous shrinkage from occurring, thus contributes to lower the risk of cracking and prolong the service life of concrete. Nevertheless, following issues are still required to be solved before fully application of self-curing concrete. Firstly, numerous of contradictory results and interpretations exist in mechanical strength and durability. Secondly, the mechanism and efficiency of different curing agents in terms of type, dosage, particle size and spatial distribution are still ambiguous. Finally, more accurate models of the effect of self-curing agent on the concrete performance needed to be put forward.

\section{Self-Sensing Concrete}

Self-sensing concrete, also known as self-monitoring or self-reporting concrete, refers to the concrete with capacity of sensing its own state (e.g., strain, stress, damage or temperature) without the need of embedded, attached or remote sensors ${ }^{[46]}$. A moderate amount of functional fillers, with a certain shape and dimension, are incorporated into concrete matrix, and then the insulated concrete becomes conductive. Influenced by the field of force and/or temperature, the conductive path of composite altered due to the variation of concrete microstructure, thus resulting in the changes of electrical properties such as resistance, capacitance, impedance, and voltage. Finally, variation of concrete microstructure is reflected in the electrical signals and can be measured by specified devices, i.e., the concrete possesses self-sensing ability.

Self-sensing concrete is mainly composed of matrix and functional fillers in macro-structure level as shown in Figure 9. The matrix of self-sensing concrete is a generalized concept including concrete, mortar and binder only (Portland cement is the most used). The conductive fillers mainly consist of carbonaceous, metallic and polymer material, among which carbonaceous and metallic fillers are the most widely used and investigated. The properties of commonly used fillers are summarized in Table 3. It has been demonstrated that, some functional fillers can not only improve the conductive characteristic of concrete but can also enhance its mechanical properties and durability ${ }^{[47]}$. In addition, a more preferable property of self-sensing concrete can be obtained by synergistically use of two or several functional fillers and the positive hybrid effect is pronounced than any of them alone ${ }^{[48]}$.

Excellent electrical property is necessary for selfsensing concrete. Therefore, a fully comprehension about the generation mechanism is the basis of controlling and improving the self-sensing properties of concrete. Unfortunately, the conductive mechanism is

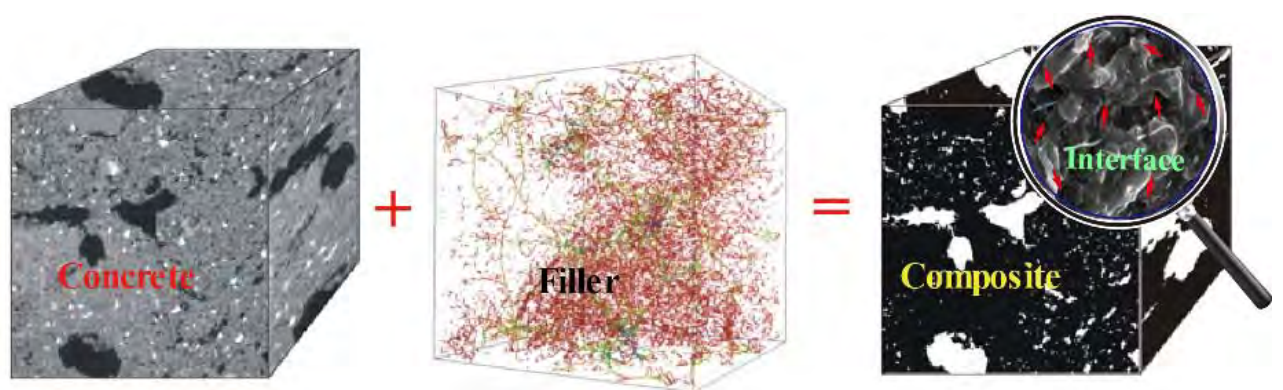

Figure 9. Structure of ISSC ${ }^{[49]}$ 
Table 3. Properties of functional fillers

\begin{tabular}{|c|c|c|c|c|c|c|}
\hline Type & $\begin{array}{l}\text { Elastic } \\
\text { modulus } \\
/ \mathrm{GPa}\end{array}$ & $\begin{array}{c}\text { Tensile } \\
\text { strength } \\
\text { /GPa }\end{array}$ & $\begin{array}{l}\text { Electrical } \\
\text { resistivity } \\
/(\mathrm{m} \Omega \times \mathrm{cm})\end{array}$ & $\begin{array}{l}\text { Elonga- } \\
\text { tion/\% }\end{array}$ & Advantages & Disadvantages \\
\hline $\begin{array}{l}\text { PAN-based } \\
\text { carbon fiber }\end{array}$ & $35-450$ & $2.0-4.5$ & $0.01-1.0$ & $0.4-1.8$ & High strength, conductivity and stability & $\begin{array}{l}\text { Expensive, difficult to dis- } \\
\text { perse }\end{array}$ \\
\hline Pitch-based CF & $160-800$ & $0.6-3.0$ & $(1-4) \times 10^{-2}$ & $0.4-2.5$ & High strength, conductivity and cheap & $\begin{array}{l}\text { Poor impact strength, easy } \\
\text { oxidized }\end{array}$ \\
\hline $\begin{array}{l}\text { Nano-carbon } \\
\text { black }\end{array}$ & - & - & $200-1000$ & - & High conductivity, easily dispersed, cheap & $\begin{array}{l}\text { Low strength, high water } \\
\text { absorption and pollution }\end{array}$ \\
\hline $\begin{array}{l}\text { Carbon } \\
\text { nanofiber }\end{array}$ & $400-600$ & $2.7-7.0$ & $5.5 \times 10^{-4}$ & 50 & $\begin{array}{l}\text { High strength, conductivity and stability, } \\
\text { cheap }\end{array}$ & Difficult to disperse \\
\hline SWCNTs & 1000 & $50-500$ & - & $30-40$ & High chemical stability & $\begin{array}{l}\text { Expensive, difficult to dis- } \\
\text { perse }\end{array}$ \\
\hline MWCNTs & $300-1000$ & 50-200 & $(5-50) \times 10^{-3}$ & $5-20$ & High strength and conductivity & Difficult to disperse \\
\hline $\begin{array}{l}\text { Graphite } \\
\text { powder }\end{array}$ & 1 060(in-plane) & - & $(4-18) \times 10^{-3}$ & - & $\begin{array}{l}\text { High electric and thermal conductivity, } \\
\text { stability }\end{array}$ & High dosage, low strength \\
\hline Steel fiber & $0.5-2.1$ & 1.15 & $(1.33-2.44) \times 10^{-2}$ & 1 & High strength, durability and sensitivity & $\begin{array}{l}\text { High SNR, easy agglomer- } \\
\text { ation and oxidized }\end{array}$ \\
\hline Steel slag & - & - & $4-50$ & - & High strength and stability, cheap & Low-purity, low conductivity \\
\hline Nickel powder & - & - & $0.6-1.0$ & - & High strength, most sensitive, anti-corrosion & Expensive \\
\hline Nano- $\mathrm{TiO}_{2}$ & - & - & $3 \times 10^{-3}$ & - & High sensitivity & Obvious polarization \\
\hline
\end{tabular}

SWCNTs: Single-walled carbon nanotubes; MWCNTs: Multi-walled carbon nanotubes; SNR: Signal to Noise Ratio

still debatable and existing interpretations are variable. One of the interpretations accepted by researchers considers the conducting modes in self-sensing concrete are as follows: the electronic and/or hole conduction (i.e., contacting, tunneling and and/or field emission conductions) coming from conductive fillers ${ }^{[50-52]}$; and the ionic conduction coming from the concrete matrix ${ }^{[53]}$. While it is noticeable that the hole conduction is only exist in carbonaceous fillers ${ }^{[3,54]}$. Correspondingly, there are four paths for current transmission: the interior of cement stone, the interface between conductive fillers and cement matrix, the contacted or overlapped conductive fillers, and the conductive network formed by conductive fillers $^{[46]}$. Concrete self-sensing property may be influenced by multiple factors such as external force, voltage, properties of fillers, water binder ratio, age, water content and service environment, etc. ${ }^{[54-58]}$. For dominating the formation and distribution of conductive networks, filler concentration is a primary parameter affecting the property of self-sensing concrete among those factors. The electrical resistivity of selfsensing concrete changing with filler concentration is depicted in Figure 10. There is a critical composition called percolation threshold ${ }^{[59]}$, beyond which the electrical resistivity is reduced sharply, thus leads to the transformation of concrete from an insulating range to a semi-conductive or conductive range. According to this percolation threshold, the conductive characteristic curves divided into three zones (as shown in Figure 10).

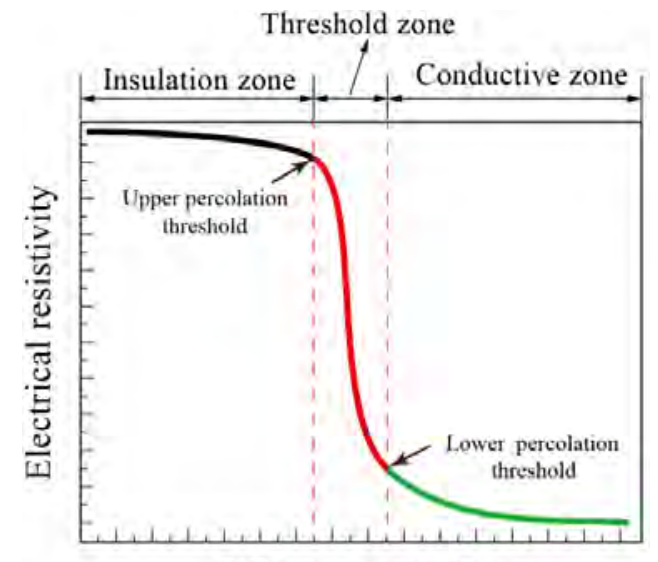

Filler concentration

Figure 10. Change of the electrical resistivity along with filler concentration $^{\text {[59] }}$

An insulation zone refers to the curve with highest resistivity, while the part with dramatically decreased resistivity is percolation zone and the last part with stabilized lowest resistivity is conductive zone. Although the conducting modes and paths mentioned above always exist simultaneously, only one or several of them dominate the status of a certain zone depending on the concentration of conductive fillers ${ }^{[60,61]}$.

Up to now, much effort has been devoted into the research on self-sensing concrete. In 1989, a moderate amount of short-cutting carbon fiber was incorporated into the concrete by Chung and found some correlation between the electrical resistivity and interior structure of 
the concrete. This marks the beginning of intelligence carbon fiber concrete ${ }^{[62]}$. Thereafter, the concept of "self-diagnosing” was first proposed by Muto in $1992^{[63]}$, stated as a concrete possessing the ability of sensing its own damage. Later in 1993, Chung put forward the concept of "smart concrete" and conducted a systematic study on smart concrete for thirty years ${ }^{[64]}$. Then, the Seebeck effect of carbon fiber reinforced concrete (CFRC) was found by $\mathrm{Li}$ in 1998, i.e., an electrical field gradient could be induced by the temperature gradient. CFRC expressed as a stable and repeatable linear relation between thermoelectric force (TEF) and temperature variation $(\Delta \mathrm{t})$, as illustrated in Figure $11^{[51]}$. With different content of carbon fiber, the thermoelectric power can reach up to $18 \mu \mathrm{V} /{ }^{\circ} \mathrm{C}^{[51]}$. All of these make it possible for fabricating a temperature sensor by carbon fiber cement-based material ${ }^{[65-67]}$. Subsequent research found that, a Positive Temperature Coefficient (PTC) or a Negative Temperature Coefficient (NTC) could generate within the conductive concrete and they may alter the development tendency along with different conductive fillers ${ }^{[68,69]}$. Moreover, a series investigation on various self-sensing concrete towards the mechanical properties, mechanical-sensitive mechanism, temperature-sensitive mechanism, measurement methods and environment influence etc., were carried out by researchers, also some prospects about engineering application were given ${ }^{[70-77]}$. In addition, micron or nano sized functional fillers, especially for fibrous fillers, are inclined to entanglement and agglomerate, which turns their dispersion in concrete into a critical issue ${ }^{[78,79]}$. To solve this problem, physical dispersion methods (i.e., high-speed shear or ultrasonic dispersion), chemical dispersion methods (i.e., surfactant or dispersant) and the combination of them were widely studied in the past few years ${ }^{[80-81]}$. It should be pointed out that an appropriate dispersion method can not only increase the electrical properties of concrete, but also improve the strength and durability ${ }^{[47,82-84]}$.

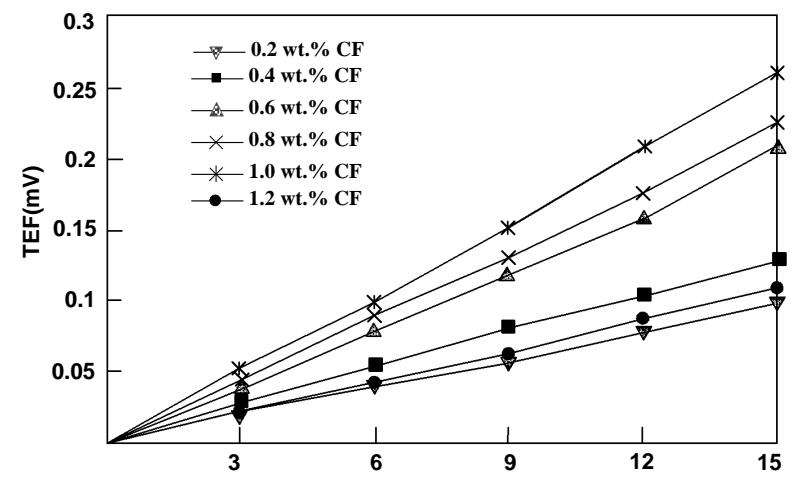

Figure 11. The relationship between temperature and TEF of CFRC $^{[51]}$

Self-sensing concrete possesses high sensitivity (the strain sensitivity coefficient is several tens or even hundreds, while strain gage is only two ${ }^{[46]}$ ), integrating structure and sensing property to a whole system. Depending on the intelligent character, dynamical and timely detection of stress, deformation, temperature, crack and damage can be realized ${ }^{[46,61,66,85-90]}$. It therefore has a wide application potential in the field of structural health monitoring and traffic detection ${ }^{[49,84,91-93]}$, as shown in Figure 12. This would be helpful for ensuring structural reliability, lowering the cost of construction and maintenance, etc.

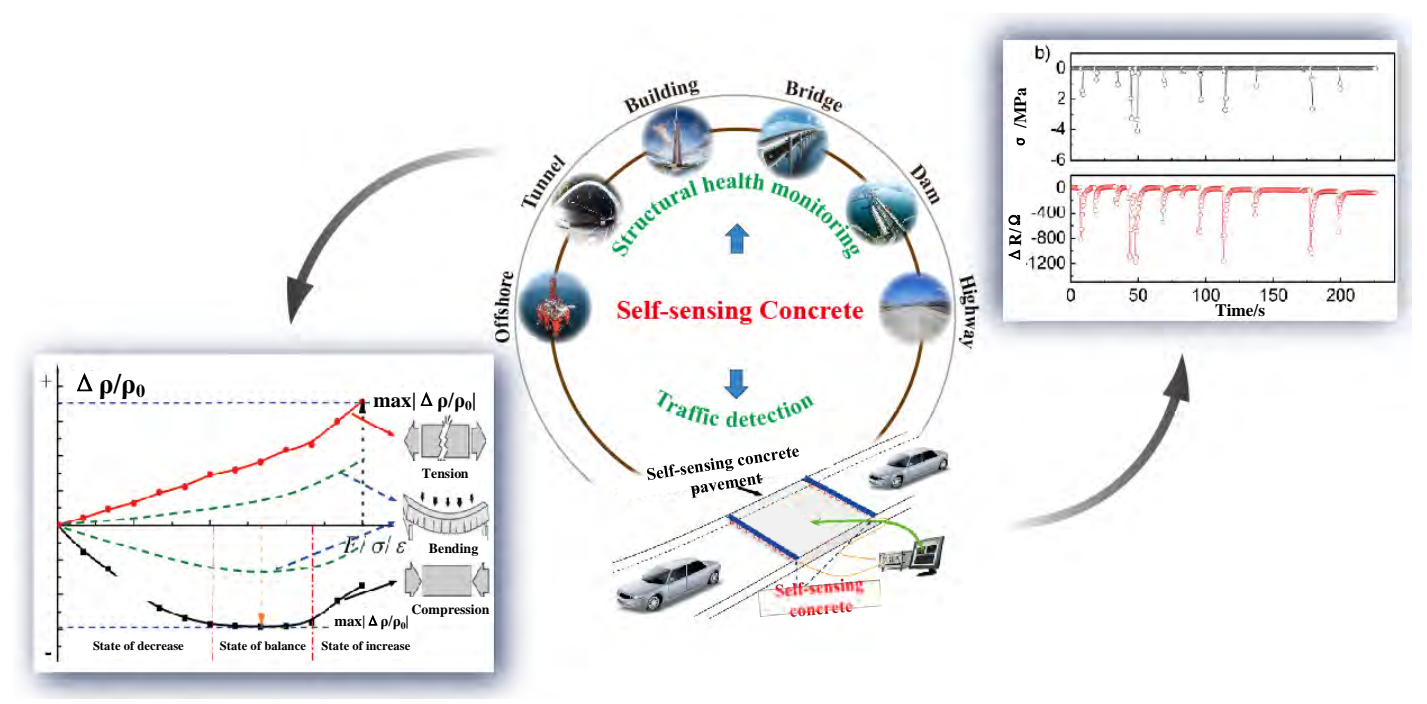

Figure 12. Applications of self-sensing concrete 
Although self-sensing concrete has emerged more than three decades, many efforts are needed to promote its development. Under harsh external environment, the electrical properties of self-sensing concrete are unstable and the measurement accuracy is sharply reduced. The sensing behaviors of self-sensing concrete under complex stress condition should be further investigated. Besides, optimization of functional fillers, influence of aggregates and selection of dispersant methods are required to be deeply explored.

\section{Self-Healing Concrete}

Influenced by inherent characteristics of concrete and complex external environments, the appearance of cracks is inevitable during the molding and service of concrete. Certain paths will be damaged or exhibiting cracks caused by water and aggressive substances intruding into the concrete, thus increasing the risk of various degradations of the material. For reinforced concrete structures, wide cracks may result in the reinforcement exposed to the environment. Consequently, total deterioration of the whole system may occur once the reinforcement starts to corrode or spall ${ }^{[94]}$. Considering the damages of crack to the concrete durability, crack maintenance is needed for sustained usage. However, repair of crack is very difficult, especially when the cracks are invisible or inaccessible. Inspired by the nature of blood clotting or remolding of fractured bones in living things, the same concept is incorporated into the engineering materials by scientists, making them possess the ability of repairing or healing damage by themselves ${ }^{[95]}$.

As a kind of self-healing material, self-healing concrete is also named self-repairing or self-sealing concrete and the essence is the concrete itself to provide necessary adhesive products which can fill in the cracks when damage happens. In general, self-healing concrete is classified into two categories: autogenous and autonomous healing concrete ${ }^{[96,97]}$.

\subsection{Autogenous healing Concrete}

The autogenous self-healing concrete is defined as the concrete with ability of sealing itself without external monitoring or human intervention. Cracks within concrete may get repaired in a time because of the continuously hydration of clinker minerals or carbonation of calcium hydroxide $\left[\mathrm{Ca}(\mathrm{OH})_{2}\right]$. Self-healing of cracks in the concrete is a combination of complicated chemical, physical and mechanical interactions ${ }^{[98]}$. Most researchers believe that autogenous self-healing of young concrete is mainly owing to continuously cement hydration, whereas at later ages, self-healing is most attributed to the formation of calcium carbonate $\left(\mathrm{CaCO}_{3}{ }^{[99,100]}\right.$. For each autogenous self-healing mechanism of concrete, the presence of water is essential due to its important role in causing chemical reaction and transporting fine particles. If crack widths restricted or crack closure is acquired, autogenous healing could be more effective. It was demonstrated that crack width of maximum $50 \mu \mathrm{m}$ show complete healing and up to 150 $\mu \mathrm{m}$ show partial recovery of mechanical and transport properties $^{[101]}$. To improve the ability of autogenous healing of concrete, latent hydraulic and pozzolanic admixture (i.e., fly ash, lime, blast furnace slag) or superabsorbent polymers (SAP) and expansive agent are usually incorporated into concrete ${ }^{[102-106]}$. Some researchers focused on the autogenous self-healing behaviors of the Ultra PC (UHPC) which is characterized by a low water to cement ratio (close to 0.2 ) and high content of admixtures. This implies that UHPC has a great amount of anhydrous clinker, and thereby a potential for self-healing by the sustained hydration of binder materials ${ }^{[107,108]}$. Three-point flexural test and numerical simulation were conducted on the UHPC specimens after initially cracked and cured in the water. The results of 1, 3, 10 and 20 weeks curing are presented in Figure 13 and show a good agreement between simulation and experiment. It can be seen that a fast recovery of global stiffness and a light improvement of resistance have been highlighted with the curing time ${ }^{[109]}$. On the other hand, arresting crack width by high performance fibers also attributes to the self-healing process. For example, Engineered Cementitious Composites (ECC) as the material involving PVA fiber realize the multiple cracking pattern and average crack width under $60 \mu \mathrm{m}^{[110,111]}$. Furthermore, concrete reinforced by chemically flax and hemp fibers can control the maximum crack width under 30um, which fully ensures a complete healing of concrete ${ }^{[112,113]}$.

The autogenous self-healing capacity of concrete is an ancient phenomenon acting positively. It is acknowledged as one of the reasons explaining the survival of many old buildings and structures. However, the work of autogenous healing is limited to small cracks and relatively low recovered strength can be offered. Meanwhile, autogenous healing is effective only accompanied with water, which is difficult to control. Thus, too many uncertain factors are needed to be taken into account explicitly and make the design of autogenous self-healing concrete challenging. In this case, the autonomous self-healing concrete is proposed. 


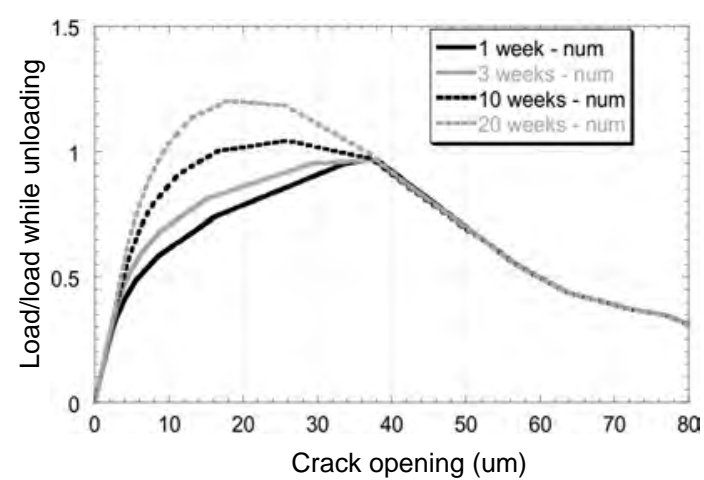

(A)

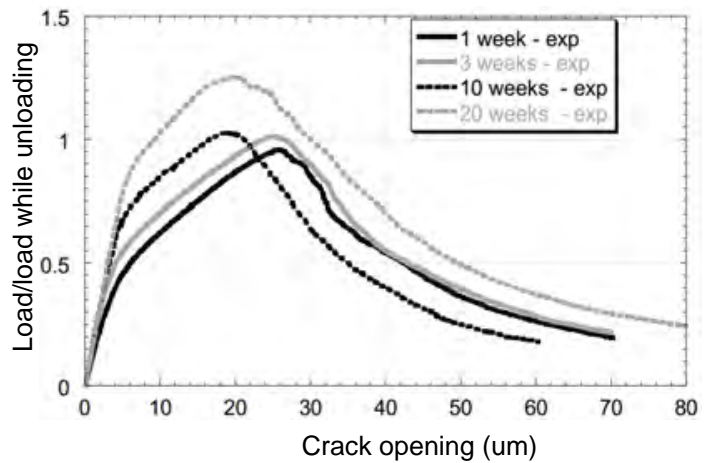

(B)

Figure 13. Numerical simulation (a) and experimental result (b) of bending test on healed UHPC concrete specimens ${ }^{\text {[109] }}$

\subsection{Autonomous healing Concrete}

The autonomous self-healing concrete, sharing the same concept with other artificial self-healing composites, is created by embedding self-healing units composed of container and healing agent in the host concrete. The container is usually hollow fibers and capsules with spherical or cylindrical shape, which both serves as the container of healing agent and acts as barrier to prevent reactions between healing agent and host material. Accordingly, an ideal healing agent is supposed to be able to continuously sense and respond to the damage, and recover the material performance without adverse effect. The autonomous healing process can be divided into two steps as illustrated in Figure 14. Firstly, the healing agent is released into the crack faces through capillary action or gravity once the container is ruptured by the propagating crack. Then, chemical reaction takes place between the healing agent and host material to
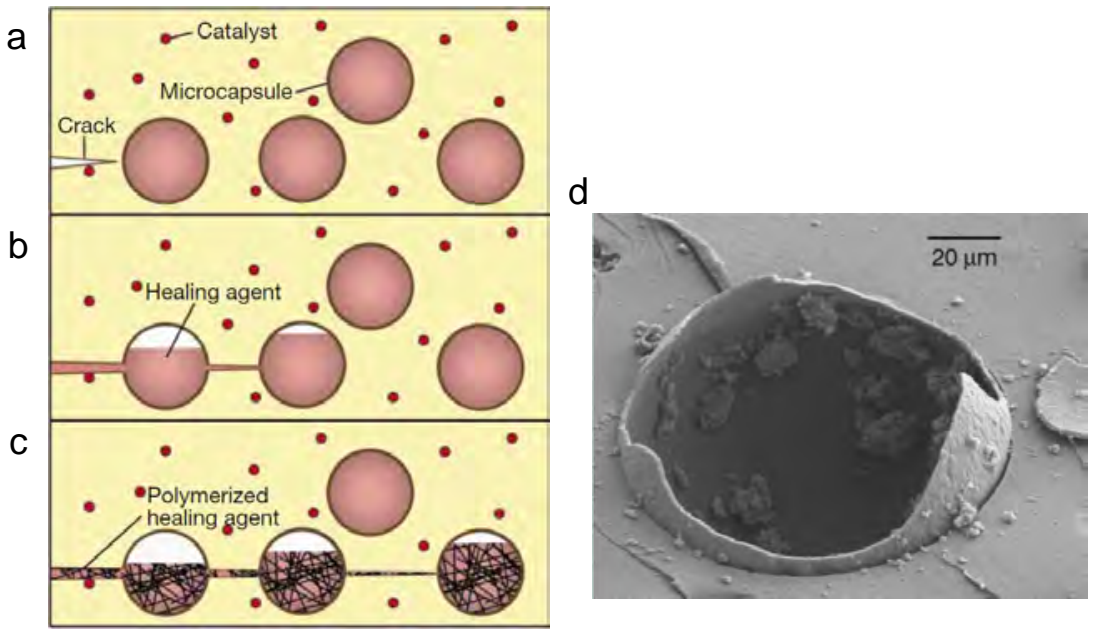

Figure 14. Basic method of the microcapsule approach. (a) Cracks form in the matrix; (b) The microcapsules ruptures, releasing the healing agent into the crack plane; (c) The healing agent contacts the catalyst, bonding the crack faces closed; d-ESEM image showing a ruptured microcapsule ${ }^{[114]}$ 
Table 4. Research methods and achievements of autonomous self-healing

\begin{tabular}{|c|c|c|c|c|c|}
\hline Healing strategy & Agent carriers & Healing agent & Way of curing & Results & Reference \\
\hline \multirow{2}{*}{$\begin{array}{c}\text { Internal } \\
\text { encapsulation }\end{array}$} & Glass/ceramics tube & Cyanoacrylate & Air & Regain $50 \%$ strength and stiffness & Tittelboom et al., 2010 ${ }^{[119]}$ \\
\hline & Glass tubes & Epoxy resin & Air & $32 \%$ higher strength than reference specimen & Thao et al..$^{[120]}$ \\
\hline \multirow{2}{*}{ Microencapsulation } & Silica gel shell & Methyl methacrylate & Heating & Recover over 80\% fracture toughness & Yang, 2009 $9^{[121]}$ \\
\hline & Polyurethane & $\mathrm{Na}_{2} \mathrm{SiO}_{3}$ solution & $\mathrm{Ca}(\mathrm{OH})_{2}$ matrix & Recover 26\% original strength & Pelletier et al. ${ }^{[122]}$ \\
\hline \multirow{2}{*}{ Bacteria } & - & Bacillus sphaericus & Water and $\mathrm{O}_{2}$ & Heal crack up to $0.46 \mathrm{~mm}$ wide & Jonker et al., 2010 $0^{[123]}$ \\
\hline & Polyurethane & Bacterial solution & $\begin{array}{c}\text { Contact } \\
\text { component }\end{array}$ & regain $60 \%$ strength & Wang et al., 2012 ${ }^{[124]}$ \\
\hline
\end{tabular}

of micro-organisms is that most bacteria are able to induce carbonate precipitation in the micro-crack region, thus repairs cracks with environmentally friendly processes.

Autonomous self-healing concrete is more reliable and not much dependent on the surrounding environment compared to autogenous self-healing concrete. Although autonomous self-healing appears as a great potential approach, it remains a great challenge to extend this idea from investigation to application. Hollow fibers, microencapsulation is difficult to cast in concrete, bacterial activity decreases a lot in the high $\mathrm{pH}(>12)$ environment as it presents in concrete. The effect of triggering mechanism of self-healing on the durability, compatibility and mechanical properties of concrete also demands a much deeper research in the future.

\section{Self-Adjusting Concrete}

Self-adjusting concrete has the ability to adjust its internal structures (e.g., pore structures) and performance (e.g., heat capacity, moisture content and hydration process) under external actions. It mainly includes anti- spalling self-adjusting concrete, moisture self-adjusting concrete, thermal parameter self-adjusting concrete and hydration heat self-adjusting concrete. Self-adjusting concrete not only has the ability to improve the comfort of habitation, but also has the ability to avoid temperature cracks which are due to the hydration heat of cement and concrete spalling caused by high temperature. The researches and applications of self-adjusting concrete have aroused a lot of concern in recent years.

\subsection{Anti-Spalling Self-Adjusting Concrete}

Concrete is prone to spalling when it encounters high temperature or fire. Anti-spalling self-adjusting concrete, which is consist of synthetic fibers (e.g., polyethylene fibers, polypropylene fibers and polyacrylonitrile fibers) or metal fibers and concrete, can adjust their pore structure and thermal performance (e.g., thermal conductivity and specific heat capacity) according to the outside temperature to prevent spalling. It was first proposed by Goldfein in 1965 . The polypropylene fibers were added in the concrete as admixtures ${ }^{[125-127]}$.

Currently, there are two main reasons widely accepted for the concrete spalling at high temperature ${ }^{[128-130]}$. The first reason is the internal vapor pressure principle. The water vapor is blocked as it escapes from the concrete pore at high temperature. It results in rising the vapor pressure and expansion stress in concrete. Then, the vapor pressure and expansion stress in the concrete increase with the rising ambient temperature. The second reason is the principle of thermal stress. It has been demonstrated that the temperature gradient is generated by a high ambient temperature. The temperature gradient can induce the thermal stress which will lead to concrete spalling eventually.

Synthetic fibers can be added into concrete to solve the concrete spalling caused by vapor pressure principle. The melting point of synthetic fibers ranges from $150^{\circ} \mathrm{C}$ to $200{ }^{\circ} \mathrm{C}$ generally ${ }^{[131]}$. Due to the uniformity of the synthetic fibers dispersion and the small volume of fibers, the synthetic fibers would melt and form numerous channels inside the concrete when the temperature reaches the melting point of synthetic fibers. The channels inside the concrete provide opportunities for water evaporating, thus reducing the pressure of concrete and the possibility of concrete spalling ${ }^{[132]}$. Xiao ${ }^{[133]}$ confirmed the presence of polypropylene fibers can effectively prevent the spalling of HPC through experiments. Kalifa et al. ${ }^{[128,134]}$ study the spalling performance and microstructure of polypropylene fiber concrete. According to permeability measurement experiments on the concrete with different fiber content, the vapor pressure inside the concrete is obviously reduced by polypropylene fibers under the high temperature. The pressure versus-time curves have a similar shape with different fiber contents. However, the height of the peaks sharply decreases with increasing fiber content as show in Figure 15. The internal peak pressure is reduced by one-fourth and the pressure gradient decreased in half when the content of polypropylene fibers increases from 0 to $3 \mathrm{~kg} / \mathrm{m}^{3}$. In addition, the fiber dosage of $2 \mathrm{~kg} / \mathrm{m}^{3}$ with 

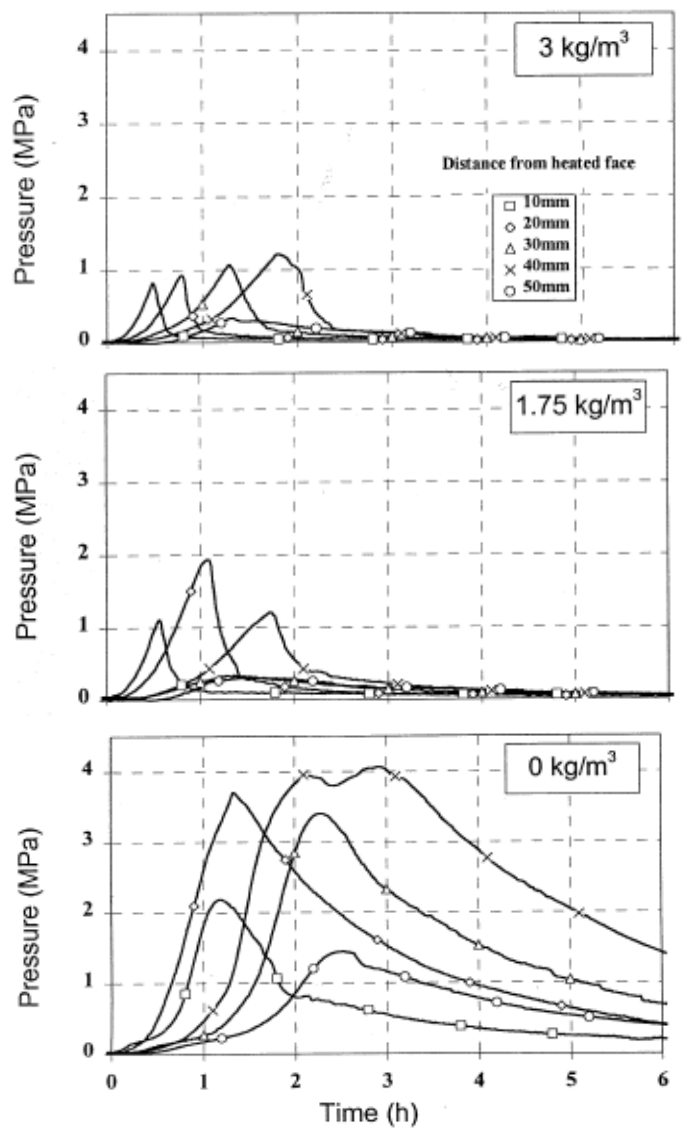

Figure 15. Pressure versus-time curves of concrete with different fiber contents ${ }^{[134]}$

the fiber length of $20 \mathrm{~mm}$ is the optimal for preventing spalling in grade C100 HPC.

Due to the low thermal conductivity of concrete, the temperature difference among the various parts of the concrete structure should be reduced in order to reduce thermal stress of concrete. Because the thermal conductivity of steel is approximately 40 times than that of conventional concrete, steel fibers are often added into the concrete to keep the consistency of temperature rise rate between inner part and the surface of the concrete, thus reducing the concrete spalling.

Although anti-spalling self-adjusting concrete can effectively reduce the possibility of concrete spalling, the durability and the compressive strength of concrete would be weaken because the addition of fibers increases the air content of concrete. Additionally, fibers will reduce the performance of fresh concrete, improving the difficulty of building operations, increasing the cost of tamping ${ }^{[135-137]}$.

\subsection{Moisture Self-Adjusting Concrete}

Humidity environment not only relates to the durability of infrastructures and energy consumption, but also has greatly effect on healthy problems. In order to make a comfortable and healthy environment, it is important to control moisture level ${ }^{[138]}$. The moisture self-adjusting concrete is made of concrete with moisture adjusting materials (e.g., zeolite, attapulgite or meerschaum), and can change the moisture content inside it with external humidity ${ }^{[139,140]}$.

The moisture self-adjusting concrete containing zeolite powder was firstly proposed by Japanese scholars. It does not need the help from any artificial energy and equipment, relying on its own moisture absorption and desorption properties. The hydrated silicate calcium of zeolite contains pores in diameter of $1 \times 10^{-10}-9 \times 10^{-10}$ $\mathrm{m}$. The water vapor adsorption capacity of concrete was improved with porous and multilayered honeycomb structure of zeolite powder, which has larger pore volume and surface area. The moisture self-adjusting concrete made of concrete with zeolite shows a big difference between various humidity conditions. The moisture self-adjusting concrete quickly reaches the moisture content equilibrium state in the low-humidity environment. In the contrast, the moisture content of the moisture self-adjusting concrete increases with time in a saturated humidity environment ${ }^{[141-144]}$.

The working principle diagram of the moisture self-adjusting concrete is shown in Figure 16. When the air relative humidity exceeds a certain value $\Phi 2$, the moisture self-adjusting concrete will absorb moisture in the air to prevent from the increasing of the air relative humidity. When the air relative humidity is lower than a certain value $\Phi 1$, the moisture self-adjusting concrete will desorb moisture to prevent from the decreasing of the air relative humidity. If the moisture content of the concrete is between $\mathrm{U} 1$ and $\mathrm{U} 2$, the indoor relative humidity will be maintained within the range of $\Phi 1-\Phi 2$ automatically $^{[145]}$. Goto et al. tested the moisture controlling performance of the moisture self-adjusting

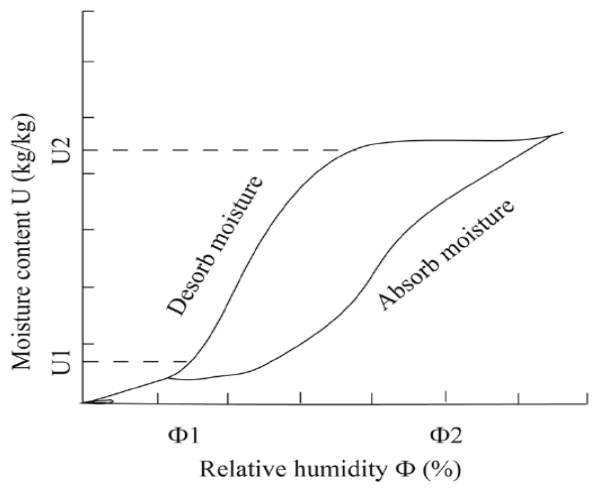

Figure 16. Equilibrium moisture absorption and desorption curves of the moisture self-adjusting concrete ${ }^{[145]}$ 
concrete with zeolite tuff. The amount of water vapor adsorption in the concrete containing fly ash can only reach half the amount of the moisture self-adjusting concrete. The water vapor adsorption isotherm of moisture self-adjusting concrete dried at $150^{\circ} \mathrm{C}$ showed rapid adsorptive variation within range of 30-50 $\mathrm{KH} \%{ }^{[146]}$. Deng et al. studied the moisture self-adjusting capacity of the concrete with different concentrations of attapulgite ( $1 \%$ and $2 \%$, respectively). The moisture desorption capacity of concrete increases with concentrations of attapulgite. The moisture desorption capacity of concrete with $2 \%$ of attapulgite is 1.8 times than that of concrete with $1 \%$ of attapulgite ${ }^{[147]}$. Li et al. made moisture self-adjusting concrete bricks in which the meerschaum-to-cement ratio is 0.144 by weight. The moisture self-adjusting concrete can adjust relative humidity in the test room from $90 \%$ to $65 \%$ in 4.5 hours ${ }^{[148]}$.

Although the moisture self-adjusting concrete has the great ability to maintain indoor relative moisture in a range of $40 \%-70 \%{ }^{[4]}$, its disadvantages are low mechanical properties and poor durability.

\subsection{Thermal Parameter Self-Adjusting Concrete}

Thermal parameter self-adjusting concrete is a kind of smart concrete which utilizes the phase change materials (PCMs) to achieve the function of thermal parameter self-adjustment. PCMs have the ability to absorb or release heat when the material changes from solid to liquid and vice versa. Thermal parameter self-adjusting concrete can maintain the temperature near the required temperature for a period of time by reducing the frequency of temperature fluctuation ${ }^{[149-152]}$. Thermal parameter self-adjusting concrete has great advantages in the field of building energy efficiency compared with the conventional concrete. It can stabilize the indoor temperature through its large specific heat capacity to guarantee the thermal comfort with low-energy when it is used to make exterior walls.

Lane ${ }^{[153]}$ manufactured the thermal parameter selfadjusting concrete by using the method of direct immersion with mirabilite in the 1980s. However, this kind of PCMs has corrosive effect on concrete matrix. Since then, new types of thermal parameter self-adjusting concrete have been developed. Hirayama et al. ${ }^{[154]}$ indicated that the specific heat capacity and the thermal mass of the concrete are increased by adding PCMs, and a building fabricated with thermal parameter self-adjusting concrete can reduce the size of air conditioning systems by adjusting the fluctuations of indoor temperature. Hunger et al. ${ }^{[155]}$ investigated the specific heat capacity of concrete with different concentrations of PCMs (from 0 to 5 wt. \%). Thermal conductivity measurements illustrated that the addition of PCMs into the concrete leads to a reduction of thermal conductivity. With the PCMs-to-cement ratios increasing, the concrete specific heat capacity raises up to 3.5 times as the PCM content is $5 \%$. Farid et al. ${ }^{[156]}$ performed tests of two concrete slabs made of thermal parameter self-adjusting concrete and conventional concrete under $8 \mathrm{~h}$ heating and $16 \mathrm{~h}$ discharging heat cycles, respectively. The surface temperature of the conventional concrete slab ranged from $22.5^{\circ} \mathrm{C}$ to $36.5^{\circ} \mathrm{C}$, while that of thermal parameter self-adjusting concrete slab ranged from $25.0^{\circ} \mathrm{C}$ to $31.5^{\circ} \mathrm{C}$. Castellón et al. ${ }^{[157]}$ tested the performances of two small house-sized cubicles. The first cubicle is made of thermal parameter self-adjusting concrete. The other one is made of conventional concrete. The two cubicles with the same characteristics are located next to each other. The cubicle with conventional concrete always keeps a bigger temperature value $\left(2^{\circ} \mathrm{C}-3^{\circ} \mathrm{C}\right)$ than the cubicle with thermal parameter selfadjusting concrete. While the maximum temperature in the cubicle with conventional concrete is $39^{\circ} \mathrm{C}$, the maximum temperature in cubicle with thermal parameter self-adjusting concrete is only $36^{\circ} \mathrm{C}$. Furthermore, the first cubicle reached the same temperature 2 hours later than the second cubicle as shown in Figure 17.

Although the thermal parameter self-adjusting concrete has better latent heat storage performance, it also has some disadvantages due to PCMs. For example, the PCMs added in concrete prone to leakage when the PCMs become liquid phase. Some kinds of PCMs have a corroding effect on concrete. In addition, the stress produced during the process of phase change of the PCMs can result in damage in the concrete, thus affecting the durability of concrete.

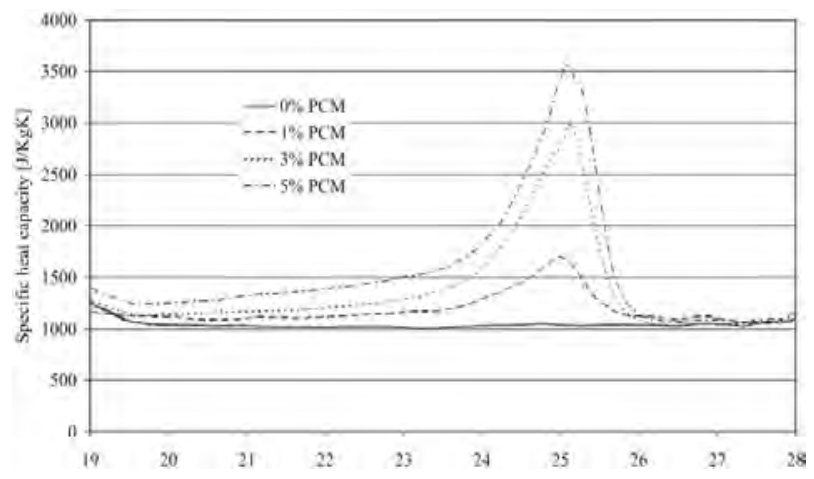

Figure 17. Specific heat capacity of the thermal parameter selfadjusting concrete with different PCM mixes versus temperature $^{[155]}$ 


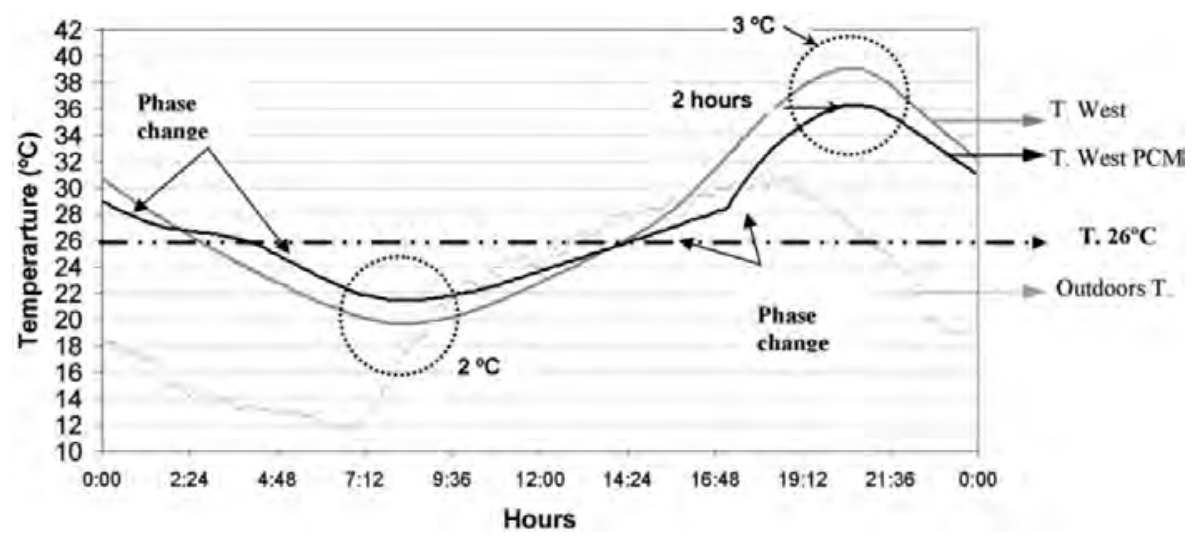

Figure 18. The temperature of the west wall of the two cubicles and the outside temperature ${ }^{[157]}$

\subsection{Hydration Heat Self-Adjusting Concrete}

Concrete is prone to emerge brittle failure after cracks due to its low tensile strength. There are many reasons for concrete cracking, but the main reason is the hydration heat of concrete. Hydration heat self-adjusting concrete is made of concrete and functional fillers. The functional fillers mainly consist of mineral admixture, retarders, starch-based polymers, PCMs, etc. It can effectively slow down the heat of hydration, thus controlling the temperature cracks in concrete ${ }^{[158,159]}$.

Concretes with low strength and low heat of hydration are mainly used in small-scale projects before 1940s. Since 1940s, the concrete with high strength is used in mass concrete constructions more and more widely. The cracking problem of concrete has been received much attention ${ }^{[160]}$. On the one hand, cracks can cause the leakage problem of concrete, increasing the maintenance costs of the project. On the other hand, cracks make it easier for corrosive medium entering into the concrete interior, thus affecting the durability of concrete $^{[161]}$. The study revealed that about 80 percent of the crack in mass concrete constructions is caused by concrete hydration heat. The heat generated by $\mathrm{C}_{3} \mathrm{~S}$ and $\mathrm{C}_{3} \mathrm{~A}$ hydration leads to the temperature rise of concrete as shown in Figure $19^{[162]}$. Because the dissipation rate of concrete internal hydration heat is slower than the dissipation rate of external heat, the temperature gradients between center and surface of concrete can generate temperature stress. When the temperature stress exceeds the ultimate tensile strength of concrete, the concrete surface will crack according to the principle of expansion and contraction ${ }^{[163]}$.

Adding proper amount of fly ash into concrete decreases the content of $\mathrm{C}_{3} \mathrm{~S}$ and $\mathrm{C}_{3} \mathrm{~A}$ in concrete, and the release quantity of hydration heat generated by fly ash is

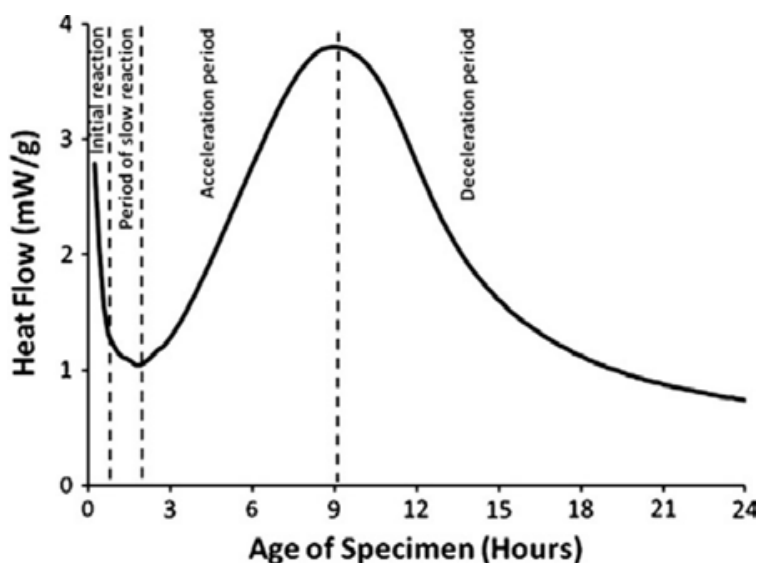

Figure 19. The concrete hydration heat flow curve $\mathrm{e}^{[162]}$

far less than that by $\mathrm{C}_{3} \mathrm{~S}$ and $\mathrm{C}_{3} \mathrm{~A}$, thus reducing the release rate and quantity of concrete hydration heat. Yang et al. ${ }^{[164]}$ observed that the hydration heat self-adjusting concrete with fly ash can not only slow down the release rate of hydration heat, but also postpone the hydration exothermic peak occurs.

Because the retarders are prone to be adsorbed on the surface of cement particles, adding retarders can improve the stability of the cement particles and restrain the agglomeration of the cement particles. Hydration heat self-adjusting concrete with retarders can effectively delay the hydration of concrete and reduce the temperature cracks in concrete. Many researches showed that the more dosage of the retarders, the stronger ability to slow down the cement hydration heat ${ }^{[165,166]}$.

Hydration heat self-adjusting concrete made of concrete and starch-based polymers is different from the hydration heat self-adjusting concrete with retarders. It could decrease the hydration heat evolution rate without changing the total heat generated. The hydration rate will be affected due to the slow release and adsorption of starch-based polymers on cement particles. The mech- 
anism of starch-based polymers on cement particles is shown in Figure 20. Plank et al. applied hydration heat self-adjusting concrete in Nanjing International airport project (China). The temperature rise of side wall was controlled within $21^{\circ} \mathrm{C}$ as shown in Figure $21^{[167]}$.
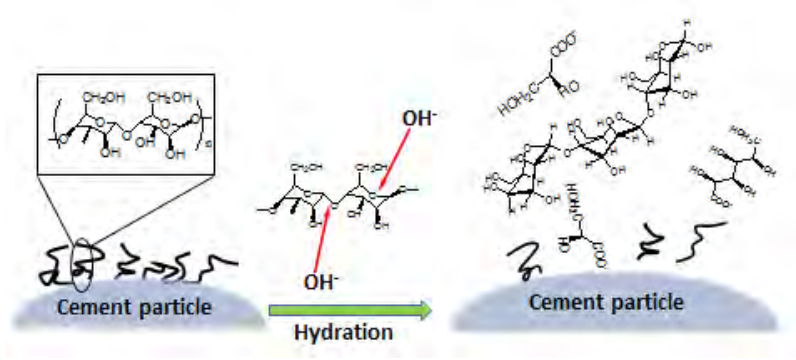

Figure 20. The mechanism action of starch-based polymers on cement particles $^{[167]}$

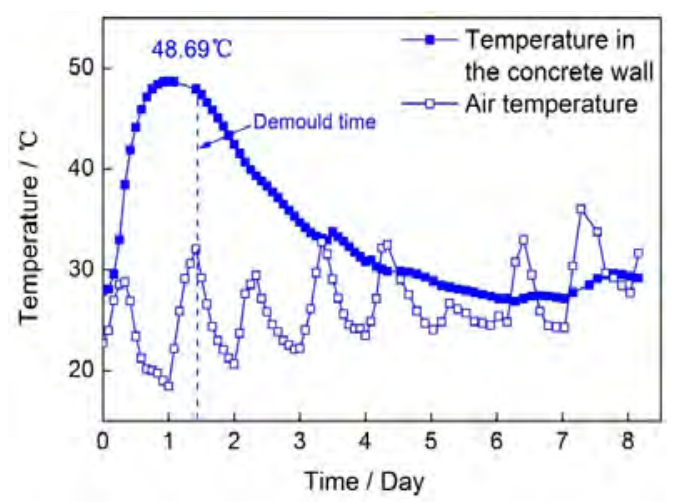

Figure 21. Curve of the temperature in hydration heat selfadjusting concrete wall and air temperature ${ }^{[167]}$

The hydration heat self-adjusting concrete with PCMs also has the ability to reduce the hydration heat of concrete. When the hydration heat of concrete reaches the melting temperature of the PCMs, the PCMs generate phase transition, thus reducing temperature crack caused by hydration heat of concrete. Xing et al. ${ }^{[168]}$ found the hydration heat self-adjusting concrete can effectively adjust the hydration heat of concrete and reduce the peak temperature by $15^{\circ} \mathrm{C}$ to $25^{\circ} \mathrm{C}$.

Although the hydration heat self-adjusting concrete could control the temperature cracks at some degree, the additives could weaken the mechanical property of the concrete $^{[169]}$.

\section{Self-Damping Concrete}

The damping function of the concrete is the capacity of changing vibration energy into other forms of energy. It is very important for reducing vibration in bridges, industrial and civilian infrastructure. Concrete is one of the main materials used in infrastructures, but the low damping property of concrete restricts its use in the structural engineering, especially for the further use in the structures which are under the frequent vibration loads. Therefore, the self-damping concrete is developed in the process of seeking solutions. The self-damping concrete improves its damping property through the introduction of functional fillers such as polymer latex, MWCNTs fibers, silica fume (SF), methylcellulose (MC) and graphite power ${ }^{[170,171]}$.

The damping property of the self-damping concrete which contains polymer latex is due to the dispersing of polymer particles in the concrete. At the same time, it forms three dimensional continuous space network structures which can not only reduce the stress concentration of the concrete effectively, but also increase the capacity of deformation and energy dissipation. Thereby, it can slow down the spread of micro-cracks in the concrete. Wong et al. ${ }^{[172]}$ studied the effect of the concentration and type of the polymers on the damping function of the concrete. It has been demonstrated that the damping function of the concrete has improved to varying degrees when the polymer cement ratio is in the context of $0 \%-25 \%$. The concrete shows better damping function when the polymer cement ratio is in the context of $10 \%-20 \%$. Fu et al. ${ }^{[173]}$ measured the storage modulus, $\tan \delta$ and loss modulus of the concrete with some admixtures under different temperatures and frequencies. They found the three quantities can be increased by adding latex, methylcellulose or silica fume to concrete. Taking into account energy applications, latex is proposed for use at $>1.5 \mathrm{~Hz}$, methylcellulose and silica fume is proposed for use at $<1.5 \mathrm{~Hz}$.

The damping property of the self-damping concrete which contains fibers, SF, and graphite power mainly comes from the interface friction and interfacial peeling caused by relative displacement. In addition, the development and extend of the micro-cracks between the matrix and fiber under the effect of tensile stress will produce energy consumption ${ }^{[174]}$. Luo et al. ${ }^{[175]}$ studied the damping ratio of concrete with different concentrations of MWCNTs (weight fraction of MWCNTs, 0, $0.1 \%, 0.2 \%, 0.5 \%, 2.0 \%$ ) and found MWCNTs in different sizes gather together, thus leading to more multi-phase interfaces and boundaries. The damping ratio of concrete with $0.5 \%$ weight fraction of MWCNTs is increased by $24.51 \%$ with respect to that of plain concrete (as exhibited in Figure 22). With the increasing of weight fraction of MWCNTs, the damping ratio of concrete has a rising trend. There are more interfaces between concrete and MWCNTs at higher weight 
fraction of MWCNTs, which result in greater damping properties of concrete (as shown in Figure 22). Koratkar et al. ${ }^{[176]}$ observed that the addition of carbon nanotubes can improve the damping ratio of concrete by $200 \%$ compared to the plain concrete. Wang et al. ${ }^{[177]}$ reported that the vibration damping ability of concrete can be increased by adding silica fume into concrete. Concrete will reduce the damping ability by adding coarse aggregate or fine aggregate. Therefore, the aggregate proportion designed for reaching high compressive strength may not be able to achieve the effect of vibration damping. Further addition of silica fume can overcome

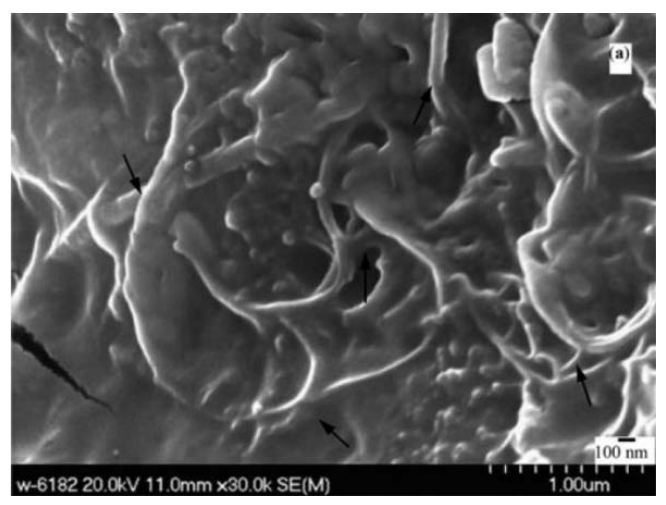

(A) Concrete with $0.5 \%$ weight fraction of MWCNTs

Figure 22. Microstructures of self-damping concrete ${ }^{[175]}$

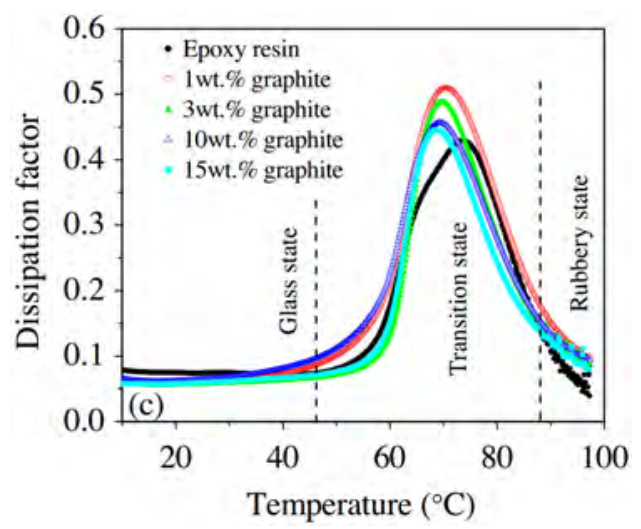

Figure 23. Dissipation factor of self-damping concrete at elevated temperature $^{[178]}$

Although the self-damping concrete has better damping property than traditional concrete, some filler may decrease the compressive strength of concrete to some extent. In addition, it is lack of systematic research for durability which contains the volume stability, impermeability and frost resistance, etc.

\section{Self-Heating Concrete}

Self-heating property of concrete also relies on the the decreased vibration damping ability of concrete which is due to the adding sand to concrete. The loss tangent of the concrete with silica fume at $0.5 \mathrm{~Hz}$ is 0.14 , and it is two orders of magnitude higher than that of plain concrete. Xu et al. ${ }^{[178]}$ provided a method of increasing the damping ratio of concrete by adding piezo-damping composites. They observed that the damping property of concrete with graphite is obviously better than that of the concrete with epoxy resin. The largest damping loss factor of the concrete is 0.51 at a glass transition temperature of $70^{\circ} \mathrm{C}$ when the graphite percentage is $1 \mathrm{wt} . \%$ as shown in Figure 23.

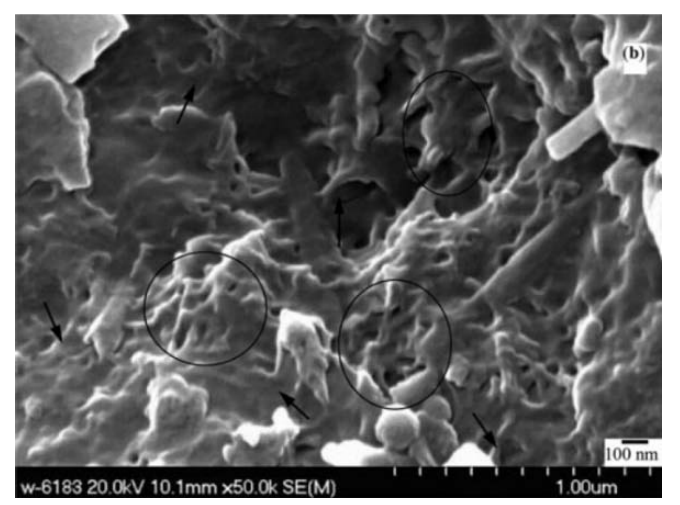

(B) Concrete with $2.0 \%$ weight fraction of MWCNTs

electrical conductivity of concrete, similar to selfsensing concrete. The objective of self-sensing concrete is to detect the variation of concrete through the measurement of electrical signals, while self-heating concrete is to generate heat by applying voltage to concrete based on the Joule law [Equation (1)]. Actually, there is a cross-coupling relationship among the properties of various conductive concretes, as shown in Figure 24 and therefore makes it possible for conductive

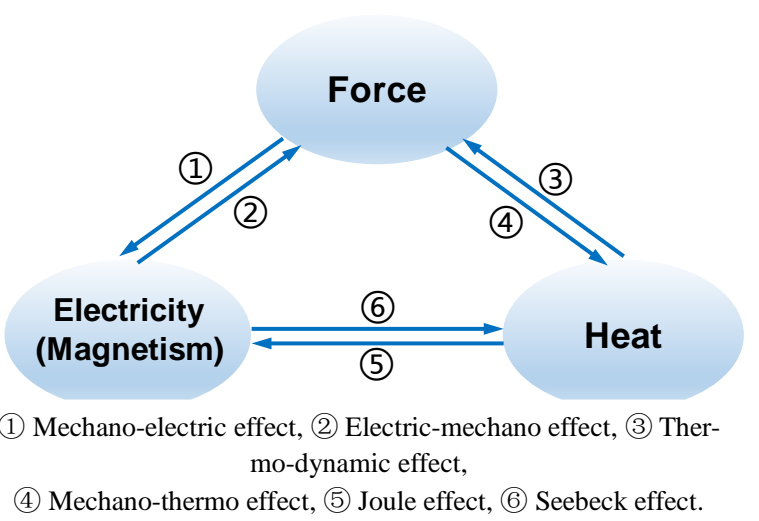

Figure 24. Properties and their cross-coupling relationship of various intelligent concrete materials 
concretes to possess multiple intelligent characters. In general, conventional concrete is hard to be heated due to its high resistivity. Then, electrically conductive fillers such as carbon fibers, steel fibers, steel shaving, nickel powders and graphite were incorporated to reduce the resistivity of concrete ${ }^{[179-187]}$. Therefore, the fabrication process of self-heating concrete is basically the same with that of self-sensing concrete.

Characterized by a heating element, conductive concrete is seen as an electric heater, thus self-heating concrete is also called electrothermal concrete. According to the formula of Joule law, resistivity is a dominant criterion which governs the effectiveness of a material for self-heating, particularly in relation to the power and the maximum temperature. There is a rational resistivity value for the concrete ${ }^{[182]}$, i.e., either excessive high or low is undesired for the materials used as heating element. Since an electric element with rather high resistivity would result in an extremely low current in the heating element (unless the voltage is very high). On the contrary, an electric element with excessive low resistivity would require an extremely high current to reach a certain power ${ }^{[186,188]}$. In addition, the stability of resistivity is a basic requirement for conductive concrete to become self-heating. Only with a stable resistivity, the steady electrothermal power will be attainable. Studies indicated that the resistivity of conductive concrete tended to be stable, on condition that the content of conductive filler closes to or more than the percolation threshold ${ }^{[189-192]}$.

$$
Q=I^{2} R t \text { or } P=I^{2} R
$$

Where $Q$ is calorific value, $I$ is current, $R$ is resistance, $t$ is time, $P$ is thermal power.

One of the applications of self-heating concrete is domestic heating. It is realized by substituting selfheating concrete for traditional concrete in the wall or floor and applying voltage to them, and then heat will be emitted continuously from the wall or floor. What's more, this kind of conductive concrete is absolutely safe to human since just a small voltage and current is needed when the concrete works and no electric can be felt even if touch it. A kind of carbon black concrete slabs (CBCS) was used as self-heating flooring material by Sun et al. ${ }^{[193]}$. The investigation manifested that the CBCS was able to raise the temperature of a small room up to $10{ }^{\circ} \mathrm{C}$ in $330 \mathrm{~min}$ and the distribution of temperature along the height of room was uniform. In addition, the heating system provided by CBCS floor was stable, sustainable and controllable. In former Soviet Union, electric heating floor and fur- ring brick were made by self-heating concrete and they were used for providing heat for residence, factory and greenhouse. Another application of self-sensing concrete is road deicing or snow-melting. In freezing climates, many transportation infrastructures (such as driveways, bridges and airport runways) are prone to ice accumulation. Ice or snow accumulation on these infrastructures may cause a number of dangerous situations for traffic ${ }^{[194]}$. Therefore, improving the conditions of transportation infrastructures in a timely and high-efficient fashion is imperative. A conclusion of deicing and snow-melting methods used in the past thirty years was made by Yehia and Tuan ${ }^{[181,195]}$. They pointed out that the traditional snow removal and deicing methods (labor or machine removal and using salt etc.) are labor intensive and time-consuming, also will cause damages to both the constructions and the ecological environment. Compared with conventional deicing methods, self-heating concrete has the advantages of high efficiency, no negative effects and without pollution. The idea of employing steel fiber and shaving as conductive fillers was presented by Tuan and a serious of experiments involving deicing on the bridge deck was conducted ${ }^{[183]}$. After that, selfheating concrete was applied to the Roca Spur highway in American and steel shaving was replaced by graphite (with content of 25\%). So far, this self-heating concrete system operates well and no conductivity reduction occurs. Preliminary cost analysis showed that the proposed conductive concrete bridge deck was less expensive than conventional concrete deicing methods ${ }^{[185]}$. Zhang et al. ${ }^{[186]}$ employed nickel particle as conductive fillers and heating elements in concrete. Experimental results indicated that the concrete with nickel particles (12.0 vol. \% and 2.6-3.3 $\mu \mathrm{m}$ in diameter) can melt $2 \mathrm{~cm}$ thickness of snow in $368 \mathrm{~s}$ at an input voltage of $15 \mathrm{~V}$. Several pictures during the snow melting experiment were given in Figure 25. Selfheating concrete was also applied to subway in London to protect passengers from slipping on frozen platform. The self-heating concretes used in platform were characterized by rapidly warmed under low voltage.

However, it should be noted that the self-heating concrete requires high property of heating element including higher thermal rate, high mechanical properties, and stable electrical conductivity. Heating efficiency may be influenced by the factors of ambient temperature, wind speed and thickness of the ice/snow layer. Steel fiber is recommended in concrete which can better meet the requirement in engineering application. 


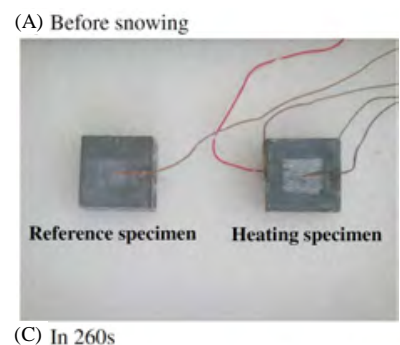

(B) After snowing, with $2 \mathrm{~cm}$ of snow

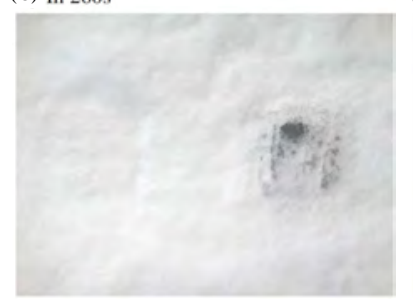

(D) In 368s

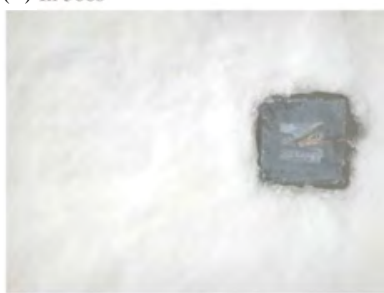

Figure 25. Snow-melting process of the self-heating concrete with nickel powders ${ }^{[186]}$

Nevertheless, the workability of concrete is inclined to become poor with higher content of steel fiber, also steel fiber is easily to corrosion. Therefore, new type self-heating concrete accompanying higher heating performance and long-term stability is still necessary to develop.

\section{Self-Sacrificing Concrete}

Self-sacrificing concrete, also called self-sacrificing anodic concrete, refers to the concrete with capacity of sacrificing itself to protect the cathode of impressed current cathodic protection (ICCP) system. Self-sacrificing concrete are made of conductive concrete, such as carbon fiber conductive concrete and steel fiber conductive concrete.

The damage caused by corrosion of the steel reinforcement is a prime factor of concrete corrosion. Cathodic protection (CP) system, in which sacrificial anodes cathodic protection and ICCP is used as two main cathodic protection components to control corrosion, is considered as a leading method for the protection against corrosion in concrete structures. As illustrated in Figure $26^{[196]}$, in the ICCP systems, a

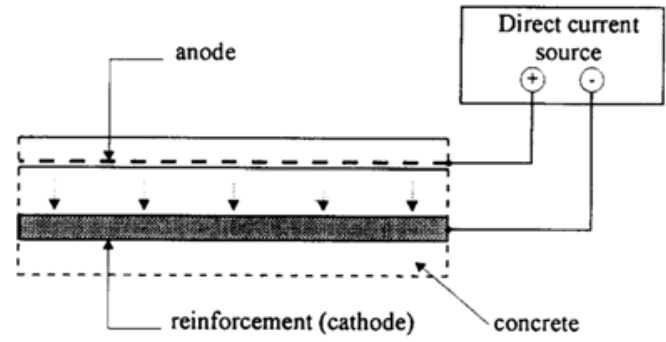

Figure 26. Schematic illustration of cathodic protection reinforcement of a concrete structure ${ }^{[196]}$ direct current flows through the concrete from a selfsacrificing concrete anode usually laid on the concrete surface to a cathode (i.e., steel reinforcement). The anode connects with the positive terminal of a low voltage direct source, and the cathode connects with the negative terminal. In order to make charge balanced; the anode would lose electrons and be destroyed after about 30 days.

At the beginning of 1970 , Stratfull ${ }^{[197]}$ firstly used self-sacrificing concrete as anode in ICCP system, which is applied on a $307 \mathrm{~m}^{2}$ bridge deck. Cañón et al. ${ }^{[198]}$ used the self-sacrificing concrete and $\mathrm{Ti}^{-} \mathrm{RuO}_{2}$ as anodes to build an ICCP system, respectively. Figure 27 shows the method of fabricating self-sacrificing concrete anode. They compared self-sacrificing anode with traditional $\mathrm{Ti}-\mathrm{RuO}_{2}$ anode and measured the chloride concentration profile of different depths, the initial chloride concentration profile, the final chloride concentration profile and the local efficiencies (in decreasing the $\mathrm{Cl}^{-}$content) as showed in Figure 28(a), while the case of using $\mathrm{Ti}-\mathrm{RuO}_{2}$ as an anode as showed in Figure 28(b). It can be seen from these two figures that the efficiency of a sprayed anode based on self-sacrificing concrete is nearly the same as traditional reference anode (i.e., $\mathrm{Ti}^{-\mathrm{RuO}_{2}}$ mesh).

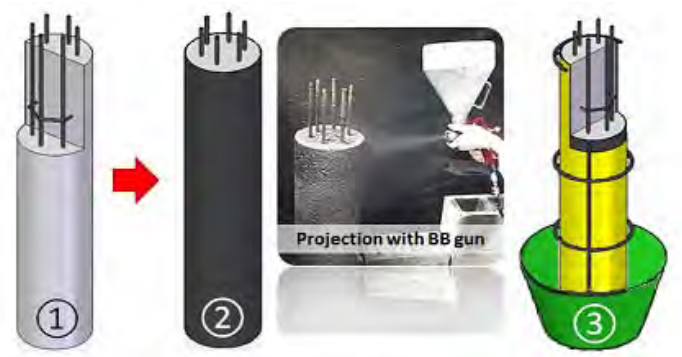

Figure 27. Device assembly with self-sacrificing concrete anode: (1) Self-sacrificing concrete is sprayed by using a compressed air gun on the surface of the specimen. (2) An absorbent layer of polypropylene is placed recovering the specimen surface. (3) The electrical circuit is installed. The positive pole of the source is connected to the anode, and the negative pole is connected to one of the longitudinal of the specimen reinforcement $^{[198]}$

Yehia et al. used self-sacrificing concrete overlay as an anode to be cast on the top of a bridge deck for preventing reinforcement corrosion. Four slabs with different electrode sizes and spacings were tested. The supplied $2 \mathrm{~V}$ voltage provided ample CP in terms of meeting the required 4 hour $100 \mathrm{mV}$ polarization in each slab at each test. Test results are shown in Table 5. It can be seen from Table 5 that there was a significant 


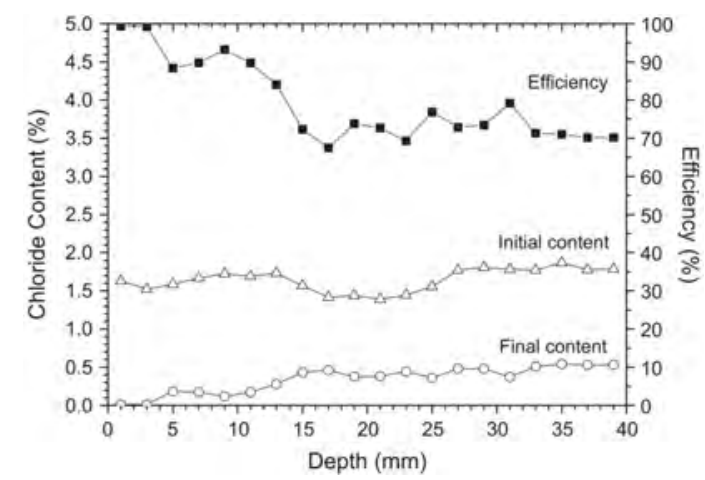

(A) Using self-sacrificing concrete as anode

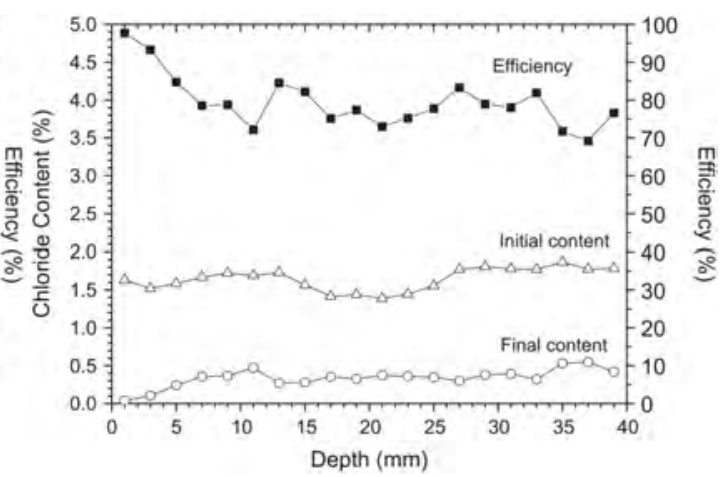

(B) Using Ti- $\mathrm{RuO}_{2}$ as anode

Figure 28. The chloride concentration profile of different depths and the local efficiencies in decreasing the $\mathrm{Cl}^{-}$content ${ }^{[198]}$

Table 5. Electrical resistance, current and polarization of four different self-sacrificing concrete overlay slabs

\begin{tabular}{|c|c|c|c|c|c|c|c|c|}
\hline Specimen & $\begin{array}{c}\text { Electrical } \\
\text { Resistance } / \Omega\end{array}$ & $\begin{array}{l}\text { Current } \\
/ \mathrm{mA}\end{array}$ & $\begin{array}{l}\text { Area between } \\
\text { electrodes } / \mathrm{m}^{2}\end{array}$ & $\begin{array}{c}\text { Current } \\
\text { density } / \mathrm{mA} / \mathrm{m}^{2}\end{array}$ & $\begin{array}{l}\text { 'Instant-off' } \\
\text { Voltage/mV }\end{array}$ & $\begin{array}{l}\text { Four-hour } \\
\text { Voltage/mV }\end{array}$ & $\begin{array}{l}\text { Polarization } \\
\quad / \mathrm{mV}\end{array}$ & $\begin{array}{c}\text { Met NACE } \\
\text { Polarization criteria }\end{array}$ \\
\hline \multirow{5}{*}{$\begin{array}{l}914 \times 914 \\
\mathrm{~mm}^{2} \text { slab }\end{array}$} & 100.00 & 20.50 & 0.84 & 44.13 & -900.0 & -126.2 & 773.8 & Yes \\
\hline & 100.00 & 19.96 & 0.84 & 42.95 & -850.0 & -131.6 & 718.4 & Yes \\
\hline & 120.70 & 16.56 & 0.84 & 35.6 & -860.0 & -139.6 & 720.4 & Yes \\
\hline & 149.60 & 13.53 & 0.84 & 29.17 & -970.0 & -152.9 & 817.1 & Yes \\
\hline & 175.00 & 11.41 & 0.84 & 24.5 & -1077.0 & -159.6 & 917.4 & Yes \\
\hline \multirow{5}{*}{$\begin{array}{c}1067 \times 1067 \\
\mathrm{~mm}^{2} \text { slab }\end{array}$} & 105.70 & 18.89 & 1.14 & 27.13 & -840.0 & -106.5 & 733.5 & Yes \\
\hline & 100.00 & 20.18 & 1.14 & 28.95 & -860.0 & -101.9 & 758.1 & Yes \\
\hline & 147.90 & 13.53 & 1.14 & 19.37 & -850.0 & -139.9 & 710.1 & Yes \\
\hline & 185.50 & 10.86 & 1.14 & 15.61 & -970.0 & -150.9 & 819.1 & Yes \\
\hline & 223.70 & 8.93 & 1.14 & 12.81 & -850.0 & -166.4 & 683.6 & Yes \\
\hline \multirow{4}{*}{$\begin{array}{l}1219 \times 1219 \\
\mathrm{~mm}^{2} \text { slab }\end{array}$} & 84.56 & 23.65 & 1.49 & 24.22 & -830.0 & -101.7 & 728.3 & Yes \\
\hline & 104.20 & 19.33 & 1.49 & 19.8 & -830.0 & -145.6 & 684.4 & Yes \\
\hline & 143.80 & 12 & 1.49 & 19.8 & -830.0 & -145.6 & 684.4 & Yes \\
\hline & 185.50 & 8.53 & 1.49 & 8.72 & -1052.0 & -156.0 & 896.0 & Yes \\
\hline \multirow{2}{*}{$\begin{array}{c}1524 \times 1524 \\
\mathrm{~mm}^{2} \text { slab }\end{array}$} & 127.40 & 15.79 & 2.3 & 9.47 & -810.0 & -197.4 & 612.6 & Yes \\
\hline & 149.14 & 13.39 & $2 . .3$ & 7.97 & -1015.0 & -229.1 & 785.9 & Yes \\
\hline
\end{tabular}

polarization during 4 hour period. The $100 \mathrm{mV}$ polarization criterion was met and hydrogen discharge was limited. In this ICCP system, the anode is destroyed after about 30 days, while through the removal of the destroyed concrete overlay, a new self-sacrificing concrete coating could be paved. As a result, the anode could continue to protect the bridge decks ${ }^{[199]}$.

Self-sacrificing concrete has a promising application prospect due to the following advantages: (1) its construction is relatively easy. It can be sprayed with a compressed air gun and used as coating to treat sizable vertical surfaces such as structural supports, especially structural concrete elements with complex shapes; (2) it not only has the structural function, but also has the replaceable function; (3) it is low-cost compared with other types of anode. However, there exist some issues needed to be addressed, such as long-term poor stability and durability of anode materials and rectifiers, limitation to monitor and to maintain the system, insufficient understanding of fundamental technology with regards to the self-sacrificing concrete, and degradation of the mechanical properties during service life of the self-sacrificing concrete.

\section{Self-Cleaning Concrete}

Self-cleaning concrete is the concrete with abilities of resisting wetting by liquids or cleaning hazardous substance in the surface of concrete by itself. To obtain self-cleaning concrete, two strategies are usually applied: superhydrophobic and photocatalytic. 
Solid materials are divided as hydrophilic and hydrophobic according to the water contact angel (WCA). Contact angel is described as the angel between solid surface and the tangent line of liquid phase in the surface of solid phases. For a contact angel more than $90^{\circ}$, hydrophobic behavior is deemed to appear and a contact angel less than $30^{\circ}$ could denote the hydrophilic phenomenon. Superhydrophobic and superhydrophibic surfaces are the subclasses of hydrophobic and hydrophibic surfaces, respectively. The contact angels formed by water droplets upon superhydrophobic surface are usually over than $150^{\circ}$, and those upon superhydrophibic surfaces are less than $10^{\circ}$, as shown in Figure 29. Normal concrete is a porous material which can absorb water and therefore considered as hydrophilic material.

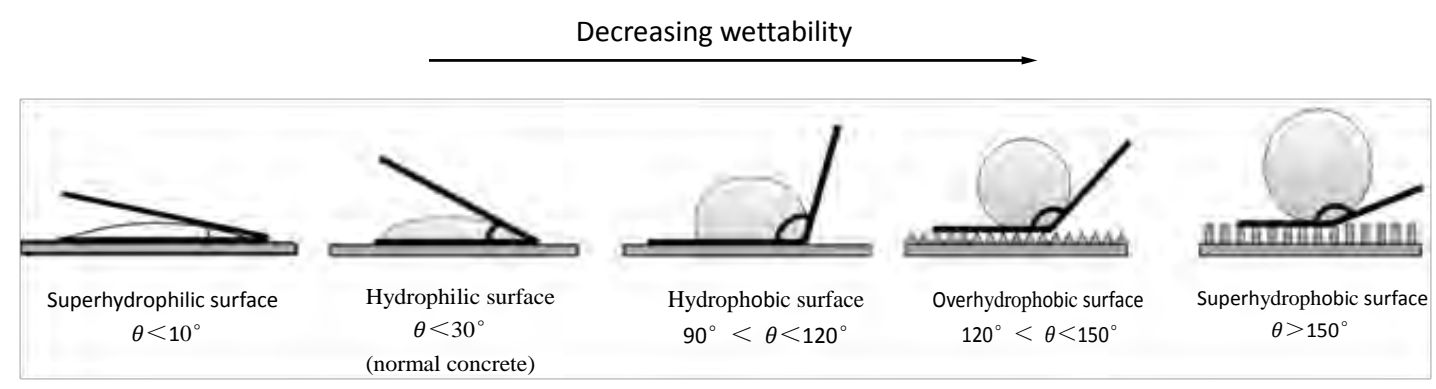

Figure 29. Superhydrophilic, hydrophibic, hydrophobic, overhydrophobic, superhydrophobic surface.

\subsection{Superhydrophobic Concrete}

Superhydrophobic self-cleaning concrete is a novel of biomimetic inventions ${ }^{[200]}$, whose inspiration comes from the Lotus Effect ${ }^{[95,201]}$. It is well known that leaves of lotus plant can remain clean and free of contaminants, although the habitats are mainly muddy rivers and lakes. This phenomenon is attributed to the superhydrophobic nature of lotus leaves, as illustrated in Figure 30. The direct contacts between water and lumps that existed on the lotus leaf can drive the water split into plenty of small spherical droplets. Then the bead could roll and tumble off the leaf even with the slightest angles. Simultaneously dirt particles and small insects are pack up as bead goes. Thus selfcleaning is realized and this process is named the Lotus Effect ${ }^{[95]}$.

The superhydrophobicity of materials is determined by the geometry and chemical constitution of material surface ${ }^{[202]}$. Usually, a specified micro and nano-structure morphology formed by the combination of high

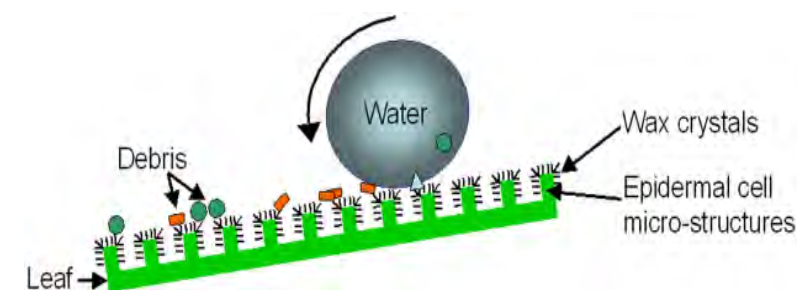

Figure 30. Water forms droplets on the tips of the epidermal protrusions and collects pollutants, dirt and small insects as it rolls off the leaf ${ }^{[95]}$ surface roughness and low surface energy is employed to achieve the superhydrophobicity ${ }^{[203]}$. It is found that the superhydrophobic self-cleaning ability of concrete can be achieved by incorporating some admixtures into concrete ${ }^{[204,205]}$. The admixtures have been reported to increase the concrete hydrophobicity including nanoparticles, oil, wax and water resistant polymers etc. ${ }^{[206,207]}$. Batrakov concluded that hydrogen can be released by the reacting of hydroxyl groups of $\mathrm{CH}$ and siloxane-based admixtures such as polymethylhydrosiloxane (PMHS) due to the Si-H bond of admixtures. As a consequence, small $(10-100 \mu \mathrm{m})$ and well dispersed air voids are created throughout the concrete ${ }^{[208]}$. The walls of these voids are then coated by submicron or nano-sized particles and a hierarchical surface roughness is produced to achieve superhydrophobic properties within the hardened cement phase/paste (Figure 31$)^{[209]}$. To obtain an optimum performance, more than $70 \%$ of the PMHS should be dispersed to the level of under $1 \mu \mathrm{m}^{[200]}$. As a result, the surfaces of the voids are covered by the hydrophobic particles, providing the effect of superhydrophobic hybridization. The idea of mixing superhydrophobic admixture with ECC to form an ultra-durable material-superhydrophobic ECC (SECC) was proposed by Sobolev ${ }^{[209,210]}$. The investigation demonstrated that the incorporation of superhydrophobic admixtures in ECC was beneficial for improving flexural toughness without adverse influence on the compressive strength. This reinforcement effect was achieved by the addition of admix 


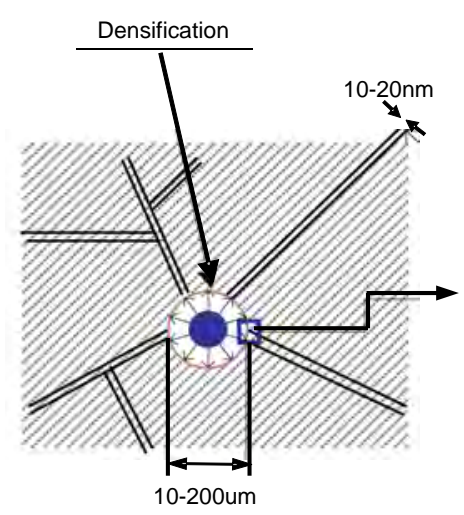

(A)

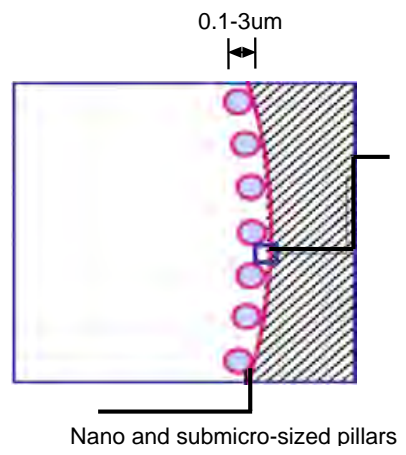

(B)

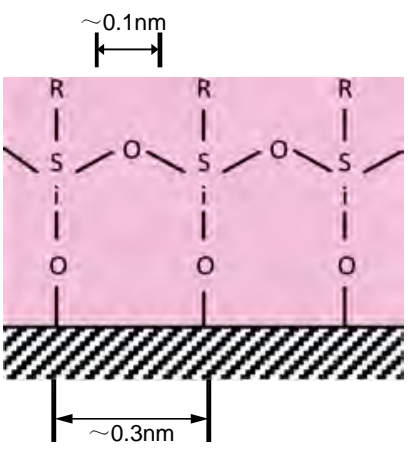

(C)

Figure 31. How the superhydrophobic hybridization of concrete works. (a) PHMS admixture, (b) Engineered superhydrophobic pore surface, (c) self-assembly of hydrophobic 2D network on the pore/pillar surface ${ }^{\text {[209] }}$

tures including 25\% PMHS along with 4.4\% polyvinyl alcohol surfactant and small quantities of submicron sized particles. And this composition of admixtures was proved to be the most ideal admixture since small and well dispersed air voids were created within the concrete.

The superhydrophobic self-cleaning concrete can not only clean the surface of concrete but also decrease the water absorption and permeability. Thereby durability of concrete can be optimized by the characteristic of superhydrophobicity which makes concrete valuable in the long run of construction for reducing the restore costs. Furthermore, superhydrophobic property of concrete can also play roles in reducing the accumulated snow or ice on the road in cold regions $^{[211]}$. However, most of superhydrophobic admixtures mixed into concrete may lower the strength of concrete.

\subsection{Photocatalytic Concrete}

Photocatalysts material is related to the materials which can catalyze chemical reaction with the involvement of light illumination ${ }^{[212]}$. Photocatalytic property of self-cleaning concrete is mainly achieved through introducing photocatalysts into it. Currently, $\mathrm{TiO}_{2}$ is the most widely investigated and used photocatalysts for the advantages of highly stable property in the dark, strong oxidizing ability under ultraviolet (UV) lighting, low cost and innoxious. The crystallographic $\mathrm{TiO}_{2}$ exists in three forms: brookite, rutile and anatase. Compared with other two forms, the anatase crystal is proved to be the most photocatalytically active due to the spherical particles and large specific surface area ${ }^{[213]}$.

One of the photocatalytic mechanisms is pho- to-induced redox reactions ${ }^{[214]}$. As a semiconductor material, the electronic structure of $\mathrm{TiO}_{2}$ is characterized by a filled conduction band (CB) and an empty valence band (VB), which are distinguished by a band gap of energy $(\Delta \mathrm{E})$. Without enough photonic excitation (i.e., $\mathrm{h}_{\mathrm{v}}<\Delta \mathrm{E}$ ), the photocatalyst is at the ground state and the electrons are confined in the range of $\mathrm{VB}$, as shown in Figure 32(a). However, once a photon containing the energy equal to or larger than $\Delta E$ (i.e., $h_{v} \geqslant \Delta E$ ) is absorbed by $\mathrm{TiO}_{2}$, the electrons will overcome the band gap barrier and move to the CB area. The activation and transition of the electrons lead to holes (electron vacancy) left in the VB zone, as shown in Figure 32(b). For the formation of highly active electrons $\left(\mathrm{e}^{-}\right)$in the $\mathrm{CB}$ and positive holes $\left(\mathrm{h}^{+}\right)$in the $\mathrm{VB}$, electron-hole pairs is then generated [as shown in Equation (2)].
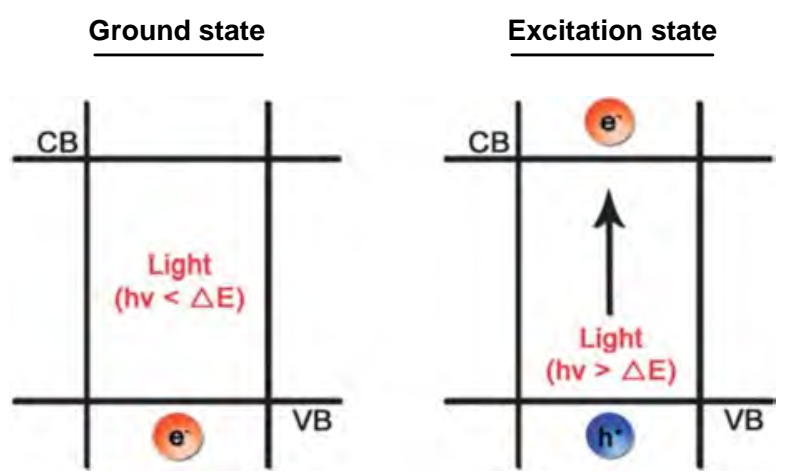

Figure 32. Schematic diagram of photo-excitation process on $\mathrm{TiO}_{2}$ surface ${ }^{[215]}$

There are three possible routes for the reaction of formed electron-hole pairs, as shown in Figure 33: (1) electron-hole pairs may recombine on the surface or 
within the photocatalyst (recombination) [Equation (2)]; (2) electrons spread onto the surface of photocatalyst and react with oxygen molecules $\left(\mathrm{O}_{2}\right)$, producing reactive oxygen radicals $\left(-\mathrm{O},-\mathrm{O}_{2},-\mathrm{O}_{3}\right)$, (photoreduction) [Equation (3)]; and (3) holes oxidize water molecules $\left(\mathrm{H}_{2} \mathrm{O}\right)$ or adsorb hydroxide ions $\left(\mathrm{OH}^{-}\right)$forming highly oxidizing hydroxyl radicals $(-\mathrm{OH})$ (photooxidation) [Equation (4)]. The generated $-\mathrm{O},-\mathrm{O}_{2},-\mathrm{O}_{3}$ and $-\mathrm{OH}$ can react with contaminants producing carbon dioxide, water or other harmless substances (Figure 33).
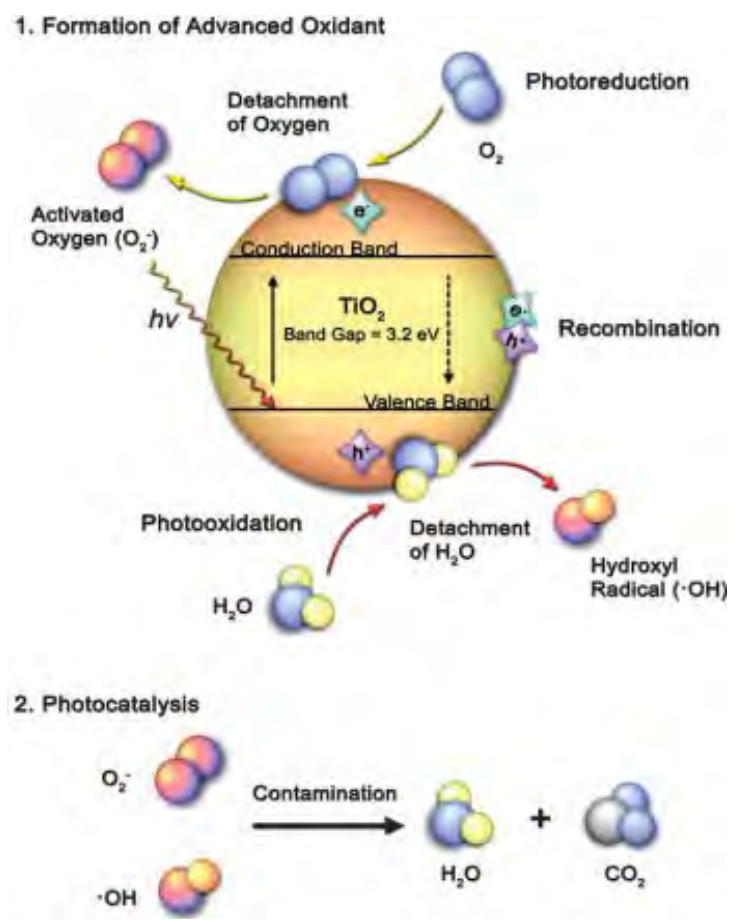

Figure 33. Schematic diagram of $\mathrm{TiO}_{2}$ photocatalysis ${ }^{[215]}$

$$
\begin{gathered}
\mathrm{TiO}_{2}+h \rightarrow \mathrm{Ne}^{-}+h^{+} \\
e^{-}+h^{+} \rightarrow \mathrm{TiO}_{2} \\
\mathrm{e}^{-}+\mathrm{O}_{2} \rightarrow \mathrm{O}_{2}^{-} \\
\mathrm{h}^{+}+\mathrm{H}_{2} \mathrm{O} \rightarrow \mathrm{OH}+\mathrm{H}^{+}
\end{gathered}
$$

Another mechanism for photocatalysis is photo-induced superhydrophilicity (Figure 34) ${ }^{[216,217]}$. The atomic binding energy of $\mathrm{Ti}$ and $\mathrm{O}$ is weakened due to the generation of $\mathrm{e}^{-}$and $\mathrm{h}^{+}$pairs after UV irradiation. Therefore, a Ti-O-Ti bond will be broken by water molecules easily and form two new Ti-OH bonds (Figure 34). Then, the external surface of $\mathrm{TiO}_{2}$ becomes superhydrophilic and forms a sheet-like layer of moisture under water and UV irradiation. Thus a transparent protector against dirt is developed. In fact, $\mathrm{TiO}_{2}$ film is not only hydrophilic but also amphiphilic after UV irradiation. Therefore adsorbed stains like oil can also be washed away when water rinsed over the superhydrophilic $\mathrm{TiO}_{2}{ }^{[216,218]}$.

Actually, the macroscopic manifestation of selfcleaning is a combined effect of photo-induced redox reactions and photo-induced superhydrophilicity. Although the redox reaction and superhydrophilicity are different processes, they could work simultaneously and are difficult to distinguish which is more important for achieving self-cleaning property. Several of novel applications have been developed depending on the synergetic effect of these two photocatalysis mechanisms. Concrete incorporated with nano- $\mathrm{TiO}_{2}$ is successfully applied in the infrastructures like walls and pavements. It has proven very effective for cleaning of building appearance, disinfecting air of indoor and reduction of urban pollutants ${ }^{[214,219,220]}$. On one hand, the applications of $\mathrm{TiO}_{2}$ concrete can maintain the aesthetic and luster of the building surface. For instance, a white photocatalytic concrete involving $\mathrm{TiO}_{2}$ has been employed for the construction of the Dives in Misericordia Church in Rome, Italy (completed in 2003). During six years monitoring, only a slight difference of lightness values between internal and external walls was observed for the church in Rome. On the other hand, pavements made by the concrete containing nano- $\mathrm{TiO}_{2}$ could trigger photocatalytic degradation of pollutant, such as nitrogen oxides
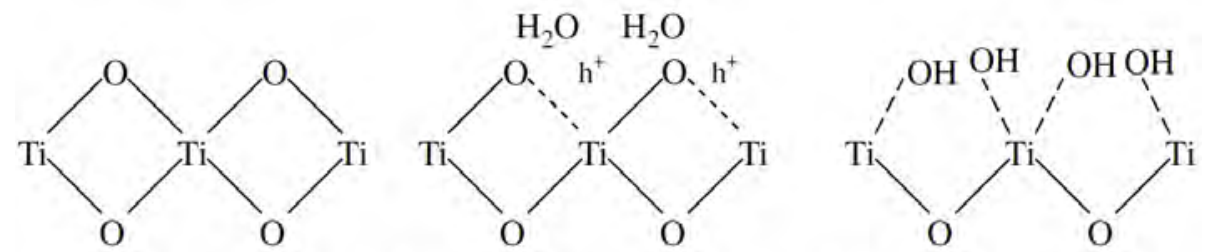

In the dark

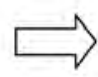

UV Irradiation

Water absorption

Figure 34. Photo-induced hydrophilic $\mathrm{TiO}_{2}$ surface 
$\left(\mathrm{NO}_{\mathrm{X}}\right.$ ), volatile organic compounds (VOCs), aldehydes exhausted from combustion engine and industrial emissions. Detrimental $\mathrm{NO}_{\mathrm{X}}$ can be transformed into uninjurious nitrate ions $\left(\mathrm{NO}_{3}^{-}\right)$by $\mathrm{TiO}_{2}$ and the final products of $\mathrm{NO}_{3}^{-}$are easily washed away by the rains, as illustrated in Figure $35^{[221]}$. Poon and Cheung ${ }^{[222]}$ evaluated the removal rate of NO by the paving blocks consisting of cement materials and $\mathrm{TiO}_{2}$. The results indicated that an optimum mix design incorporating cement, sand, recycled glass and $10 \%$ $\mathrm{TiO}_{2}$ could achieve a NO removal rate of $4.01 \mathrm{mg} / \mathrm{hm}^{2}$. Another typical investigation of NO removed by the photocatalytic paving blocks obtained in laboratory is diagramed in Figure $36^{[223]}$. A block located in the center of Bergamo (Italy) city was re-paved using photocatalytic concrete paving blocks with a total area of about $12,000 \mathrm{~m}^{2}$. An air monitoring campaign was then conducted for two weeks and showed an average decrease of NOx by $45 \%$ in daily time from 9 am to 5 $\mathrm{pm}^{[224]}$. In Guerville (France), three artificial street canyons covered by photocatalytic mortar were built to evaluate the performance against pollution. Continuous monitoring of $\mathrm{NO}_{\mathrm{X}}$ was taken and showed that the $\mathrm{NO}_{\mathrm{X}}$ concentrations observed in the $\mathrm{TiO}_{2}$-treated canyon were $36.7-82.0 \%$ lower than that control

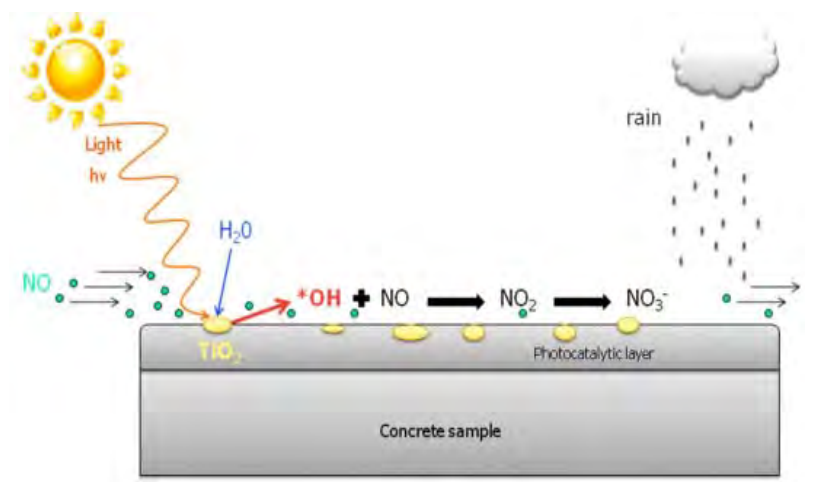

Figure 35. Illustration of the photocatalytic process $^{[221]}$

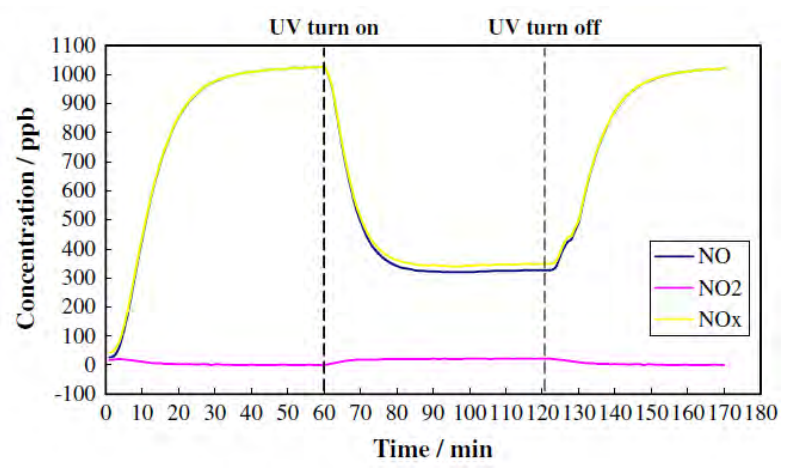

Figure 36. Photocatalytic $\mathrm{NO}_{\mathrm{X}}$ removal results of photocatalytic paving block obtained in laboratory ${ }^{[223]}$ canyons $^{[225]}$. Additionally, the versatile nano- $\mathrm{TiO}_{2}$ photocatalytic reactions can also eliminate the harmful organisms like bacteria and virus. Therefore, high standard hygiene demand can be satisfied in some venues where sterile conditions are extremely crucial.

The greatest advantage of photocatalytic self- cleaning concrete is the simple reaction conditions, which just requires sunlight, oxygen, water and $\mathrm{TiO}_{2}{ }^{[213]}$. It is important that $\mathrm{TiO}_{2}$ is well compatible with concrete without any adverse effect on mechanical properties. However, once they are used in real-life applications, the durability and efficiency of the photocatalytic selfcleaning concrete is still needed to be improved ${ }^{[226]}$. Furthermore, whether it is safe to apply the photocatalytic materials, especially the possible health effects of the by-products formed in incomplete photo-oxidation is still a controversy question ${ }^{[227]}$.

\section{Self-Shaping Concrete}

Three dimensional printing (3DP) technology, started in the late 1980's in Japan, has undergone rapid development in the last thirty years. As a subgroup of additive manufacturing process, three dimensional solid objects would be directly printed by 3DP technology from a digital model ${ }^{[228]}$. 3DP can meet the demand to manufacture any desired geometry shapes with the advantage of reducing material consumption and the associated labor force. To date, this technology has been successfully used in medical, aerospace and automotive manufacturing, etc. ${ }^{[229]}$. It is also promising for printing architectural and structural components.

A concrete printing machine and its delivery system are shown in Figure 37. The main operation principle

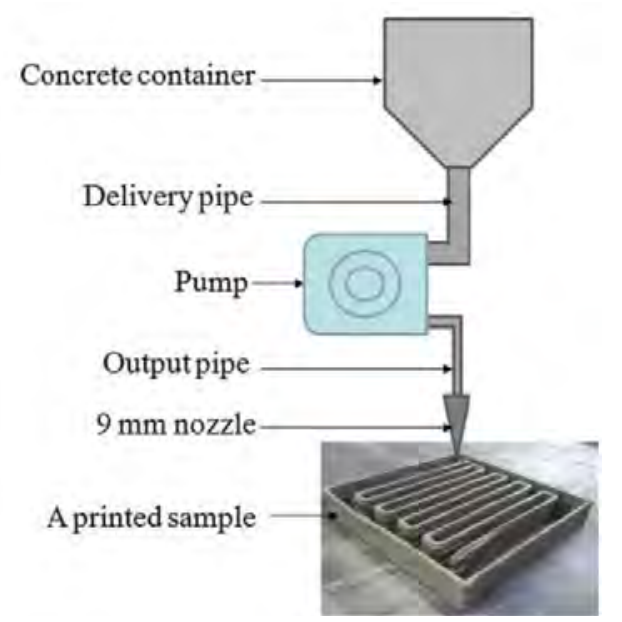

Figure 37. Schematic of concrete delivery system ${ }^{[230]}$ 
of 3DP concrete is that the nozzle circumnavigates following the predetermined paths with fresh concrete extruded out of it one layer at a time. When all layers are stacked one atop another, a completed 3D structure component is finished. Since framework and vibration are needless, concrete employed in 3DP is expected to combine the features of spray concrete with self-compacting concrete. So far, there is not a uniform definition for this special concrete and "self-shaping concrete" is named here based on its working process.

Self-shaping concrete as the "ink" of 3D printer, its workability is critical to the quality of printed constructions. The concrete should easily pass through the pipe-pump-nozzle system to extrude small concrete filaments. Meanwhile, sufficient adhesion and rigidity are required for concrete to print structures with a certain height or layers but no detrimental deformation occurs. From the point of rheology view, a relatively higher viscosity and lower yield stress are beneficial for concrete to achieve good plasticity. Moreover, the concrete should provide short setting time and high early strength ${ }^{[231]}$. As is well-known, the workability of concrete is mainly dominated by the mix proportions (i.e., cementitious binder-aggregate ratio, water-binder ratio and the usage of admixture). Experiments based on the rheological approaches had been conducted by Le et al. ${ }^{[230]}$ to achieve the optimum mix design of a high performance fiber-reinforced fine-aggregate self-shaping concrete. And the effects of admixtures such as retarder dosage, accelerator dosage and superplasticizer dosage on the workability and the variation of workability with time have also been studied. Since the structure of small concrete filaments is stacked layer by layer, the anisotropic structure is likely to act as small voids in their interlayers, leading to the weakened structural capability. Le et al. ${ }^{[232]}$ tested the mechanical properties of self-printing concrete invented earlier in reference ${ }^{[230]}$ and the results indicated that its mechanical strength significantly depends on the orientation of the load relative to the layers. The bond strength between concrete filaments can also largely influence the hardened properties of concrete. Plaster cementitious material with major ingredients of plaster, vinyl polymer and carbohydrate, humectant and water was adopted to print 3D concrete specimens and then the mechanical properties of these specimens were studied by Feng [as shown in Figure 38(a)]. Similar to the conclusions of Le et al., there exists an apparent orthotropic behavior in the mechanical properties of specimens. Based on the experimental results, a model for the stress-strain relationship was proposed from uniaxial compressive test as shown in Figure $38(\mathrm{~b})^{[233]}$. Gibbons applied rapid hardening Portland cement (RHPC) along with 3\% PVA as powder and demineralized water as liquid to optimize the resolution and robustness of the uncured specimens. The measured modulus of rupture (MOR) value was apparently increased due to the reduced porosity after the specimens immersed in water for curing $^{[234]}$.

The application of 3DP technology has been reported in US, China and Europe in recent years. Architectural components showed in Figure 39 were constructed by different concrete printing technique in different country ${ }^{[235]}$. In 2015, an apartment block with five stories was shaped using glass fiber reinforced concrete by a Chinese company in Shanghai. And it is stated that the houses in apartment block were in full compliance with the relevant national standards ${ }^{[236]}$. Surprisingly, American scientists with the National

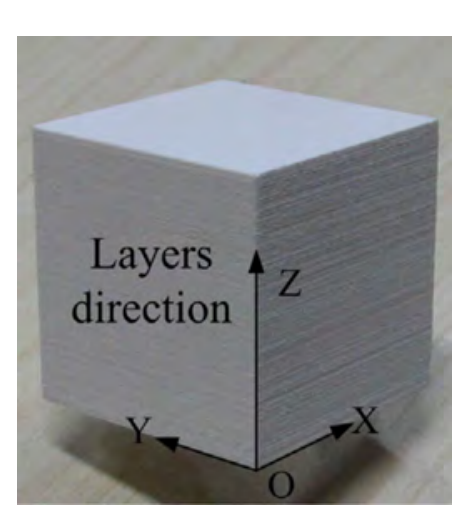

(A)

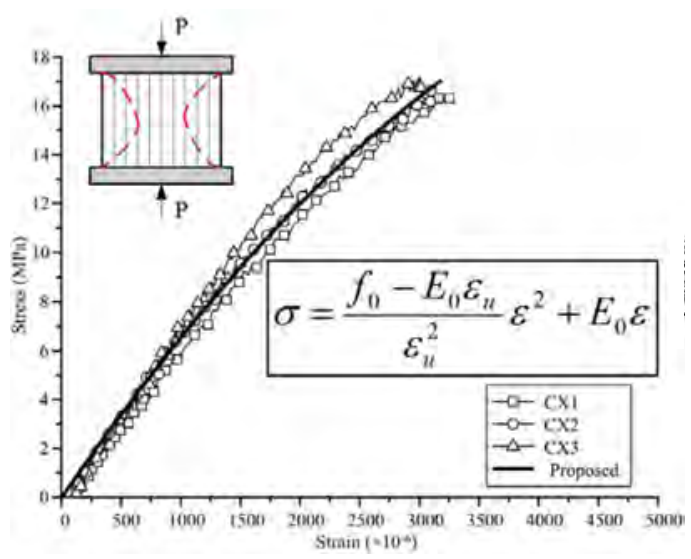

(B)

Figure 38. (a) 3D printing concrete specimen; (b) stress-strain relationship under compression ${ }^{[233]}$ 
(A)

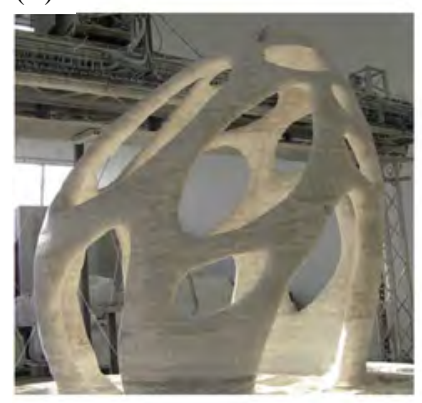

(C)

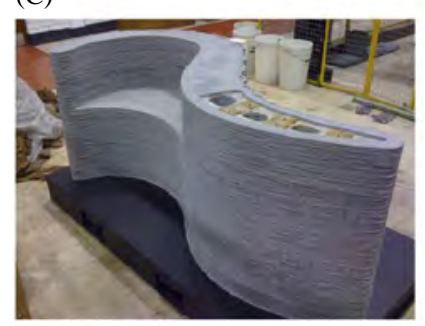

(B)

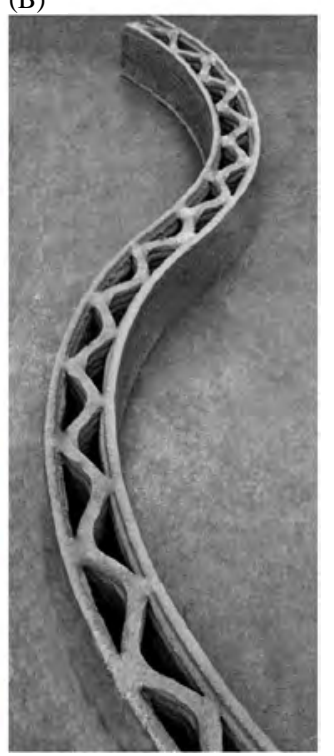

Figure 39. Examples of full scale builds from each process, (a) D-Shape, top left, (b) Contour Crafting, right and (c) Concrete Printing, bottom left ${ }^{[235]}$

Aeronautics and Space Agency (NASA) attempt to apply such a technique to build extraterrestrial settlement infrastructures using lunar soil as the raw material $^{[237]}$. Simulations and experimental tests in vacuum condition have been conducted by European scientists to verify the feasibility of idea stated above ${ }^{[238]}$.

Although 3D printing of full-scale construction is a new concept, it will create a new era of sustainable infrastructure. Structures with complex shapes can be fabricated by self-shaping concrete for its unnecessary of formwork and vibration. Thus, it can be realized in prompting construction speed, reducing labor force and engineering cost. However, there are a few studies focusing on the design and properties of this type of

concrete. Self-shaping concrete requires good plasticity, short setting time, high early strength and it should bear its own weight and dynamic load during printing without distinct deformation. All these requirements cannot be satisfied simultaneously by conventional concrete design approaches. Further research should be conducted in the choice of raw materials, mix proportion design and the usage of admixtures.

\section{Self-Draining Concrete}

Self-draining concrete is the concrete containing interconnected voids inside to allow air or water moving through it. This kind of concrete is also known as pervious, porous and permeable concrete. When self-draining concrete is utilized as paving material, water is easy to percolate through paving matrix into the subsoil beneath. Thus, it is beneficial for conserving storm water and recharging groundwater.

Self-draining concrete is mainly consisted by cement paste and uniform coarse aggregate, little or no fine aggregate. A model for the structure of self-draining concrete is shown in Figure 40. The skeleton of concrete is formed by coarse aggregate and they are bound together by a limited amount of cement paste. Without the filling effect of fine aggregate, plenty of open voids exist among coarse aggregates and the typical size of voids ranges from $2 \mathrm{~mm}$ to $8 \mathrm{~mm}^{[239]}$.

Excellent water permeability is the primary goal for designing self-draining concrete. In numerous studies, the water permeability of concrete has been proven to increase with increasing porosity. However, the compressive strength of concrete shows an adverse tendency with porosity ${ }^{[240-242]}$. In order to balance the conflict of permeability and compressive strength, the porosity of concrete is usually designed as $15 \%-25 \%$

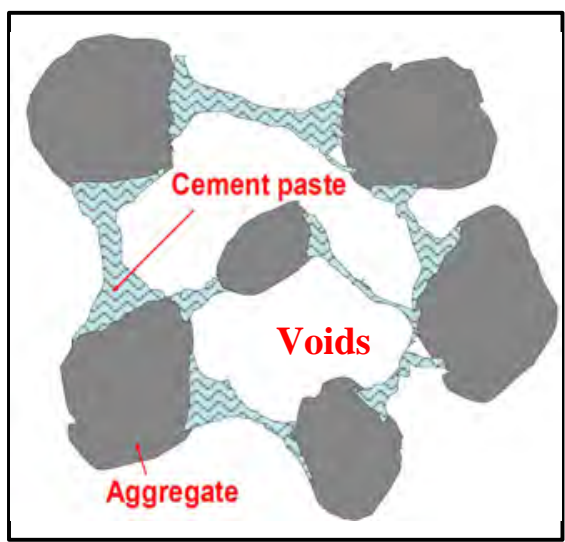

(A)

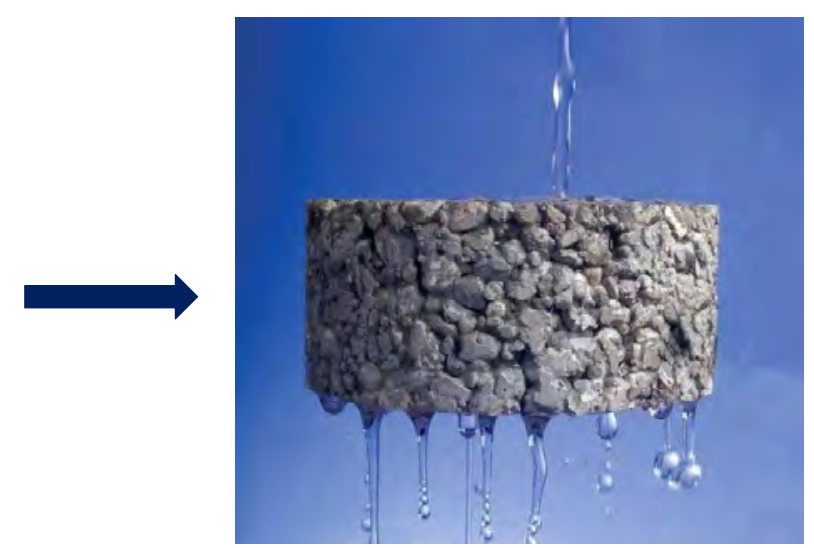

(B)

Figure 40. (a) Model of self-draining concrete; (b) schematic diagram of permeability 
based on the correlation between porosity and permeability, porosity and compressive strength, as shown in Figure 41. In this case, the compressive strength of concrete locates in 2.8-28.0 MPa at $7 \mathrm{~d}$ and water permeability coefficient range from 0.2 to $5.4 \mathrm{~mm} / \mathrm{s}^{[243]}$.

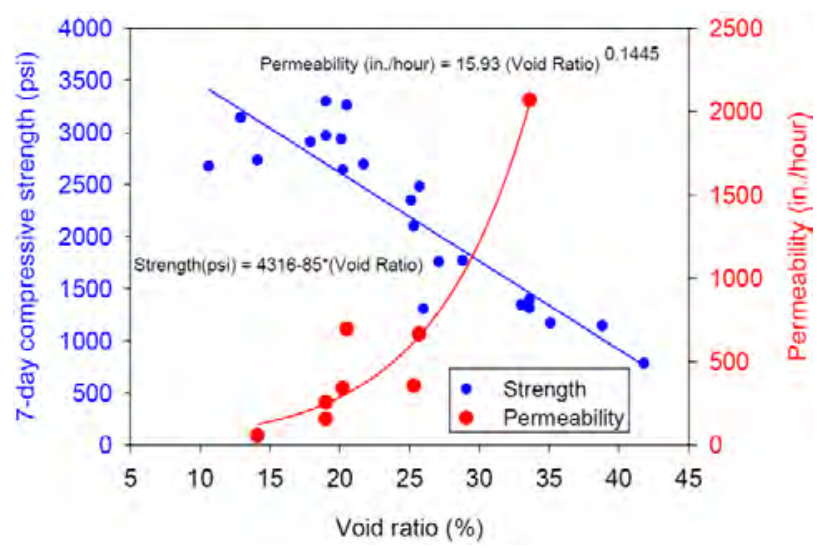

Figure 41. Relationship between strength, void ratio and permeability for several trial mixes of pervious concrete ${ }^{[244]}$

The concept of self-draining concrete has been around for nearly 60 years and it is often used under paving to help aid drainage. Since 1980s, self-draining concrete has been widely used in parking lots, squares, pedestrian walkways and other areas with light traffic. Recently, a UK building material company named Lafarge Tarmac has developed a new type of self-draining concrete with crushed granite as coarse aggregate. This concrete is permeable enough to let average $600 \mathrm{~L} /\left(\mathrm{min} \cdot \mathrm{m}^{2}\right)$ water through to the ground level, as shown in Figure $42^{[245]}$. However, the application of self-draining concrete is still limited in heavy traffic roads by the relatively low strength ${ }^{[246-248]}$. Based on the structure model in Figure 1a, once the concrete is subjected to loading, the load will be transferred among the aggregates by cement paste. Although the strength of

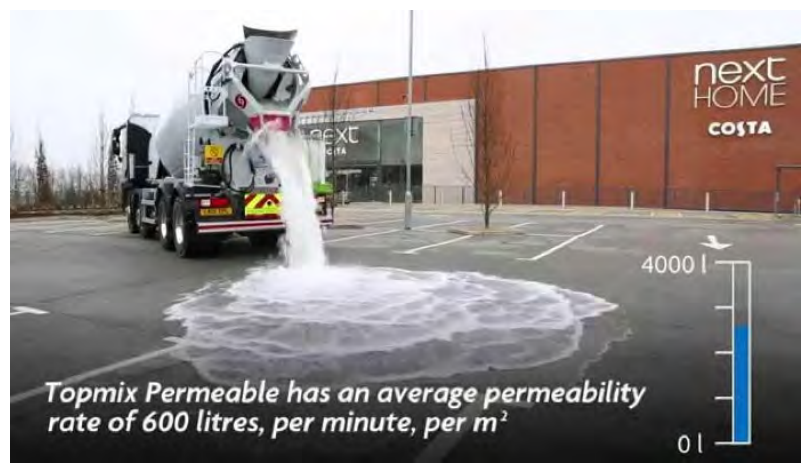

Figure 42. Test of permeability of self-draining concrete ${ }^{[245]}$ aggregate is high enough, the cement paste and the interfacial transition zone (ITZ) are relatively weak for the thin binding layer. Therefore, the concrete always fails at the cement paste and ITZ. To improve the mechanical strength of pervious concrete while maintaining its high porosity, two methods are proposed. One is to increase the cement paste binder area. Smaller sized aggregate are employed to increase the number of particles per unit volume of concrete. The specific surface of aggregate and the binding area are then increased resulting in the improved strength. The other is to enhance the strength of cement binder. Except for applying high strength cement and reducing water cement ratio, supplementary materials such as silica fume, organic intensifiers and other special chemical reinforcing agents are usually used ${ }^{[249-250]}$.

Self-draining concrete plays a key role in water purification and alleviating the drainage burden of sewage system. The Environmental Protection Agency of the United States has recognized the usage of self-draining concrete as one of the best management practices in storm-water conservation. In addition, the special porous structure of self-draining concrete generates excellent performance in antiskid, thermal insulation and acoustic absorption. However, the defects of poor mechanical strength and freeze-thaw resistance need to be paid enough attention. Besides, the open voids of the self-draining concrete structures prone to clogging and periodic cleaning or replace should be considered.

\section{Self-Luminous Concrete}

Recently, self-luminous concrete was developed in Michoacan University (Mexico) by Rubio et al. Selfluminous concrete (also called light-emitting cement) is solar-powered material that traps solar energy during the daytime and emits light at night. The whole process completes without consuming any electricity ${ }^{[251]}$.

Conventional concrete is an opaque substance. When water is mixed with cement, crystal flakes are formed that doesn't allow light to pierce its interior. In order to address this issue, researchers paid much attention on modifying the micro-structure of cement aiming to eliminate the crystals. Eventually, a translucent gel-like substance enabling the adsorption of solar energy during the day and converting the energy into light at night was developed ${ }^{[251]}$. Detailed information about the compositions of raw materials and fabrication methods applied in self-luminous concrete is unavailable on the internet, since this new concrete 


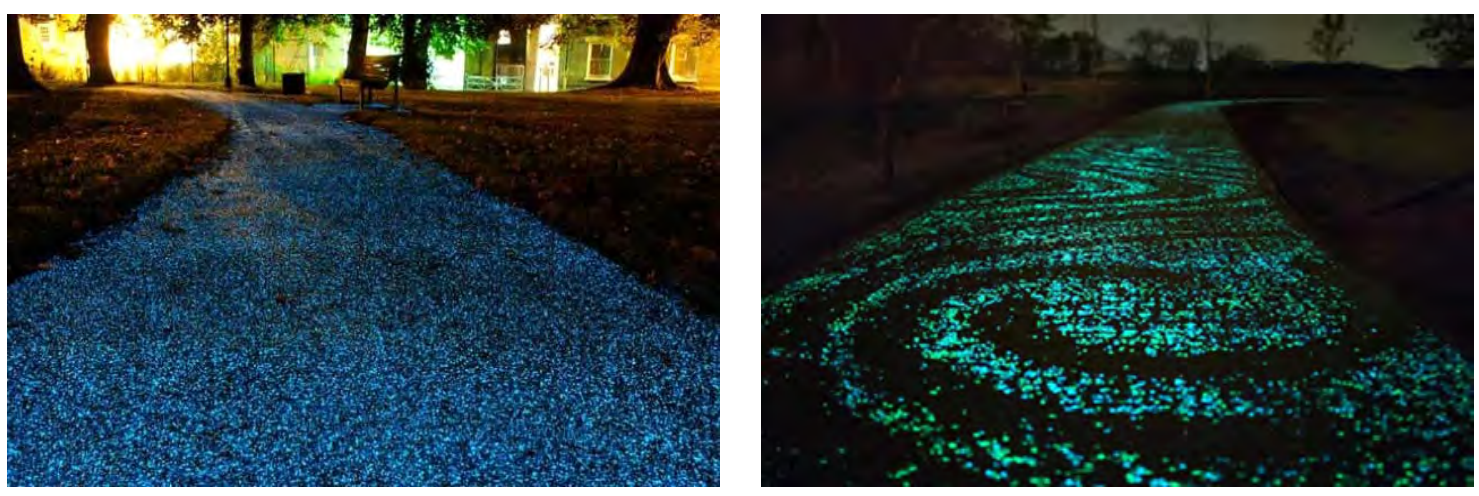

Figure 43. Self-luminous concrete could illuminate dark roads, highways without electricity ${ }^{[251,252]}$

is being patented.

Self-luminous concrete can be used in illuminating roads, pavements and bicycle lanes. Currently, this concrete is available in emitting blue and green light. Additionally, the brightness can be fine-tuned to meet the application requirements. Predictably, the role of self-luminous concrete in reducing the utilization of road lamp and decreasing the traffic accidents rate is of great significance in the future.

Most of the fluorescent materials are made of plastic and will be degraded by ultraviolet radiation after a few years. However, the researchers claimed that self-luminous concrete is sun resistant and its lifespan is estimated for as long as 100 years.

\section{Conclusions}

As a strong, versatile and economical material, concrete has been utilized in constructions world widely. It will still remain to be the indispensable and uppermost building materials for a long time in the future. Concrete has been endowed with new functions continually during the development and utilization. Intrinsically intelligent capacity of self-x concrete achieved new functions through combining traditional concrete with functional fillers or improving the composition of raw materials. This paper systematically introduced the intelligent concrete with performances of self-compacting, self-expanding, self-curing, selfsensing, self-healing, self-adjusting, self-damping, self-heating, self-sacrificing, self-cleaning, self-shaping, self-draining and self-luminous.

Intelligent concrete, as an innovative technology in the field of construction materials, injects novel vitality for construction materials despite challenges. The development of intelligent concrete will promote the application of concrete to a broader prospect and pro- duce enormous socioeconomic performance. However, as an emerging technology, the investigation on intelligent concrete is still in primary stage and the following issues are needed to be solved before largescale application.

(1) Properties of functional fillers are the key factors for achieving intelligence of concrete. Therefore, further exploration and exploitation of suitable functional fillers is crucial. The nanotechnology and bionic technology may provide inspiration for seeking more efficient functional fillers.

(2) Mechanical properties and durability of intelligent concrete are needed to be deeply analyzed. It is necessary for studying the intelligent concrete in a state of multi-axial stress, since existing investigations are always confined in the range of uniaxial stress which is far from the engineering applications. Moreover, the effect of different environment factors on the functionality and durability of intelligent concrete should be further researched.

(3) Although there are numerous reasonable explanations and forecasting models, the mechanism of intelligent concrete is still ambiguous due to the complex system of intelligent concretes in multi-component, multi-phase, and multi-scale characteristics. Therefore, more precise constitutive model based on advanced experimental facilities and numerical analysis is needed to be established for describing and predicting the behaviors of intelligent concrete.

(4) Lack of unitary criterion makes it difficult for intelligent concrete to be normatively designed and tested, and further limits the applications. Thus, a uniform standard providing method, guidance and specification for the research and application of intelligent concrete is urgent to be established.

In general, intrinsically intelligent concrete is an in- 
terdisciplinary field involving bionics, physics, chemistry, material science and civil engineering, etc. Therefore, cross-disciplinary collaboration and communication among researchers with different expertise will be of utmost importance to fulfill further investigation on intelligent concrete. The utilization of intelligent concrete is a logical choice for maintaining sustainable development of concrete constructions and developing intelligent infrastructures, thus building Smart Cities and Smarter Planet. Undoubtedly, intelligent concrete will bring a deep revolution to the field of construction materials and infrastructures. Its widespread applications will make beneficial effects on society, economics and environment in the future.

\section{Conflict of Interest and Funding}

The authors declared that they have no conflicts of interest to this work.

The authors thank the funding supported from the National Science Foundation of China (51578110 and 51428801).

\section{References}

1. Aitcin P C, 2000, Cements of yesterday and today: Concrete of tomorrow, Cement and Concrete Research, vol.30(9): 1349-1359.

http://dx.doi.org/10.1016/S0008-8846(00)00365-3

2. Spillman Jr W B, Sirkis J S and Gardiner P T, 1996, Smart materials and structures: What are they? Smart Materials and Structures, vol.5(3): 247.

https://doi.org/10.1088/0964-1726/5/3/002

3. Sun M, Li Z and Liu Q, 2002, The electromechanical effect of carbon fiber reinforced cement, Carbon, vol.40(12): 2273-2275.

http://dx.doi.org/10.1016/S0008-6223(02)00189-6

4. Han B, Wang Y, Dong S, et al., 2015, Smart concretes and structures: A review, Journal of Intelligent Material Systems and Structures, vol.26(11): 1303-1345. https://doi.org/10.1177/1045389X15586452

5. The Self-Compacting Concrete European Project Group, 2005, The European Guidelines for Self-Compacting Concrete, viewed (01/15/2016), http://www.efnarc.org/pdf/SCCGuidelinesMay2005.pdf

6. Domone P L, 2007, A review of the hardened mechanical properties of self-compacting concrete, Cement and Concrete Composites, vol.29(1): 1-12. http://dx.doi.org/10.1016/j.cemconcomp.2006.07.010

7. Najim K B and Hall M R, 2010, A review of the fresh/hardened properties and applications for plain(PRC) and self-compacting rubberised concrete (SCRC),
Construction and Building Materials, vol.24(11): 20432051.

http://dx.doi.org/10.1016/j.conbuildmat.2010.04.056

8. Okamura H and Ouchi M, 2003, Self-compacting concrete, Journal of Advanced Concrete Technology, vol.1(1): 5-15.https://doi.org/10.3151/jact.1.5

9. CECS 203: 2006 (2006), Technical Specifications for self compacting concrete Application, Standardization Institute of Chinese Construction Standard, Beijing, China.

10. Persson B, 2001, A comparison between mechanical properties of self-compacting concrete and the corresponding properties of normal concrete, Cement and Concrete Research, vol.31(2): 193-198.

http://dx.doi.org/10.1016/S0008-8846(00)00497-X

11. Nagamoto $\mathrm{N}$ and Ozawa K, 1999, Mixture properties of self-compacting, high-performance concrete, ACI Special Publication, vol.172: 623-636.

12. Kesler C E and Pfeifer D W, 1970, Expansive cement concretes-present state of knowledge.

13. Nagataki S and Gomi H, 1998, Expansive admixtures (mainly ettringite), Cement and Concrete Composites, vol.20(2-3): 163-170. http://dx.doi.org/10.1016/S0958-9465(97)00064-4

14. Wu Z W and Zhang H Z, 1990, Expansive concrete, China Railway Publishing House, Beijing, China. (in Chinese)

15. Carballosa P, Calvo J G and Revuelta D, et al., 2015, Influence of cement and expansive additive types in the performance of self-stressing and self-compacting concretes for structural elements, Construction and Building Materials, vol.93: 223-229.

http://dx.doi.org/10.1016/j.conbuildmat.2015.05.113

16. Klein A, Karby T and Polivka M, 1961, Properties of an expansive cement for chemical prestressing, ACI Materials Journal, vol.58: 59.

17. Lees J M, Gruffydd-Jones B and Burgoyne CJ, 1995, Expansive cement couplers: A means of pre-tensioning fibre-reinforced plastic tendons, Construction and Building Materials, vol.9(6): 413-423. http://dx.doi.org/10.1016/0950-0618(95)00070-4

18. Huang K, Deng M, Mo L, et al., 2013, Early age stability of concrete pavement by using hybrid fiber together with $\mathrm{MgO}$ expansion agent in high altitude locality, Construction and Building Materials, vol.48: 685-690. http://dx.doi.org/10.1016/j.conbuildmat.2013.07.089

19. Yan P and Qin X, 2001, The effect of expansive agent and possibility of delayed ettringite formation in shrinkage-compensating massive concrete, Cement and Concrete Research, vol.31(2): 335-337. http://dx.doi.org/10.1016/S0008-8846(00)00453-1

20. Yan P, Zheng F, Peng J, et al., 2004, Relationship be- 
tween delayed ettringite formation and delayed expansion in massive shrinkage-compensating concrete, $\mathrm{Ce}$ ment and Concrete Composites, vol.26(6): 687-693. http://dx.doi.org/10.1016/S0958-9465(03)00060-X

21. Mo L, Deng M and Tang M, 2010, Effects of calcination condition on expansion property of MgO-type expansive agent used in cement-based materials, Cement and Concrete Research, vol.40(3): 437-446. http://dx.doi.org/10.1016/j.cemconres.2009.09.025

22. Mehta P K and Pirtz D, 1980, Magnesium oxide additive for producing selfstress in mass concrete, In 7th International Congress on the Chemistry of Cement Vol. III, Paris, 6-9.

23. Mo L, Deng M, Tang M, et al., 2014, MgO expansive cement and concrete in China: Past, present and future, Cement and Concrete Research, vol.57: 1-12. http://dx.doi.org/10.1016/j.cemconres.2013.12.007

24. Chatterji S, 1995, Mechanism of expansion of concrete due to the presence of dead-burnt $\mathrm{CaO}$ and $\mathrm{MgO}, \mathrm{Ce}$ ment and Concrete Research, vol.25(1): 51-56. http://dx.doi.org/10.1016/0008-8846(94)00111-B

25. Weber S and Reinhardt H W, 1997, A new generation of high performance concrete: Concrete with autogenous curing, Advanced Cement Based Materials, vol.6(2): 59-68. http://dx.doi.org/10.1016/S1065-7355(97)00009-6

26. Jensen O M and Hansen P F, 2001, Water-entrained cement-based materials: I. Principles and theoretical background, Cement and Concrete Research, vol.31(4): 647-654. http://dx.doi.org/10.1016/S0008-8846(01)00463-X

27. Powers T C and Brownyard T L, 1946, Studies of the physical properties of hardened Portland cement paste. Bulletin 22.

28. Neville A M, 1995, Properties of concrete, Wiley Press.

29. Henkensiefken R, Castro J, Bentz D, et al., 2009, Water absorption in internally cured mortar made with water-filled lightweight aggregate, Cement and Concrete Research, vol.39(10): 883-892. http://dx.doi.org/10.1016/j.cemconres.2009.06.009

30. Jensen O M and Hansen P F, 2002, Water-entrained cement-based materials: II. Experimental observations, Cement and Concrete Research, vol.32(6): 973-978. http://dx.doi.org/10.1016/S0008-8846(02)00737-8

31. Geiker M R, Bentz D P and Jensen O M, 2004) Mitigating autogenous shrinkage by internal curing, ACI Special Publications: 143-154.

32. Piérard J, Pollet V and Cauberg N, et al., 2006, Mitigating autogenous shrinkage in HPC by internal curing using superabsorbent polymers, In RILEM proceedings PRO, 97-106.

33. Craeye B, 2006, Reduction of autogenous shrinkage of concrete by means of internal curing, Master Dissertation, Ghent University (in Dutch).

34. Bentz D P, 2007, Internal curing of high-performance blended cement mortars, ACI Materials Journal, vol.104: 408.

35. Lura P, 2003, Autogenous deformation and internal curing of concrete: TU Delft, Delft University of Technology.

36. Craeye B, Geirnaert M and De Schutter G, 2011, Super absorbing polymers as an internal curing agent for mitigation of early-age cracking of high-performance concrete bridge decks, Construction and Building Materials, vol.25(1): 1-13.

http://dx.doi.org/10.1016/j.conbuildmat.2010.06.063

37. Hasholt M T, Jensen O M, Kovler K, et al., 2012, Can superabsorent polymers mitigate autogenous shrinkage of internally cured concrete without compromising the strength? Construction and Building Materials, vol.31: 226-230.

http://dx.doi.org/10.1016/j.conbuildmat.2011.12.062

38. Bentz D P, 2009, Influence of internal curing using lightweight aggregates on interfacial transition zone percolation and chloride ingress in mortars, Cement and Concrete Composites, vol.31(5): 285-289.

http://dx.doi.org/10.1016/j.cemconcomp.2009.03.001

39. Liu X, Chia K S and Zhang M, 2010, Development of lightweight concrete with high resistance to water and chloride-ion penetration, Cement and Concrete Composites, vol.32(10): 757-766.

40. Liu X, Chia K S and Zhang M, 2011, Water absorption, permeability, and resistance to chloride-ion penetration of lightweight aggregate concrete, Construction and Building Materials, vol.25(1): 335-343. http://dx.doi.org/10.1016/j.conbuildmat.2010.06.020

41. Bentz D P and Jensen O M, 2004, Mitigation strategies for autogenous shrinkage cracking, Cement and Concrete Composites, vol.26(6): 677-685. http://dx.doi.org/10.1016/S0958-9465(03)00045-3

42. Lura P, Ye G, Cnudde V, et al., 2008, Preliminary results about 3D distribution of superabsorbent polymers in mortars, In Proc Int Conf Microstructure-related durability of cementitious composites, RILEM Pro, 13411348.

43. Oh B H, Cha S W, Jang BS, et al., 2002, Development of high-performance concrete having high resistance to chloride penetration, Nuclear Engineering and Design, vol.212(1-2): 221-231. http://dx.doi.org/10.1016/S0029-5493(01)00484-8

44. Villarreal V H and Crocker D A, 2007, Better pavements through internal hydration, Concrete International, vol.29: 32-36.

45. Bentz D P and Weiss W J, 2011, Internal curing: A 2010 state-of-the-art review: US Department of Commerce, 
National Institute of Standards and Technology. https://doi.org/10.6028/NIST.IR.7765

46. Sun S, Yu X and Han B, 2014, Sensing mechanism of self-monitoring CNTs cementitious composite, Journal of Testing and Evaluation, vol.42(1): 1-5. https://doi.org/10.1520/JTE20120302

47. Vera-Agullo J, Chozas-Ligero V, Portillo-Rico D, et al., 2009, Mortar and concrete reinforced with nanomaterials, Nanotechnology in Construction, vol.3: 383-388.

48. Banthia N, Djeridane S and Pigeon M, 1992, Electrical resistivity of carbon and steel micro-fiber reinforced cements, Cement and Concrete Research, vol.22(5): 804-814. http://dx.doi.org/10.1016/0008-8846(92)90104-4

49. Han B, Ding S and Yu X, 2015, Intrinsic self-sensing concrete and structures: A review, Measurement, vol.59: 110-128. http://dx.doi.org/10.1016/j.measurement.2014.09.048

50. Han B, Han B and Yu X, 2009, Experimental study on the contribution of the quantum tunneling effect to the improvement of the conductivity and piezoresistivity of a nickel powder-filled cement-based composite, Smart Materials and Structures, vol.18, 065007(7pp). http://dx.doi.org/10.1088/0964-1726/18/6/065007

51. Sun M, Li Z, Mao Q, et al., 1998, Study on the hole conduction phenomenon in carbon fiber-reinforced concrete, Cement and Concrete Research, vol.28(4): 549554.http://dx.doi.org/10.1016/S0008-8846(98)00011-8

52. Han B, Han B, Yu X, et al., 2011, Ultrahigh pressuresensitive effect induced by field emission at sharp nano-tips on the surface of spiky spherical nickel powders, Sensor Letters, vol.9: 1629-1635.

https://doi.org/10.1166/sl.2011.1719

53. Han B, Zhang K, Yu X, et al., 2012, Electrical characteristics and pressure-sensitive response measurements of carboxyl MWNT/cement composites, Cement and Concrete Composites, vol.34: 794-800. http://dx.doi.org/10.1016/j.cemconcomp.2012.02.012

54. Han B, Zhang L, Sun S, et al., 2015, Electrostatic self-assembly CNT/NCB composite fillers reinforced cement-based materials with multifunctionality, Composites Part A: Applied Science and Manufacturing, vol.79: 103-115.

http://dx.doi.org/10.1016/j.compositesa.2015.09.016

55. Han B, Yu X, Kwon E, et al., 2012, Effects of CNT concentration level and water/cement ratio on the piezoresistivity of CNT/cement composites, Journal of Composite Materials, vol.46(1): 19-25. http://dx.doi.org/10.1177/0021998311401114

56. Kim H, Park I and Lee H, 2014, Improved piezoresistive sensitivity and stability of CNT/cement mortar composites with low water-binder ratio, Composite Structures, vol.116: 713-719.

http://dx.doi.org/10.1016/j.compstruct.2014.06.007

57. Han B, Yu X, Kwon E, et al., 2010, Piezoresistive MWNTs filled cement-based composites, Sensor Letters, vol.8(2): 344-348.https://doi.org/10.1166/sl.2010.1275

58. Materazzi A L, Ubertini F and D’Alessandro A, 2013, Carbon nanotube cement-based transducers for dynamic sensing of strain, Cement and Concrete Composites, vol.37: 2-11.

http://dx.doi.org/10.1016/j.cemconcomp.2012.12.013

59. Stauffer D and Aharony A, 1994, Introduction to percolation theory: CRC press.

60. Han B, Zhang L, Zhang C, et al., 2016, Reinforcement effect and mechanism of carbon fibers to mechanical and electrically conductive properties of cement-based materials, Construction and Building Materials, vol.125: 179-189. http://dx.doi.org/10.1016/j.conbuildmat.2016.08.063

61. Dong S, Han B, Ou J, et al., 2016, Electrically conductive behaviors and mechanisms of short-cut super-fine stainless wire reinforced reactive powder concrete, Cement and Concrete Composites, vol.72:48-65. http://dx.doi.org/10.1016/j.cemconcomp.2016.05.022

62. Chen P and Chung D, 1993, Carbon fiber reinforced concrete as an electrical contact material for smart structures, Smart Materials and Structures, vol.2(1): 181. https://doi.org/10.1088/0964-1726/2/1/004

63. Muto N, Yanagida H, Nakatsuji T, et al., 1992, Design of intelligent materials with self-diagnosing function for preventing fatal fracture, Smart Materials and Structures, vol.1(4): 324. https://doi.org/10.1088/0964-1726/1/4/007

64. Fu X and Chung D, 1998, Radio-wave-reflecting concrete for lateral guidance in automatic highways, $\mathrm{Ce}$ ment and Concrete Research, vol.28(6): 795-801. http://dx.doi.org/10.1016/S0008-8846(98)00057-X

65. Sun M, Li Z, Mao Q, et al., 1998, Thermoelectric percolation phenomena in carbon fiber-reinforced concrete, Cement and Concrete Research, vol.28(12): 1707-1712. http://dx.doi.org/10.1016/S0008-8846(98)00161-6

66. Sun M, Li Z, Mao Q, et al., 1999, A study on thermal self-monitoring of carbon fiber reinforced concrete, Cement and Concrete Research, vol.29(5): 769-771. http://dx.doi.org/10.1016/S0008-8846(99)00006-X

67. Sun M, Li Z, Liu Q, et al., 2000, A study on thermal self-diagnostic and self-adaptive smart concrete structures, Cement and Concrete Research, vol.30(8): 12511253.http://dx.doi.org/10.1016/S0008-8846(00)00284-2

68. García-Macías E, D'Alessandro A, Castro-Triguero R, et al., 2017, Micromechanics modeling of the electrical conductivity of carbon nanotube cement-matrix composites. Composites Part B: Engineering, vol.108: 451- 
469.http://dx.doi.org/10.1016/j.compositesb.2016.10.025

69. Wen S and Chung D, 2001, Cement-based thermocouples, Cement and Concrete Research, vol.31(3): 507510.http://dx.doi.org/10.1016/S0008-8846(00)00391-4

70. Han B, Wang Y, Sun S, et al., 2014, Nanotip-induced ultrahigh pressure-sensitive composites: principles, properties and applications, Composites Part A: Applied Science and Manufacturing, vol.59: 105-114. http://dx.doi.org/10.1016/j.compositesa.2014.01.005

71. Han B, Guan X and Ou J, 2007, Electrode design, measuring method and data acquisition system of carbon fiber cement paste piezoresistive sensors, Sensors and Actuators A: Physical, vol.135(2): 360-369. http://dx.doi.org/10.1016/j.sna.2006.08.003

72. Han B, Yu X and Ou J, 2010, Effect of water content on the piezoresistivity of MWNT/cement composites, Journal of Materials Science, vol.45(14): 3714-3719. https://doi.org/10.1007/s10853-010-4414-7

73. Han B, Zhang K, Burnham T, et al., 2013, Integration and road tests of aself-sensing CNT concrete pavement system for traffic detection, Smart Materials and Structures, vol.22, 015020 (8pp).

http://dx.doi.org/10.1088/0964-1726/22/1/015020

74. Han B, Sun S, Ding S, et al., 2015, Review of nanocarbon-engineered multifunctional cementitious composites, Composites Part A: Applied Science and Manufacturing, vol.70: 69-81.

http://dx.doi.org/10.1016/j.compositesa.2014.12.002

75. Han B, Han B and Ou J, 2009, Experimental study on use of nickel powder-filled Portland cement-based composite for fabrication of piezoresistive sensorswith high sensitivity, Sensors and Actuators: A physical, vol. 149(1): 51-55.

http://dx.doi.org/10.1016/j.sna.2008.10.001

76. Ou J and Han B, 2009, Piezoresistive cement-based strain sensors and self-sensing concrete components, Journal of Intelligent Material Systems and Structures, vol.20 (3): 329-336.

http://dx.doi.org/10.1177/1045389X08094190

77. Han B, Han B, Yu X, et al., 2009, Piezoresistive characteristic model of nickel/cement composites based on field emission effect and inter-particle separation, Sensor Letters, vol.7(6): 1044-1050.

https://doi.org/10.1166/sl.2009.1232

78. Fu X, Lu W and Chung D, 1998, Improving the strainsensing ability of carbon fiber-reinforced cement by ozone treatment of the fibers, Cement and Concrete Research, vol.28(2): 183-187. http://dx.doi.org/10.1016/S0008-8846(97)00265-2

79. Wang W, Dai H and Wu S, 2008, Mechanical behavior and electrical property of CFRC- strengthened RC beams under fatigue and monotonic loading.Materials
Science and Engineering A, vol.479: 191-196. http://dx.doi.org/10.1016/j.msea.2007.06.046

80. Wang S, Liang R, Wang B, et al., 2009, Dispersion and thermal conductivity of carbon nanotube composites, Carbon, vol.47(1): 53-57. http://dx.doi.org/10.1016/j.carbon.2008.08.024

81. Konsta-Gdoutos M S, Metaxa Z S and Shah S P, 2010, Highly dispersed carbon nanotube reinforced cement based materials, Cement and Concrete Research, vol.40(7): 1052-1059.

http://dx.doi.org/10.1016/j.cemconres.2010.02.015

82. Han B, Zhang K, Yu X, et al., 2011, Fabrication of piezoresistive CNT/CNF cementitious composites with superplasticizer as dispersant, Journal of Materials in Civil Engineering, vol.24(6): 658-665.

https://doi.org/10.1061/(ASCE)MT.1943-5533.0000435

83. Han B, Yu X and Ou J, 2011, Multifunctional and smart carbon nanotube reinforced cement-based materials, Nanotechnology in Civil Infrastructure: 1-47.

84. Han B, Yu X and Ou J, 2014, Self-sensing concrete in smart structures: Elsevier.

85. Chen P W and Chung D, 1995, Carbon-fiber-reinforced concrete as an intrinsically smart concrete for damage assessment during dynamic loading, Journal of the American Ceramic Society, vol.78(3): 816-818. https://doi.org/10.1111/j.1151-2916.1995.tb08254.x

86. Zhang L, Ding S, Sun S, et al., 2016, Chapter 2: Nano-scale behavior and nano-modification of cement and concrete materials. Book: Advanced Research on Nanotechnology for Civil Engineering Applications, Publisher: IGI Global, Editors: Anwar Khitab, Waqas Anwar. 28-79.

87. Han B, Yu Y, Han B, et al., 2008, Development of a wireless stress/strain measurement system integrated with pressure-sensitive nickel powder-filled cementbased sensors, Sensors and Actuators: A physical, vol.147(2): 536-543.

http://dx.doi.org/10.1016/j.sna.2008.06.021

88. Han B and Ou J, 2007, Embedded piezoresistive cement-based stress/strain sensor, Sensors and Actuators: A physical, vol.138(2): 294-298.

http://dx.doi.org/10.1016/j.sna.2007.05.011

89. Wang W, Wu S and Dai H, 2006, Fatigue behavior and life prediction of CFRC under cyclic flexural loading, Materials Science and Engineering, vol.434: 347-351. http://dx.doi.org/10.1016/j.msea.2006.07.080

90. Wu S, Dai H and Wang W, 2007, Effect of CFRC layers on the electrical properties and failure mode of RC beams strengthened with CFRC composites, Smart Materials and Structures, vol.16(6): 2056-2062. http://dx.doi.org/10.1088/0964-1726/16/6/008

91. Han B, Sun S, Ding S, et al., 2015, Chapter 8: Nano 
carbon materials filled cementitious composites: fabrication, properties and application. Book: Innovative Developments of Advanced Multifunctional Nanocomposites in Civil and Structural Engineering, Publisher: Elsevier, Editors: Kenneth J. Loh, Satish Nagarajaiah. 153-181.

92. Han B, Yu X and Kwon E, 2009, A self-sensing carbon nanotube/cement composite for traffic monitoring, Nanotechnology, vol.20(44): 445501.

https://doi.org/10.1088/0957-4484/20/44/445501

93. Han B, Zhang K, Yu X, et al., 2011, Nickel particlebased self-sensing pavement for vehicle detection, Measurement, vol.44(9): 1645-1650.

http://dx.doi.org/10.1016/j.measurement.2011.06.014

94. Yunovich M and Thompson NG, 2003, Corrosion of highway bridges: Economic impact and control methodologies, Concrete International, vol.25: 52-57.

95. Poole B, 2012, Biomimetics: Borrowing from biology, viewed September 9, 2012,

http://www.thenakedscientists.com/HTML/articles/articl e/biomimeticsborrowingfrombiology/

96. Zwaag S, 2008, Self healing materials: An alternative approach to 20 centuries of materials science: Springer Science+ Business Media BV.

97. Ghosh S K, 2009, Self-healing materials: fundamentals, design strategies, and applications: John Wiley and Sons.

98. Kishi T, Ahn T H, Hosoda A, et al., 2007, Self-healing behavior by cementitious recrystallization of cracked concrete incorporating expansive agent, In First international conference on self-healing materials. Springer, Dordrecht.

99. Edvardsen C, 1999, Water permeability and autogenous healing of cracks in concrete, ACI Materials Journal, vol.96: 448-454.

100. Neville A, 2002, Autogenous healing-a concrete miracle? Concrete International, vol.24: 76-82.

101. Yang Y Z, Lepech M D, Yang E H, et al., 2009, Autogenous healing of engineered cementitious composites under wet-dry cycles, Cement and Concrete Research, vol.39(5): 382-390.

http://dx.doi.org/10.1016/j.cemconres.2009.01.013

102. Termkhajornkit P, Nawa T, Yamashiro Y, et al., 2009, Self-healing ability of fly ash-cement systems, Cement and Concrete Composites, vol.31(3): 195-203. http://dx.doi.org/10.1016/j.cemconcomp.2008.12.009

103. Van Tittelboom K, Gruyaert E, Rahier H, et al., 2012, Influence of mix composition on the extent of autogenous crack healing by continued hydration or calcium carbonate formation, Construction and Building Materials, vol.37: 349-359. http://dx.doi.org/10.1016/j.conbuildmat.2012.07.026

104. Snoeck D, Steuperaert S, Van Tittelboom K, et al., 2012,
Visualization of water penetration in cementitious materials with superabsorbent polymers by means of neutron radiography, Cement and Concrete Research, vol.42(8): $1113-1121$. http://dx.doi.org/10.1016/j.cemconres.2012.05.005

105. Snoeck D and De Belie N, 2015, Repeated autogenous healing in strain-hardening cementitious composites by using superabsorbent polymers, Journal of Materials in Civil Engineering, vol.28(1): 4015086.

https://doi.org/10.1061/(ASCE)MT.1943-5533.0001360

106. Yildirim G, Sahmaran M and Ahmed HU, 2014, Influence of hydrated lime addition on the self-healing capability of high-volume fly ash incorporated cementitious composites, Journal of Materials in Civil Engineering, vol.27(6): 4014187.

https://doi.org/10.1061/(ASCE)MT.1943-5533.0001145

107. Granger S, Loukili A, Pijaudier-Cabot G, et al., 2007, Experimental characterization of the self-healing of cracks in an ultra high performance cementitious material: Mechanical tests and acoustic emission analysis, Cement and Concrete Research, vol.37(4): 519-527. http://dx.doi.org/10.1016/j.cemconres.2006.12.005

108. Jacobsen S and Sellevold EJ, 1996, Self healing of high strength concrete after deterioration by freeze/thaw, Cement and Concrete Research, vol.26(1): 55-62. http://dx.doi.org/10.1016/0008-8846(95)00179-4

109. Granger S, Pijaudier-Cabot G and Loukili A, 2007, Mechanical behavior of self-healed ultra high performance concrete: from experimental evidence to modeling, In The 6th international conference on fracture mechanics of concrete and concrete structures, Catalina, Italy.

110. Li V C, Wang S and Wu C, 2001, Tensile strain-hardening behavior of polyvinyl alcohol engineered cementitious composite (PVA-ECC), ACI Materials Journal, vol.98: 483-492.

111. Dhawale A W and Joshi V P, 2013, Engineered cementitious composites for structural applications, International journal of application or Innovation in Engineering \& Management, vol.2: 198-205.

112. Snoeck D and De Belie N, 2012, Mechanical and self-healing properties of cementitious composites reinforced with flax and cottonised flax, and compared with polyvinyl alcohol fibres, Biosystems Engineering, vol.111(4): 325-335. http://dx.doi.org/10.1016/j.biosystemseng.2011.12.005

113. Snoeck D, Smetryns P and De Belie N, 2015, Improved multiple cracking and autogenous healing in cementitious materials by means of chemically-treated natural fibres, Biosystems Engineering, vol.139: 87-99. http://dx.doi.org/10.1016/j.biosystemseng.2015.08.007

114. White S R, Sottos N R, Geubelle P H, et al., 2001, Autonomic healing of polymer composites, Nature, vol.409: 
794-797. https://doi.org/10.1038/35057232

115. Dry C, 1994, Matrix cracking repair and filling using active and passive modes for smart timed release of chemicals from fibers into cement matrices, Smart Materials and Structures, vol.3(2): 118. https://doi.org/10.1088/0964-1726/3/2/006

116. Mihashi H, Kaneko Y, Nishiwaki T, et al., 2001, Fundamental study on development of intelligent concrete characterized by self-healing capability for strength, Transactions of the Japan Concrete Institute, vol.22: 441-450.

117. Ramachandran S K, Ramakrishnan V and Bang S S, 2001, Remediation of concrete using micro-organisms, ACI Materials Journal, 98: 3-9.

118. Ramakrishnan V, 2007, Performance characteristics of bacterial concrete-a smart biomaterial, In Proceedings of the First International Conference on Recent Advances in Concrete Technology, 67-78.

119. Van Tittelboom K and De Belie N, 2010, Self-healing concrete: Suitability of different healing agents, Int. J. 3R's 1: 12-21.

120. Thao T D P, 2011, Quasi-brittle self-healing materials: numerical dodelling and applications in civil engineering, PhD thesis, National University of Singapore, Singapore.

121. Yang Z, Hollar J, He X, et al., 2011, A self-healing cementitious composite using oil core/silica gel shell microcapsules, Cement and Concrete Composites, vol. 33(4): 506-512.

http://dx.doi.org/10.1016/j.cemconcomp.2011.01.010

122. Pelletier M M, Brown R, Shukla A, et al., 2011, Self-healing concrete with a microencapsulated healing agent, Technical Report, Kingston.

123. Jonkers H M, Thijssen A, Muyzer G, et al., 2010, Application of bacteria as self-healing agent for the development of sustainable concrete, Ecological Engineering, vol.36(2): 230-235.

http://dx.doi.org/10.1016/j.ecoleng.2008.12.036

124. Wang J, Van Tittelboom K, De Belie N, et al., 2012, Use of silica gel or polyurethane immobilized bacteria for self-healing concrete, Construction and Building Materials, vol.26(1): 532-540.

http://dx.doi.org/10.1016/j.conbuildmat.2011.06.054

125. Chan Y N, Luo X and Sun W, 2000, Compressive strength and pore structure of high-performance concrete after exposure to high temperature up to $800{ }^{\circ} \mathrm{C}$, Cement and Concrete Research, vol.30(2): 247-251. http://dx.doi.org/10.1016/S0008-8846(99)00240-9

126. Peng G, Yang W, Zhao J, et al., 2006, Explosive spalling and residual mechanical properties of fiber-toughened high-performance concrete subjected to high temperatures, Cement and Concrete Research, vol.36(4): 723-
727. http://dx.doi.org/10.1016/j.cemconres.2005.12.014

127. Kodur V, Cheng F, Wang T, et al., 2003, Effect of strength and fiber reinforcement on fire resistance of highstrength concrete columns, Journal of Structural Engineering, vol.129(2): 253-259.

https://doi.org/10.1061/(ASCE)0733-9445(2003)129:2(253)

128. Kalifa P, Menneteau F and Quenard D, 2000, Spalling and pore pressure in HPC at high temperatures, Cement and Concrete Research, vol.30(12): 1915-1927. http://dx.doi.org/10.1016/S0008-8846(00)00384-7

129. Hertz K D, 1992, Danish investigations on silica fume concretes at elevated temperatures, ACI Materials Journal, vol.89: 345-347.

130. Ahmed G N and Hurst J P, 1997, An analytical approach for investigating the causes of spalling of high-strength concrete at elevated temperatures, In International Workshop on Fire Performance of High-Strength Concrete, 13-14.

131. Han C, Hwang Y, Yang S, et al., 2005, Performance of spalling resistance of high performance concrete with polypropylene fiber contents and lateral confinement, Cement and Concrete Research, vol.35(9): 1747-1753. http://dx.doi.org/10.1016/j.cemconres.2004.11.013

132. Lau A and Anson M, 2006, Effect of high temperatures on high performance steel fibre reinforced concrete, Cement and Concrete Research, vol.36(9): 1698-1707. http://dx.doi.org/10.1016/j.cemconres.2006.03.024

133. Xiao J and Falkner H, 2006, On residual strength of high-performance concrete with and without polypropylene fibres at elevated temperatures, Fire Safety Journal, vol.41(2): 115-121. http://dx.doi.org/10.1016/j.firesaf.2005.11.004

134. Kalifa P, Chene G and Galle C, 2001, High-temperature behaviour of HPC with polypropylene fibres: From spalling to microstructure, Cement and Concrete Research, vol.31(10): 1487-1499. http://dx.doi.org/10.1016/S0008-8846(01)00596-8

135. Chen B and Liu J, 2004, Residual strength of hybrid-fiber-reinforced high-strength concrete after exposure to high temperatures, Cement and Concrete Research, vol.34(6): 1065-1069. http://dx.doi.org/10.1016/j.cemconres.2003.11.010

136. Xiao J and König G, 2004, Study on concrete at high temperature in China-an overview, Fire Safety Journal, vol.39(1): 89-103. http://dx.doi.org/10.1016/S0379-7112(03)00093-6

137. Poon C S, Shui Z H and Lam L, 2004, Compressive behavior of fiber reinforced high-performance concrete subjected to elevated temperatures, Cement and Concrete Research, vol.34(12): 2215-2222. http://dx.doi.org/10.1016/j.cemconres.2004.02.011

138. Hou G, Ji Z, Wang J, , et al., 2008, Domestic and abroad 
research status of humidity-control materials. Materials Review 22(8):78-81 (in Chinese)

139. Zhang $\mathrm{H}$ and Yoshino H, 2010, Analysis of indoor humidity environment in Chinese residential buildings, Building and Environment, vol.45(10): 2132-2140. http://dx.doi.org/10.1016/j.buildenv.2010.03.011

140. Jensen O M and Hansen P F, 1999, Influence of temperature on autogenous deformation and relative humidity change in hardening cement paste, Cement and Concrete Research, vol.29(4): 567-575.

http://dx.doi.org/10.1016/S0008-8846(99)00021-6

141. Nehdi M and Hayek M, 2005, Behavior of blended cement mortars exposed to sulfate solutions cycling in relative humidity, Cement and Concrete Research, vol. 35(4): 731-742.

http://dx.doi.org/10.1016/j.cemconres.2004.05.032.

142. Vu D, Wang K, Bac B H, et al., 2013, Humidity control materials prepared from diatomite and volcanic ash, Construction and Building Materials, vol.38: 1066- 1072. http://dx.doi.org/10.1016/j.conbuildmat.2012.09.040

143. Arundel A V, Sterling E M, Biggin J H, et al., 1986, Indirect health effects of relative humidity in indoor environments, Environmental Health Perspectives, vol.65: 351.https://doi.org/10.1289/ehp.8665351

144. Horikawa T, Kitakaze Y, Sekida T, et al., 2010, Characteristics and humidity control capacity of activated carbon from bamboo, Bioresource Technology, vol.101(11): 3964-3969. http://dx.doi.org/10.1016/j.biortech.2010.01.032

145. Wang $\mathrm{J}$ and Wang Z, 2007, Advances in humidity-controlling composite materials, Materials Review, vol.6: 13 (in Chinese)

146. Goto K and Terao S, 2005, Structures and humidity controlling performances of zeolite-cement hardened body, Journal of the Ceramic Society of Japan, vol.113 (1323): 739-742.https://doi.org/10.2109/jcersj.113.736

147. Deng L, Zheng B, and Fu L. 2007, Studies on the self-humidity controlling characteristic of cement-based composite material modified by attapulgite, Non-Metallic Mines, vol.4: 10.

148. Li Z, Wei F and Liu W, 2011, Manufacture on building blocks of humidity-controlling composite materials used in greenhouse, In Materials for Renewable Energy \& Environment (ICMREE), 2011 International Conference on IEEE, 1125-1128.

149. Kuznik F, Virgone J and Noel J, 2008, Optimization of a phase change material wallboard for building use, $A p$ plied Thermal Engineering, vol.28(11-12): 1291-1298. http://dx.doi.org/10.1016/j.applthermaleng.2007.10.012

150. Regin A F, Solanki S C and Saini J S, 2008, Heat transfer characteristics of thermal energy storage system using PCM capsules: A review, Renewable and Sustaina- ble Energy Reviews, vol.12(9): 2438-2458.

http://dx.doi.org/10.1016/j.rser.2007.06.009

151. Khudhair A M and Farid M M, 2004, A review on energy conservation in building applications with thermal storage by latent heat using phase change materials, Energy Conversion and Management, vol.45(2): 263275.http://dx.doi.org/10.1016/S0196-8904(03)00131-6

152. Pérez-Lombard L, Ortiz J and Pout C, 2008, A review on buildings energy consumption information, Energy and Buildings, vol.40(3): 394-398.

http://dx.doi.org/10.1016/j.enbuild.2007.03.007

153. Lane G A, 1983, Solar heat storage: Latent heat materials. CRC Press.

154. Hirayama Y, Jolly S and Batty W J, 1997, Investigation of thermal energy storage within building thermal mass in northern Japan through dynamic building and building services simulation, In Proceedings of Seventh International Conference on Thermal Energy Storage, Sapporo, Japan, 355-360.

155. Hunger M, Entrop A G, Mandilaras I, et al., 2009, The behavior of self-compacting concrete containing micro-encapsulated phase change materials, Cement and Concrete Composites, vol.31(10): 731-743. http://dx.doi.org/10.1016/j.cemconcomp.2009.08.002

156. Farid M and Kong W J, 2001, Underfloor heating with latent heat storage. Proceedings of the Institution of Mechanical Engineers, Part A: Journal of Power and Energy 215: 601-609.

157. Castellón C, Medrano M, Roca J, et al., 2007, Use of microencapsulated phase change materials in building applications, ASHRAE, Project ENE2005-08256-C0201/ALT.

158. Zach J, Sedlmajer M, Hroudova J, et al., 2013, Technology of Concrete with Low Generation of Hydration Heat, Procedia Engineering, vol.65: 296-301.

http://dx.doi.org/10.1016/j.proeng.2013.09.046

159. Chu I, Lee Y, Amin M N, et al., 2013, Application of a thermal stress device for the prediction of stresses due to hydration heat in mass concrete structure, Construction and Building Materials, vol.45: 192-198. http://dx.doi.org/10.1016/j.conbuildmat.2013.03.056

160. De Rojas M S, Luxán M P D, Frías M, et al., 1993, The influence of different additions on portland cement hydration heat, Cement and Concrete Research, vol.23(1): 46-54.http://dx.doi.org/10.1016/0008-8846(93)90134-U

161. Kim J K, Kim K H and Yang J K, 2001, Thermal analysis of hydration heat in concrete structures with pipecooling system, Computers and Structures, vol.79(2): 163-171. http://dx.doi.org/10.1016/S0045-7949(00)00128-0

162. Bullard J W, Jennings H M, Livingston R A, et al., 2011, Mechanisms of cement hydration, Cement and Concrete 
Research, vol.41(12): 1208-1223.

http://dx.doi.org/10.1016/j.cemconres.2010.09.011

163. Pane I and Hansen W, 2005, Investigation of blended cement hydration by isothermal calorimetry and thermal analysis, Cement and Concrete Research, vol.35(6): 1155-1164.

http://dx.doi.org/10.1016/j.cemconres.2004.10.027

164. Yang H, Tan L L and Dong W J, 2001, Influence of fly ash and superplasticizer on the heat of hydraion in cement, Concrete, vol.12: 9-12 (in Chinese)

165. Nocuń-Wczelik W and Czapik P, 2013, Use of calorimetry and other methods in the studies of water reducers and set retarders interaction with hydrating cement paste, Construction and Building Materials, vol.38: 980-986.

http://dx.doi.org/10.1016/j.conbuildmat.2012.09.048

166. Pang X, Boontheung P and Boul PJ, 2014, Dynamic retarder exchange as a trigger for Portland cement hydration, Cement and Concrete Research, vol.63: 20-28. http://dx.doi.org/10.1016/j.cemconres.2014.04.007

167. Plank J, Sakai E, Miao C W, et al., 2015, Chemical admixtures-Chemistry, applications and their impact on concrete microstructure and durability, Cement and Concrete Research, vol.78(A): 81-99.

http://dx.doi.org/10.1016/j.cemconres.2015.05.016

168. Xing J J and Guan X J, 2006, Study on the control over the cement hydration heat of the phase change materials, Research \& Application of Building Materials, vol.6: 4-6 (in Chinese).

169. Rahhal V and Talero R, 2005, Early hydration of Portland cement with crystalline mineral additions, Cement and Concrete Research, vol.35(7): 1285-1291. http://dx.doi.org/10.1016/j.cemconres.2004.12.001

170. Orak S, 2000, Investigation of vibration damping on polymer concrete with polyester resin, Cement and Concrete Research, vol.30(2): 171-174. http://dx.doi.org/10.1016/S0008-8846(99)00225-2

171. Ou J, Liu T and Li J, 2008, Dynamic and seismic property experiments of high damping concrete and its frame models, Journal of Wuhan University of TechnologyMater. Sci. Ed., vol.23: 1-6.

172. Wong W G, Fang P and Pan J K, 2003, Polymer effects on the vibration damping behavior of cement, Journal of Materials in Civil Engineering, vol.15(6): 554-556. https://doi.org/10.1061/(ASCE)0899-1561(2003)15:6(5 54)

173. Fu X and Chung D D L, 1996, Vibration damping admixtures for cement, Cement and Concrete Research, vol.26(1): 69-75. http://dx.doi.org/10.1016/0008-8846(95)00177-8

174. Wen S and Chung D, 2000, Enhancing the vibration reduction ability of concrete by using steel reinforcement and steel surface treatments, Cement and Concrete Research, vol.30(2): 327-330. http://dx.doi.org/10.1016/S0008-8846(99)00238-0

175. Luo J, Duan Z, Xian G, et al., 2015, Damping performances of carbon nanotube reinforced cement composite, Mechanics of Advanced Materials and Structures, vol.22(3): 224-232.

https://doi.org/10.1080/15376494.2012.736052

176. Koratkar N, Wei B Q and Ajayan P M, 2002, Carbon nanotube films for damping applications, Advanced Materials, vol.14(13-14): 997-1000.

https://doi.org/10.1002/1521-4095(20020705)14:13/14

\%3C997::AID-ADMA997\%3E3.0.CO;2-Y

177. Cui X, Sun S, Han B, , et al., 2017 Mechanical, thermal and electromagenetic properties of nano graphite platelets modified cementitious composites. Composites Part A: Applied Science and Manufacturing, 93:49-58. http://dx.doi.org/10.1016/j.compositesa.2016.11.017

178. Xu D, Cheng X, Guo X, et al., 2015, Design, fabrication and property investigation of cement/polymer based 1-3 connectivity piezo-damping composites, Construction and Building Materials, vol.84(1): 219-223. http://dx.doi.org/10.1016/j.conbuildmat.2015.03.043

179. Xie P and Beaudoin J J, 1995, Electrically conductive concrete and its application in deicing, ACI Special Publication, vol.154: 399-418.

180. Yehia S, Tuan C Y, 1999, Conductive concrete overlay for bridge deck deicing, ACI Materials Journal, vol.96(3): 382-391.

181. Yehia S, Tuan C Y, Ferdon D, et al., 2000, Conductive concrete overlay for bridge deck deicing: mixture proportioning, optimization, and properties, ACI Materials Journal, vol.97: 172-181.

182. Hou Z, Li Z and Tang Z, 2003, Finite element analysis and design of electrically conductive concrete for roadway deicing or snow-melting system, ACI Materials Journal, vol.100: 469-476.

183. Tuan C Y, 2004, Electrical resistance heating of conductive concrete containing steel fibers and shavings, ACI Materials Journal, vol.101: 65-71.

184. Tuan C Y and Yehia S, 2004, Evaluation of electrically conductive concrete containing carbon products for deicing, ACI Materials Journal, vol.101: 287-293.

185. Baldwin K, 1998, Electrically conductive concrete: properties and potential. Construction Canada, 98: 28- 29.

186. Zhang K, Han B and Yu X, 2011, Nickel particle based electrical resistance heating cementitious composites, Cold Regions Science and Technology, vol.69(1): 64-69. http://dx.doi.org/10.1016/j.coldregions.2011.07.002

187. Wu J, Liu J and Yang F, 2015, Three-phase composite conductive concrete for pavement deicing, Construction and Building Materials, vol.75: 129-135. 
http://dx.doi.org/10.1016/j.conbuildmat.2014.11.004

188. Chung D D L, 2004, Self-heating structural materials, Smart Materials and Structures, vol.13(3): 562. https://doi.org/10.1088/0964-1726/13/3/015

189. Chen P and Chung D D L, 1995, Improving the electrical conductivity of composites comprised of short conducting fibers in a nonconducting matrix: The addition of a nonconducting particulate filler, Journal of Electronic Materials, vol.24(1): 47-51. https://doi.org/10.1007/BF02659726

190. Zhou X, Yang Z J, Chang C, et al., 2011, Numerical assessment of electric roadway deicing system utilizing emerging carbon nanofiber paper, Journal of Cold Regions Engineering, vol.26(1): 1-15. https://doi.org/10.1061/(ASCE)CR.1943-5495.0000033

191. Xie P, Gu P and Beaudion J J, 1996, Electrical percolation phenomena in cement composites containing conductive fibers, Journal of Materials Science, vol.31(15): 4093-4097. https://doi.org/10.1007/BF00352673

192. Gomis J, Galao O, Gomis V, et al., 2015, Self-heating and deicing conductive cement. Experimental study and modeling, Construction and Building Materials, vol.75: 442-449. http://dx.doi.org/10.1016/j.conbuildmat.2014.11.042

193. Sun M, Mu X, Wang X, et al., 2008, Experimental studies on the indoor electrical floor heating system with carbon black mortar slabs, Energy and Buildings, vol.40(6): 1094-1100.

http://dx.doi.org/10.1016/j.enbuild.2007.10.009

194. Li S and Ye X, 2009, Study on the bridge surface deicing system in Yuebei section of Jingzhu highway, International Journal of Business and Management, vol. 3(12): 116.http://dx.doi.org/10.5539/ijbm.v3n12p116

195. Yehia S, Tuan C Y, Ferdon D, et al., 2000, Conductive concrete overlay for bridge deck deicing: mixture proportioning, optimization, and properties, ACI Materials Journal, vol.97: 172-181.

196. Pedeferri P, 1996, Cathodic protection and cathodic prevention, Construction and Building Materials, vol.10(5): 391-402. http://dx.doi.org/10.1016/0950-0618(95)00017-8

197. Stratfull R F, 1974, Experimental cathodic protection of a bridge deck, Transportation Research Record, vol.500: $1-15$

198. Cañón A, Garcés P, Climent M A, et al., 2013, Feasibility of electrochemical chloride extraction from structural reinforced concrete using a sprayed conductive graphite powder-concrete paste as anode, Corrosion Science, vol.77: 128-134. http://dx.doi.org/10.1016/j.corsci.2013.07.035

199. Yehia S and Host J, 2010, Conductive Concrete for Cathodic Protection of Bridge Decks, ACI Materials Jour- nal, vol.107.

200. Sobolev K G and Batrakov V G, 2007, Effect of a polyethylhydrosiloxane admixture on the durability of concrete with supplementary cementitious materials, Journal of Materials in Civil Engineering, vol.19(10): 809-819.

https://doi.org/10.1061/(ASCE)0899-1561(2007)19:10 (809)

201. Koch K, Bhushan B and Barthlott W, 2008, Diversity of structure, morphology and wetting of plant surfaces, Soft Matter, vol.4: 1943-1963. https://doi.org/10.1039/b804854a

202. Liu Y, Chen X and Xin J H, 2006, Super-hydrophobic surfaces from a simple coating method: a bionic nanoengineering approach, Nanotechnology, vol.17(13): 3259. https://doi.org/10.1088/0957-4484/17/13/030

203. Ganesh V A, Raut H K, Nair A S, et al., 2011, A review on self-cleaning coatings, Journal of Materials Chemistry, vol.21: 16304-16322. https://doi.org/10.1039/c1jm12523k

204. Popovics S, 1982, Fundamentals of Portland Cement Concrete-a Quantitative Approach: Fresh concrete: John Wiley \& Sons 10: 332.

205. Hekal E E, Abd-El-Khalek M, El-Shafey G M, et al., 1999, Mechanical and physico-chemical properties of hardened Portland cement pastes containing hydrophobic admixtures. Part 1: Compressive strength and hydration kinetics, ZKG International, vol.52: 697-700.

206. Fratesi R, Moriconi G, Tittarelli R, et al., 1997, The influence of hydrophobized concrete on the corrosion of rebars, ACI Special Publication, vol.173: 105-122.

207. Tittarelli F, Moriconi G and Fratesi R, 2000, Influence of silane-based hydrophobic admixture on oxygen diffusion through concrete cement matrix, ACI Special Publication, vol.195: 431-446.

208. Batrakov V G, 1998, Modified concrete-Theory and practice, Tekhnoproekt, Moscow.

209. Ramachandran R, Sobolev K and Nosonovsky M, 2015, Dynamics of droplet impact on hydrophobic/icephobic concrete with potential for superhydrophobicity. Langmuir, 31(4):1437-1444.

http://pubs.acs.org/doi/abs/10.1021/la504626f

210. J. de Vries I and Polder R B, 1997, Hydrophobic treatment of concrete. Construction and Building Materials, 11(4): 259-265.

211. Ding X, Zhou S, Gu G, et al., 2011, A facile and largearea fabrication method of superhydrophobic selfcleaning fluorinated polysiloxane/TiO2 nanocomposite coatings with long-term durability, Journal of Materials Chemistry, vol.21: 6161-6164. https://doi.org/10.1039/c0jm04546b

212. Mills A and Le Hunte S, 1997, An overview of semi- 
conductor photocatalysis, Journal of Photochemistry and Photobiology A: Chemistry, vol.108(1): 1-35. http://dx.doi.org/10.1016/S1010-6030(97)00118-4

213. Oh W S, Xu C, Kim D Y, et al., 1997, Preparation and characterization of epitaxial titanium oxide films on Mo(100), Journal of Vacuum Science and Technology-Section A-Vacuum Surfaces and Films, vol.15: 1710-1716. https://doi.org/10.1116/1.580925

214. Fujishima A, Hashimoto $\mathrm{K}$ and Watanabe T, 1999, $\mathrm{TiO}_{2}$ photocatalysis: fundamentals and applications: BKC Incorporated.

215. Tung W S and Daoud W A, 2011, Self-cleaning fibers via nanotechnology: A virtual reality, Journal of Materials Chemistry, vol.21: 7858-7869.

https://doi.org/10.1039/c0jm03856c

216. Wang R, Hashimoto K, Fujishima A, et al., 1997, Lightinduced amphiphilic surfaces, Nature, vol.388: 431432. https://doi.org/10.1038/41233

217. Hashimoto $\mathrm{K}$, Irie $\mathrm{H}$ and Fujishima A, 2005, $\mathrm{TiO}_{2}$ photocatalysis: A historical overview and future prospects, Japanese Journal of Applied Physics, vol.44(1): 8269.

https://doi.org/10.1143/JJAP.44.8269

218. Sakai N, Fujishima A, Watanabe T, et al., 2003, Quantitative evaluation of the photoinduced hydrophilic conversion properties of $\mathrm{TiO}_{2}$ thin film surfaces by the reciprocal of contact angle, The Journal of Physical Chemistry B, vol.107(4): 1028-1035. https://doi.org/10.1021/jp022105p

219. Cassar L, 2004, Photocatalysis of cementitious materials: clean buildings and clean air, MRS Bulletin, vol.29(5): 328-331.https://doi.org/10.1557/mrs2004.99

220. Chen J and Poon C, 2009, Photocatalytic construction and building materials: From fundamentals to applications, Building and Environment, vol.44(9): 1899-1906. http://dx.doi.org/10.1016/j.buildenv.2009.01.002

221. Guerrini G L, Plassais A, Pepe C, et al., 2015, Use of photocatalytic cementitious materials for self-cleaning applications, Newsletter: 219-226.

222. Poon C S and Cheung E, 2007, NO removal efficiency of photocatalytic paving blocks prepared with recycled materials, Construction and Building Materials, vol. 21(8): 1746-1753.

https://doi.org/10.1016/j.conbuildmat.2006.05.018

223. Dylla H, Hassan M M, Schmitt M, et al., 2010, Laboratory investigation of the effect of mixed nitrogen dioxide and nitrogen oxide gases on titanium dioxide photocatalytic efficiency in concrete pavements, Journal of Materials in Civil Engineering, vol.23(7): 1087-1093. https://doi.org/10.1061/(ASCE)MT.1943-5533.0000248

224. Guerrini G L and Peccati E, 2015, Photocatalytic cementitious roads for depollution, Newsletter: 179-186.
225. Maggos T, Plassais A, Bartzis J G, et al., 2008, Photocatalytic degradation of $\mathrm{NO}_{\mathrm{X}}$ in a pilot street canyon configuration using $\mathrm{TiO}_{2}$-mortar panels, Environmental Monitoring and Assessment, vol.136(1): 35-44. https://doi.org/10.1007/s10661-007-9722-2

226. Lackhoff M, Prieto X, Nestle N, et al., 2003, Photocatalytic activity of semiconductor-modified cement-influence of semiconductor type and cement ageing, Applied Catalysis B: Environmental, vol.43(3): 205-216. http://dx.doi.org/10.1016/S0926-3373(02)00303-X

227. Auvinen J and Wirtanen L, 2008, The influence of photocatalytic interior paints on indoor air quality, Atmospheric Environment, vol.42(18): 4101-4112. http://dx.doi.org/10.1016/j.atmosenv.2008.01.031

228. Buswell R A, Soar R C, Gibb A G, et al., 2007, Freeform construction: mega-scale rapid manufacturing for construction, Automation in Construction, vol.16(2): 224-231.http://dx.doi.org/10.1016/j.autcon.2006.05.002

229. Buswell R A, Thorpe A, Soar R C, et al., 2008, Design, data and process issues for mega-scale rapid manufacturing machines used for construction, Automation in Construction, vol.17(8): 923-929. http://dx.doi.org/10.1016/j.autcon.2008.03.001

230. Le T T, Austin S A, Lim S, et al., 2012, Mix design and fresh properties for high-performance printing concrete, Materials and Structures, vol.45(8): 1221-1232. https://doi.org/10.1617/s11527-012-9828-z

231. Perrot A, Rangeard D and Pierre A, 2015, Structural built-up of cement-based materials used for 3D-printing extrusion techniques, Materials and Structures: 1-8.

232. Le T T, Austin S A, Lim S, et al., 2012, Hardened properties of high-performance printing concrete, Cement and Concrete Research, vol.42(3): 558-566. http://dx.doi.org/10.1016/j.cemconres.2011.12.003

233. Feng P, Meng X, Chen J, et al., 2015, Mechanical properties of structures 3D printed with cementitious powders, Construction and Building Materials, vol.93: 486497.http://dx.doi.org/10.1016/j.conbuildmat.2015.05.132

234. Gibbons G J, Williams R, Purnell P, et al., 2010, 3D Printing of cement composites, Advances in Applied Ceramics, vol.109(5): 287-290. https://doi.org/10./174367509X12472364600878

235. Lim S, Buswell R A, Le T T, et al., 2012, Developments in construction-scale additive manufacturing processes, Automation in Construction, vol.21: 262-268. http://dx.doi.org/10.1016/j.autcon.2011.06.010

236. Charron K, 2015, WinSun China builds world's first 3D printed villa and tallest 3D printed apartment building, viewed January 18 2015, http://www.3ders.org/articles/20150118-winsun-buildsworld-first-3d-printed-villa-and-tallest-3d-printed-buildi 
ng-in-china.html/

237. Khoshnevis B, Thangavelu M, Yuan X, et al., 2013, Advances in contour crafting technology for extraterrestrial settlement infrastructure buildup, AIAA, vol.5438: 10-12. http://dx.doi.org/10.2514/6.2013-5438

238. Cesaretti G, Dini E, De Kestelier X, et al., 2014, Building components for an outpost on the Lunar soil by means of a novel 3D printing technology, Acta Astronautica, vol.93: 430-450.

http://dx.doi.org/10.1016/j.actaastro.2013.07.034

239. Neithalath N, Bentz D P and Sumanasooriya M S, 2010, Advances in pore structure characterization and performance prediction of pervious concretes, Concrete International, vol.32: 35-40.

240. Ghafoori N and Dutta S, 1995, Laboratory investigation of compacted no-fines concrete for paving materials, Journal of Materials in Civil Engineering, vol.7(3): 183-191. https://doi.org/10.1061/(ASCE)0899-1561(1995)7:3(183)

241. Zheng M, Chen S and Wang B, 2012, Mix design method for permeable base of porous concrete, International Journal of Pavement Research and Technology, vol.5: 102-107.

242. Nguyen D H, Sebaibi N, Boutouil M, et al., 2014, A modified method for the design of pervious concrete mix, Construction and Building Materials, vol.73: 271282. http://dx.doi.org/10.1016/j.conbuildmat.2014.09.088

243. ACI committee 522, 2006, Pervious concrete, Report No. 522R-10, American Concrete Institute (ACI), Detroit, USA.

244. Schaefer V R, Wang K and Suleiman M T, 2006, Mix Design Development for Pervious Concrete in Cold Weather Climates, Technical report, National Concrete
Pavement Technology Center, Iowa State University, USA.

245. Weller C, 2015, This 'thirsty' concrete absorbs 880 gallons of water a minute-here's how it works, viewed September 28 2015, http://www.techinsider.io/how-magical-concrete-absorbs -water-2015-9/.

246. Malhotra V M, 1976, No-fines concrete-its properties and applications, In Journal Proceedings, 628-644.

247. Ghafoori N and Dutta S, 1995, Development of no-fines concrete pavement applications, Journal of Transportation Engineering, vol.121(3): 283-288. https://doi.org/10.1061/(ASCE)0733-947X(1995)121:3 (283)

248. Scholz M and Grabowiecki P, 2007, Review of permeable pavement systems, Building and Environment, vol.42(11): 3830-3836. http://dx.doi.org/10.1016/j.buildenv.2006.11.016

249. Yang J and Jiang G, 2003, Experimental study on properties of pervious concrete pavement materials, Cement and Concrete Research, vol.33(3): 381-386. http://dx.doi.org/10.1016/S0008-8846(02)00966-3

250. Kevern J T, 2008, Advancement of pervious concrete durability. Ames, IA, USA: Iowa State University.

251. Energy Matters, 2016, Solar Powered, Light Emitting Cement, viewed May 11, 2016,

http://www.energymatters.com.au/renewable-news/solar -light-cement-em5466/

252. News Nation, 2016, Scientists develop solar-powered light-emitting cement with a life of 100 years, viewed May 11, 2016, http://www.newsnation.in/article/130313-scientists-creat e-light-emitting-cement-that-has-a-life-of-100-years.html/. 